Review Article

\title{
Placing Ion Channels into a Signaling Network of T Cells: From Maturing Thymocytes to Healthy T Lymphocytes or Leukemic T Lymphoblasts
}

\author{
Oxana Dobrovinskaya, ${ }^{1}$ Iván Delgado-Enciso, ${ }^{2}$ Laura Johanna Quintero-Castro, ${ }^{1,2}$ \\ Carlos Best-Aguilera, ${ }^{3}$ Rocío Monserrat Rojas-Sotelo, ${ }^{3}$ and Igor Pottosin ${ }^{1}$ \\ ${ }^{1}$ Center for Biomedical Research, University of Colima, 28045 Colima, COL, Mexico \\ ${ }^{2}$ School of Medicine, University of Colima, 28045 Colima, COL, Mexico \\ ${ }^{3}$ Departamento de Hematología, Hospital General de Occidente, 45170 Guadalajara, JAL, Mexico
}

Correspondence should be addressed to Oxana Dobrovinskaya; oxana@ucol.mx

Received 14 August 2014; Accepted 19 September 2014

Academic Editor: Yoshinori Marunaka

Copyright (C) 2015 Oxana Dobrovinskaya et al. This is an open access article distributed under the Creative Commons Attribution License, which permits unrestricted use, distribution, and reproduction in any medium, provided the original work is properly cited.

\begin{abstract}
$\mathrm{T}$ leukemogenesis is a multistep process, where the genetic errors during $\mathrm{T}$ cell maturation cause the healthy progenitor to convert into the leukemic precursor that lost its ability to differentiate but possesses high potential for proliferation, self-renewal, and migration. A new misdirecting "leukemogenic" signaling network appears, composed by three types of participants which are encoded by (1) genes implicated in determined stages of T cell development but deregulated by translocations or mutations, (2) genes which normally do not participate in T cell development but are upregulated, and (3) nondifferentially expressed genes which become highly interconnected with genes expressed differentially. It appears that each of three groups may contain genes coding ion channels. In $\mathrm{T}$ cells, ion channels are implicated in regulation of cell cycle progression, differentiation, activation, migration, and cell death. In the present review we are going to reveal a relationship between different genetic defects, which drive the T cell neoplasias, with calcium signaling and ion channels. We suggest that changes in regulation of various ion channels in different types of the T leukemias may provide the intracellular ion microenvironment favorable to maintain self-renewal capacity, arrest differentiation, induce proliferation, and enhance motility.
\end{abstract}

\section{Introduction}

T cell acute lymphoblastic leukemias (T-ALL) are aggressive neoplastic disorders of the lymphoblasts committed to the $\mathrm{T}$ lineage. T-ALL accounts for $15 \%$ of pediatric and $25 \%$ of adult ALL cases [1]. It is widely accepted that the $\mathrm{T}$ cell leukemogenesis is tightly related to the normal $\mathrm{T}$ cell development. Various genetic errors during $\mathrm{T}$ cell maturation may cause the healthy progenitor to convert into a leukemic precursor cell that lost its ability to differentiate but possesses high potential for proliferation and self-renewal. Accordingly, leukemogenesis is a multistep process, where the genes encoding proteins implicated in the normal $\mathrm{T}$ cell development are deregulated. Among them there are transcriptional factors and tumor suppressors, receptors and signal transduction molecules, secreted molecules and growth factors, ion channels, and transporters. Specific genetic alterations define distinct groups of T-ALL with different profiles and levels of gene expression denominated as a gene expression signature. Moreover, gene expression signatures may vary in every special clinical case. Although numerous experimental and clinical reports and detailed reviews dealing with T-ALL are available, the relationships between various components of transcriptional and signaling regulatory networks are very complex and many issues are still to be addressed.

In the present review we are going to reveal a relationship between different abnormalities that drive the $\mathrm{T}$ cell neoplasias, with special accent on those occurring in the 
expression of ion channels in this type of lymphoproliferative disorders. We suggest that changes in regulation of various ion channels in different types of the T-ALL may provide an intracellular ion microenvironment favorable to maintain self-renewal capacity, arrest differentiation, induce proliferation in T cell precursors, and enhance their motility.

We first review normal $\mathrm{T}$ cell maturation and recurrent cytogenetic abnormalities reported in the T-ALL, with their relation to main signaling pathways that contributed to leukemogenesis. Next, we address the question how $\mathrm{Ca}^{2+}$ signals may be involved in the T-ALL signaling network. Then we provide an overview of the current knowledge on the abnormal expression of ion channels in leukemias, from the point of view of their possible contribution to shaping and maintenance of $\mathrm{Ca}^{2+}$ signal, and other mechanisms where ion channels may be involved. And finally, we will discuss the possibility of targeting ion channels to improve the existing protocols of the T-ALL treatment.

\section{T Cell Maturation in the Thymus}

It is widely accepted that $\mathrm{T}$ leukemogenesis is a multistep process where several genetic lesions drastically mislead the normal thymocyte maturation [2]. A short overview of key events in early thymocyte development and their links to the leukemogenesis is presented at Figure 1.

$\mathrm{T}$ cells can be distinguished from other lymphoid lineages by the presence of the unique antigen-specific $\mathrm{T}$ cell receptor (TCR) on the cell surface. TCR is a transmembrane heterodimer composed of two chains, either $\alpha \beta$ or $\gamma \delta$. T cells of TCR $\alpha \beta$ lineage constitute the bulk of T cell populations in lymphoid organs and recognize antigen-derived peptides bound to the molecules of a major histocompatibility complex, of classes I or II (MHC-I or MHC-II), on the surface of antigen-presenting cells. T cells of TCR $\gamma \delta$ lineage are generally not MHC-restricted and particularly play an important role in protection of the mucosal tissues from the external infection $([3,4]$; revised in $[5,6])$. Intracellular signaling through TCR depends on its association with a multimeric complex of membrane proteins referred to as CD3 and composed of four distinct polypeptide chains that assemble and function as three pairs of dimers $(\varepsilon \gamma, \varepsilon \delta$, and $\zeta \zeta)$. Accordingly, TCR/CD3 protein complexes are defining features of $\mathrm{T}$ lineage and therefore are used as $\mathrm{T}$ cell markers. In addition, mature TCR $\alpha \beta$ lymphocytes bear CD 4 or CD8 transmembrane proteins that serve as coreceptors for TCR in two subpopulations: T helpers $\left(\mathrm{CD}^{+}\right)$and cytotoxic $\mathrm{T}$ cells $\left(\mathrm{CD}^{+}\right)$. The extracellular domains of $\mathrm{CD} 4$ and $\mathrm{CD} 8$ bind to conserved regions of MHC class II and MHC class I molecules, respectively. The coengagement of $\mathrm{MHC}$ molecule by both TCR and CD4 or CD8 enhances the avidity of T cell binding to its target and helps to initiate the cascade of intracellular signaling events.

Each of the several millions of T cells circulating in the organism possesses a unique TCR capable of recognizing its own MHC molecules, which present specific antigenic structure, distinct for every $\mathrm{T}$ cell clone and without crossreactivity to self-antigens. Maturation of self-tolerant T cells, which differ in specificity of their TCR receptors and which are restricted to self-MHC, takes place in the thymus. The broad repertoire of TCR is generated by strictly ordered gene rearrangements in TCR loci encoding $\alpha, \delta, \beta$, and $\gamma$ chains. The genomic locus coding every TCR chain contains gene clusters corresponding to the variable (V), the diversity (D), the join (J), and the constant (C) regions. Functional TCR genes are produced by the recombination process that assembles V, D, J, and C segments dispersed along a large genetic locus into a single transcriptable gene. Recombination activating genes RAG1 and RAG2 and terminal deoxynucleotidyl transferase (TdT) play a central role in the TCR rearrangement. At this phase, only those thymocytes survive, in which genetic rearrangements were productive and resulted in the appearance of a final unique lineal coding sequence of TCR chains. The apoptotic program is triggered in the rest of cells, which managed the rearrangement task poorly $[5,6]$. The earliest T cells, lacking detectable CD4 and CD8 $\left(\mathrm{CD} 4^{-} \mathrm{CD} 8^{-}\right)$, are, therefore, referred to as double-negative (DN) cells. Later on, they start to express both CD4 and $\mathrm{CD} 8\left(\mathrm{CD}^{+} \mathrm{CD}^{+}\right)$and are denominated as double-positive (DP) cells. Finally, DP differentiates into single positive (SP) cells, either $\mathrm{CD} 4^{+} \mathrm{CD} 8^{-}$or $\mathrm{CD} 4^{-} \mathrm{CD} 8^{+}$, which leave to periphery. DN $\mathrm{T}$ cells are subdivided into four subsets (DN1-4), based on the presence or absence of other cell surface molecules, including CD117, the receptor for stem cell growth factor c-kit; CD44, an adhesion molecule; CD25, the $\alpha$ chain of the IL- 2 receptor (IL-2R), determining the IL-2R affinity [5, 7]. In every DN stage, characteristic events of TCR rearrangements take place. DN1 thymocytes express only c-kit and CD44 (c-kit ${ }^{++} \mathrm{CD} 44^{+} \mathrm{CD} 25^{-}$), but once they encounter the thymic environment and become resident in the cortex, they express CD25 and proliferate, becoming DN2 thymocytes (c-kit ${ }^{++} \mathrm{CD} 44^{+} \mathrm{CD} 25^{+}$). During this stage, rearrangement and transcription of germ line $\mathrm{D} \beta$ and $\mathrm{J} \beta$ segments belonging to TCR $\gamma$ and TCR $\delta$ gene locus begin. However, the TCR $\alpha$ locus does not rearrange, because the regions of DNA encoding TCR $\alpha$ genes are not yet accessible to the recombinase machinery. At the late DN2 stage, T cell precursors are fully committed to the $\mathrm{T}$ cell lineage and reduce expression of both c-kit and CD44. Cells in transition from the DN2 to DN3 (c-kit ${ }^{+} \mathrm{CD} 44^{-} \mathrm{CD} 25^{+}$) stages continue rearrangement of the TCR $\gamma, \operatorname{TCR} \delta$, and TCR $\beta$ chains, start to express CD3, and make the first major decision in $\mathrm{T}$ cell development: whether to join the TCR $\gamma \delta$ or TCR $\alpha \beta$ lineage $[4,5,8,9]$. The choice to become a $\alpha \beta$ or $\gamma \delta$ T cell is dictated by when and how fast the genes, coding for each of the four receptor chains, successfully rearrange. Rearrangement of the $\beta, \gamma$, and $\delta$ loci begins during the DN2 stage. To become a TCR $\alpha \beta$, T cell must generate a TCR $\beta$ chainan event that depends on successful VDJ rearrangement. To become a TCR $\gamma \delta$, however, a thymocyte must generate two functional proteins that depend on two separate inframe rearrangement events [5]. Germline V $\beta$ transcription and rearrangement to assembled $\mathrm{DJ} \beta$ complex occur in DN3 cells. Those DN3 cells that successfully rearrange their $\beta$ chain and therefore commit to the TCR $\alpha \beta$ lineage lose expression of CD25 halt proliferation and enter the final 


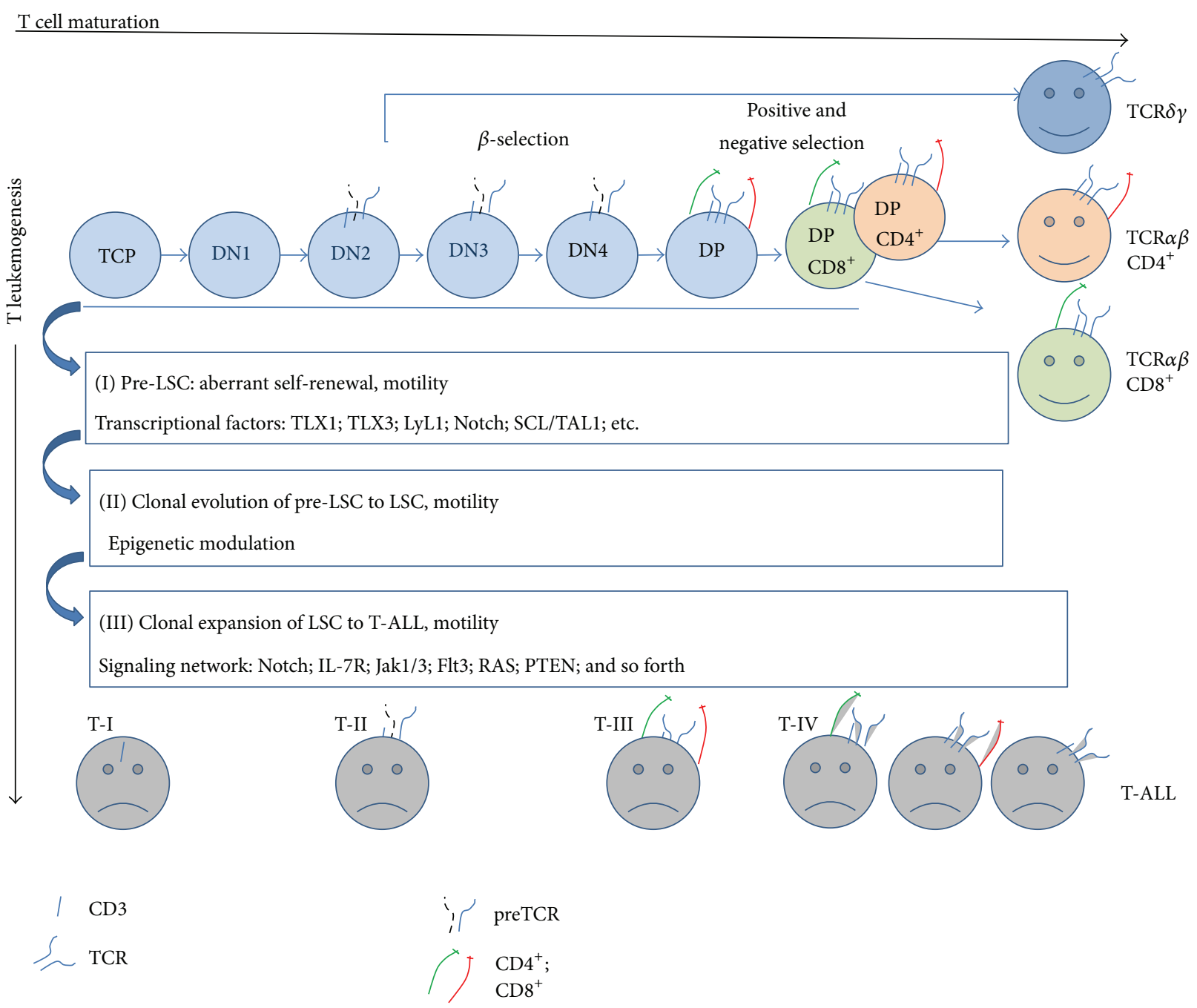

FIgURE 1: Hierarchical mutagenesis during T cell maturation causes different types of T-ALL (see text for details).

phase of their DN stage of development, DN4 (c-kit ${ }^{\text {low/- }}$ $\mathrm{CD} 44^{-} \mathrm{CD} 25^{-}$), which maturate directly into DP thymocytes $[5,8]$. Cellular differentiation involves epigenetic changes that regulate the transcription of genes encoding lineagespecific proteins and pluripotency factors. Developmental stage-specific regulation of transcriptional accessibility helps control V(D)J or VJ recombination. For example, V $\beta$ segments on nonrearranged TCR $\beta$ alleles are accessible in DN thymocytes, when they recombine, and inaccessible in DP thymocytes, when they do not rearrange [8]. Assembly and expression of functional TCR $\gamma$ and TCR $\delta$ chains that can pair to form TCR $\gamma \delta$ complexes in DN2/3 thymocytes drive cellular proliferation and promote differentiation into $\gamma \delta \mathrm{T}$ cells. In contrast, DN thymocytes that have successfully rearranged their TCR $\beta$ chains are valuable and are identified and expanded via a process known as $\beta$-selection. At this stage of development, DN3 thymocytes express the unique pre-T $\alpha$ chain. It acts as a surrogate for the real TCR $\alpha$ chain, which has yet to rearrange, and assembles with a successfully rearranged and translated $\operatorname{TCR} \beta$ chain, as well as CD3 complex. This precursor TCR/CD3 complex, known as the pre-TCR, is an important player in the next stages of thymocyte maturation. It initiates a signal transduction pathway resulting in maturation to the DN4 stage (c-kit ${ }^{-}$ $\mathrm{CD} 44^{-} \mathrm{CD} 25^{-}$), rapid proliferation in the subcapsular cortex, and suppression of further rearrangement of TCR $\beta$ chain genes, resulting in allelic exclusion of the $\beta$-chain locus, and induces development to the DP stage. After entering into the DP stage, cessation of proliferation and initiation of TCR $\alpha$ chain rearrangement occurs. Once a TCR $\alpha$ chain has successfully rearranged, it will dimerize with the TCR $\beta$, replacing the pre-T $\alpha$ chain. The mature TCR $\alpha \beta$ generates signals that lead to the next stages of positive and negative selection. During positive selection, only $\mathrm{T}$ cells are able to recognize host $\mathrm{MHC}$ survives, ensuing $\mathrm{MHC}$-restriction. T cells that recognize self-MHC molecules and peptides with high affinity are deleted from the repertoire of cells during negative selection, providing self-tolerance [7]. The vast majority of DP thymocytes (more than 95\%) never meets the selection criteria and dies by apoptosis within thymus. Upon its positive selection, TCR $\alpha \beta$ activates intracellular signals that stop TCR $\alpha$ rearrangements and promote differentiation 
of DP cells into SP thymocytes, which leave the thymus as $\mathrm{CD}^{+}$or $\mathrm{CD} 8^{+} \mathrm{TCR} \alpha \beta$ cells $[4,5,7,8]$.

Key steps in $\mathrm{T}$ cell maturation are controlled by several transcriptional regulators. The most important players in $\mathrm{T}$ cell ontogeny that are afterward deregulated in T leukemogenesis are Notch receptors proteins, and transcriptional factors of helix-loop-helix (HLH, the E2A, and HEB) and Homeobox (HOX) families $[2,6,10]$.

Notch signaling pathway is evolutionarily conserved and operates in many cell types of different tissues at various developmental stages [11]. It is an important coordinator of different stages of the $\mathrm{T}$ cell maturation prior to the DP stage, including self-renewal of common lymphoid progenitor (CLP), commitment decision of the CLP toward T cell versus B-cell fate choice, and assembly of pre-TCR in immature thymocytes $[2,12,13]$. Mammals possess four Notch receptors (Notch 1-4) and five corresponding ligands (Delta-like 1, 3, 4 , and Jagged 1 and 2). Mature Notch (1-4) receptor is a heterodimer that consists of Notch extracellular (NEC) and Notch transmembrane (NTM) domains associated noncovalently with the heterodimerization domain (HD). Ligand binding initiates the chain of proteolytic cleavages in NEC, culminating in the formation of intracellular Notch (ICN). Subsequently ICN translocates to the nucleus, to form a part of the large transcription activator complex. Notch signaling is regulated at multiple levels. Primarily, expression of Notch receptors and their ligands is restricted to a certain cell population within certain context. Another level of regulation is to insure that ICN is a short-lived protein, due to ubiquitylation within its degradation PEST domain rich in proline $(\mathrm{P})$, glutamic acid $(\mathrm{E})$, serine $(\mathrm{S})$, and threonine $(\mathrm{T})$ [11].

Notchl activation in maturing thymocytes occurs upon engagement with its ligand, expressed on the thymic stromal cells $[14,15]$. Among multiple Notch target genes, identified in $\mathrm{T}$ cells, there are transcriptional factors hes1 (and hes-related genes), Myc, NFAT, and NF $\kappa$ B [13].

Myc exhibits a steady expression at early stages and an abrupt drop in DP thymocytes [16]. A burst of proliferation, triggered by $\beta$-selection, requires preTCR, Notch, and Myc signaling [17] and is augmented by IL-7 [10]. The preTCR expression shuts down Notch signaling and therefore negatively regulates these mitogenic pathways [10]. Transcriptional factors NFAT and NF $\kappa$ B were shown to be upregulated in thymus at the transition of $\mathrm{DN}$ cells to the DP stage governed by pre-TCR signaling $[18,19]$. Both NF$\kappa \mathrm{B}$ and NFAT regulate the transcription of genes, encoding cytokines, antiapoptotic proteins, and cell cycle regulators [20], and their activation is related to mitogen-activated protein kinase (Raf-MEK-Erk) pathway during positive selection [21].

E2A and HEB proteins bind DNA at specific E-box sites in the enhancers of many $\mathrm{T}$ cell specific regulatory genes like $\mathrm{CD} 4$ and $\operatorname{preT} \alpha$ [2]. Members of the HOX family contribute, in some phases of early development, to coordinating the differentiation block, expression of the IL7 receptor, and choice of the $\alpha \beta$ versus $\gamma \delta$ lineage in DN2 [2].

Other important regulators of $\mathrm{T}$ cell maturation are numerous cytokines, produced by thymocytes themselves or by thymus stromal cells [22]. Among them, IL-2 and IL-7 are of special importance. IL-2 is an autocrine factor coming into the play as early as at DN2 (see above) and regulating the TCR-dependent clone expansion from this moment over the entire life of a T cell. In contrast, IL-7 is paracrine thymic cytokine produced by stromal cells in subcapsular zone, where DN cells are located. IL-7 participates in a coordination of the basic processes of early thymocyte development, namely, survival (through Bcl-2 upregulation), proliferation, and TCR rearrangement.

\section{T-ALL as a False Mirror of the T Cell Maturation}

As far as neoplastic transformation may occur at different stages of $\mathrm{T}$ cell differentiation (Figure 1), T-ALLs represent a very heterogeneous group of tumors with regard to their immunophenotype, cytogenetic, and clinical features and response to treatment. Arrest of differentiation program at specific stage of normal thymocyte development is a priming event in the T leukemogenesis. Simultaneously, uncontrolled cell growth and clonal expansion occur as a result of several mutations in the genes, involved in regulation of cellular metabolism, cell cycle control, and self-renewal of stem cells. The most of T-ALL oncogenes are downregulated at early stages of the thymocyte development or are not at all expressed in the normal thymus. Different mechanisms of genetic structural rearrangements are implicated in the TALL leukemogenesis: (1) translocations involving TCR loci, (2) gene fusion encoding chimeric proteins, and (3) deletions of tumor suppressive genes. As a result, corresponding gene is upregulated (activating mutation) or downregulated (suppressing mutation) (for detailed review, see [2]).

A hierarchical model of mutations, which contributed to the $\mathrm{T}$ leukemogenesis, was recently proposed [23]. In accordance with this model, the leukemogenesis occurs in several consequent steps (Figure 1). At the first stage, genetic alterations of transcription factors, leading to the activation of self-renewal program, occur in the immature $\mathrm{T}$ cell progenitors and generate the preleukemic stem cells (preLSCs). Self-renewal phenotype is essential for acquisition and accumulation of subsequent mutations. Activating mutations of signaling pathways important for $\mathrm{T}$ cell maturation allow expansion of pre-LSC, independent of the thymic microenvironment (niche). At the next stage, acquisition of mutations in epigenetic regulators results in transformation of pre-LSCs in LSCs. Finally, apparent T-ALL is generated by a clonal expansion of LSCs, retaining activating mutations in the cytokine signaling pathways.

Considering a rearrangement of gene loci, encoding variable regions of the TCR chains as a key event during the $\mathrm{T}$ cell maturation, it is not surprising that, in more than $30 \%$ of T-ALL patients, oncogenes are activated while being translocated and juxtaposed to one of the TCR loci [24, 25]. Partner oncogenes, involved in the TCR gene translocation, encode developmentally regulated transcription factors and signaling molecules. They are transcribed simultaneously at early stages of the thymocytes maturation and possess open chromatin configuration, which is vulnerable to the action 
of recombinase enzymes RAG1 and RAG2. As a result, target genes are put adjacent to strong promoter or enhancer elements of the TCR genes.

The data about frequency of cytogenetic and molecular changes in T-ALL clinical cases are reviewed in detail elsewhere $[2,26]$. Here we present summarizing remarks of the most frequent genetic lesions. Microarray-based gene expression analysis revealed that T-ALL patients cluster into four major groups based on the aberrant, subtype-specific expression of transcriptional factors TLX1 or TLX3 (HOX family), LYL1 (HLH family), and TAL1 oncogenes [27].

TLX1 and TLX3 are normally involved in the early embryogenesis being implicated in the organogenesis and differentiation of specific cell types. They are not expressed in developing $\mathrm{T}$ cells but seem to be involved in spleen development. In leukemogenesis, they are the most frequent aberrantly expressed genes becoming active due to the translocation involving the TCR loci $[1,28]$. TLX1 is expressed in $7 \%$ of children and in about $30 \%$ of adults with T-ALL, displaying an early cortical phenotype. TLX3 is detected in $20 \%$ of children and in $13 \%$ of adults. Specific mechanisms of $\mathrm{T}$ cell transformation downstream of TLX1 involve the repression of the TCR $\alpha$ enhanceosome activity, the blockage of TCR $\alpha$ rearrangement, and downregulation of mitotic control genes, which induces the loss of the mitotic checkpoint in nontransformed preleukemic thymocytes $[29,30]$.

The LYL1 gene is not normally expressed in T lineage. Its upregulation in the T-ALL is due to chromosomal translocation, which juxtaposes it with the $\mathrm{T}$ cell receptor $\beta$ gene locus. LYL1 reflects an early arrest in the T cell differentiation. Accordingly, related T-ALLs universally express the early hematopoietic marker CD34 and for the most part lack the expression of both CD4 and CD8 [31]. LYL was shown to be also important for the angiogenesis [27]. Overexpression of TLX3 and LYL1 in leukemic patients correlates with a worse prognosis [27].

TAL1 is a homologue of LYL1. It is involved in the embryonic and adult hematopoiesis and in the angiogenesis but is not normally expressed in maturating $\mathrm{T}$ cells. It has been shown that TAL1 and its partners LMO1/2 are coexpressed in the most primitive thymocytes [2]. Genetic evidences that the TAL-1 aberrant overexpression may involve $t(1 ; 14)$ (p32:q11) translocation or submicroscopic interstitial 1p32 deletion with resulting fusion of TAL1 with SIL promoter were provided. TAL1/SCL induces leukemia by inhibiting the transcriptional activity of E47/HEB and interfering with several E47/HEB target genes critical for the thymocyte differentiation [32]. TAL1-positive leukemias show the transcriptional upregulation of CD3 and TCR genes, developmental arrest in DP stage, and an overexpression of antiapoptotic gene $\mathrm{Bcl} 2$ $[1,33]$. Recently, Sanda and coworkers (2012) have identified a set of transcriptional regulators that collaborate with TAL1 to generate a "core" regulatory circuit that contributes to the initiation and maintenance of human T-ALL [34]. Among TAL1 regulatory partners other transcriptional factors like LMO1/2, HEB, E2A, GATA3, and RUNX1 were found among others. An elevated expression of the TAL1/SCL is detected in over $60 \%$ of children and adults [35]. Patients with TAL1/SCL activation respond poorly to existing therapy, ensuing that no more than $50 \%$ of patients survive 5 years after diagnostics [1].

Cryptic deletion of the INK4/ARF locus is another frequent anomaly, detected in about 65\% T-ALL, which results in cell cycle control defects [2].

Notch mutations are very frequent genetic alterations found in over $50 \%$ of T-ALL clinical cases, irrespective to their stage of the differentiation arrest $[27,36]$. In contrast to TALL, Notchl mutations are not found in B-ALL [36] and are seen only rarely in acute myeloid leukemia (AML) [37]. Since Notch coordinates self-renewal program of early lymphoid progenitors, activating Notchl mutations increase the selfrenewal capacity of the LSC, resulting in their susceptibility to acquire and accumulate additional genetic abnormalities. Thus, Notchl signaling deregulation is considered to be crucial for the $\mathrm{T}$ cell leukemogenesis. Most common causes in Notch1 signaling deregulation are activating mutations clustered in regions coding HD and PEST domains [38], whereas HD mutations seem to enable the ligand-independent Notch cleavage resulting in the constitutive activation of the Notch protein [39], PEST domain mutations are thought to stabilize the structure and prolong the half-life of the active Notch 1 [40]. In rare cases ( $<1 \%$ of T-ALL), the expression of truncated ligand-independent and constitutively active Notchl receptor is caused by rearrangement translocation, which juxtaposes the C-terminal region of human Notch1 gene to the TCR- $\beta$ enhancer [41]. Additionally, the half-life of Notch protein may be also increased due to loss-of-function mutations in the FBXW7 gene, coding for a component of ubiquitin ligase complex. In addition to the Notchl, it degrades various proteins, important for the T-ALL pathogenesis such as Myc and cyclin E. The FBXW7 mutations result in inability to bind to its target proteins (Notch1) or bind its targets but fail to tag them for degradation (Myc), in both cases prolonging their half-life. FBXW7 gene lesion was identified in various T-ALL cell lines and in significant number $(20 \%)$ of T-ALL patients, most of those undergoing disease relapse and resistance to treatment $[1,28]$.

Aberrant Notchl activation in T-ALL is suggested to promote deregulated proliferation and prevent apoptosis. Molecular mechanism of Notch-mediated cell-cycle progression was shown to involve activation of c-myc $[36,42]$, NFAT $[43,44]$, and AKT/PI3K pathway and inhibition of PTEN expression [45] (Figure 2). Among the targets, activated by the Notch1 in the T-ALL, transcriptional factors HES1, HERPI 1\&2, and EGF-containing fibulin-like extracellular matrix protein 1 (EFEMP1), vascular endothelial growth factor VEGF, inhibitor of DNA binding 1 (ID1), and SnoRNAs of the box H/ACA quantitative accumulation (SHQ1), immune associated nucleotide 4 like 1 IAN4L1/GIMAP5, and coreceptor CD28 were also reported [46, 47]. Notch1 upregulation enhances the G1/S transition through the induction of Skp2 expression; Skp2 is the component of E-3 ligase complex that degrades p27Kip1 and p21Cip1, inhibitors of cyclinCDK2/4 complexes [48]. NF- $\kappa$ B cascade seems also to be activated by the Notchl upregulation, and attenuation of NF$\kappa \mathrm{B}$ resulted in T-ALL suppression, both in vivo and in vitro [49]. Inhibition of apoptosis may occur through Notch1 


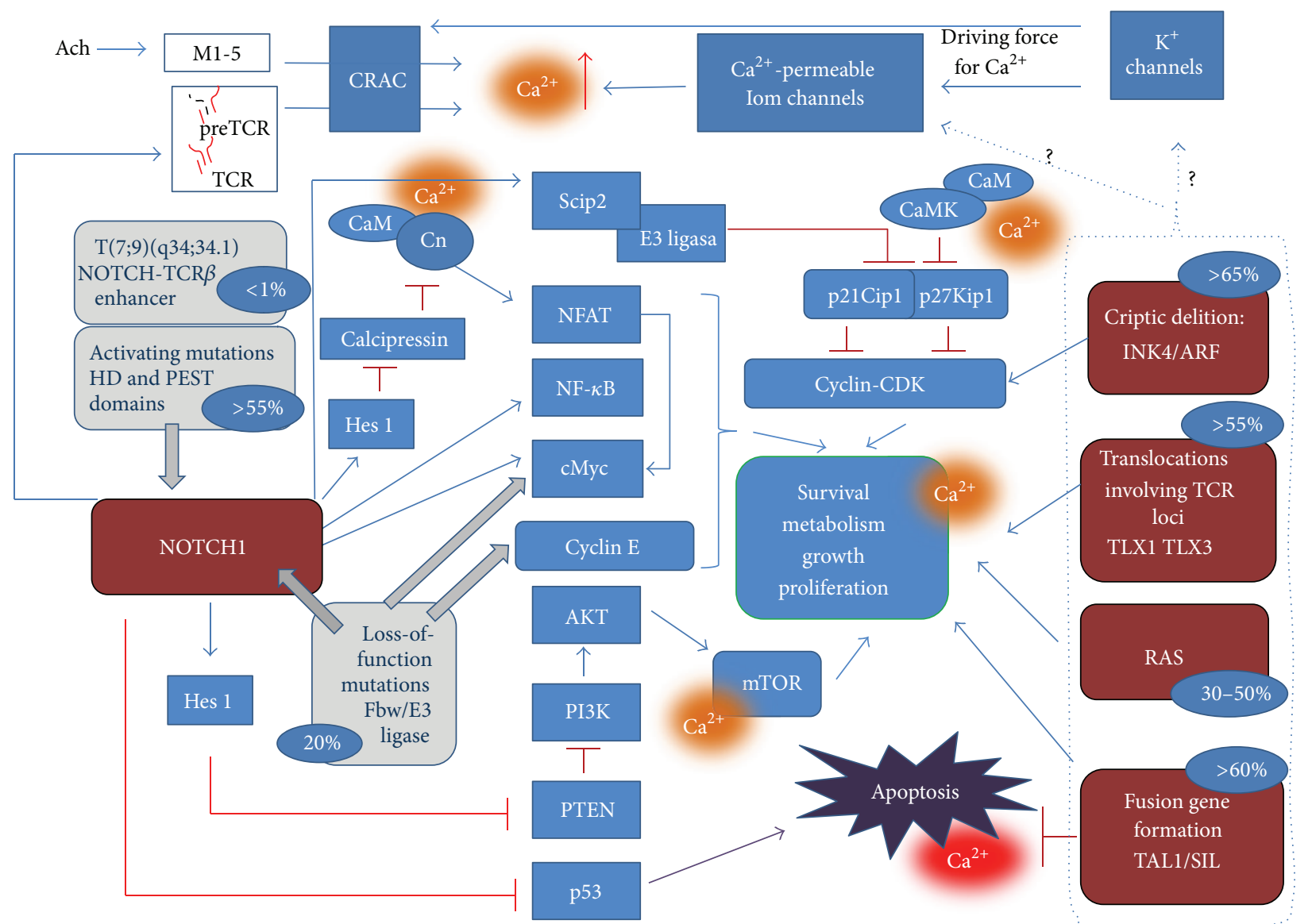

FIGURE 2: $\mathrm{Ca}^{2+}$-dependent signaling pathways in T-ALL. $\mathrm{Ca}^{2+}$ influx may occur through CRAC channels, activated in receptor-dependent manner: (a) muscarinic receptors (M1-M5) are stimulated by Ach produced by leukemic cells themselves, but mechanisms of elevated Ach production are not studied yet; (b) TCR or preTCR receptors are activated through mechanisms which may engage Notch upregulation. Another mechanism for $\mathrm{Ca}^{2+}$ influx involves activation of nonselective $\mathrm{Ca}^{2+}$-permeable channels, activated by different mechanisms. Driving force for sustained $\mathrm{Ca}^{2+}$ influx is generated by $\mathrm{K}^{+}$efflux through selective $\mathrm{K}^{+}$channels. Most important genetic lesions and signaling pathways are indicated, together with percentages for each type of lesion recognized in clinical cases. For more details, see the text.

activation of different pathways, including the NF- $\kappa \mathrm{B}$ or the $\mathrm{PKB} / \mathrm{AKT} / \mathrm{mTOR}$ ones, leading to the $\mathrm{p} 53$ inhibition [25].

The question whether Notch aberrant expression is sufficient to induce T-ALL on its own was addressed. For this, different human gain-of-function Notch1 alleles were tested for their ability to drive an ectopic $\mathrm{T}$ cell development and to induce leukemia, when expressed in murine bone marrow progenitors $[40,50]$. It was shown that the induction of the $\mathrm{T}$ cell leukemia is dependent on the Notchl signal strength. Only rare Notch1 mutations with strong downstream signaling were able to drive the T cell leukemia per se, whereas common weak gain-of-function alleles were effective only in combination with a constitutively active Ras oncogene; nonetheless they gave rise to tumors sensible to inhibition of Notchl signaling. Thus, Notch1 mutations, being indispensable for the majority of clinical T-ALL, require additional mutations in order to drive the leukemogenic process.

Ras proteins play a critical role in the transmission of survival signals from the cell membrane receptors to the intracellular transduction pathways. Mutations of RAS genes are common and have been described in various malignancies including acute leukemias [2]. They lead to the constitutive activation of the RAS-MAPK signaling cascade. Indeed, RAS lesions and activation of the tyrosine kinase genes, as a result of FLT3 and Janus kinase JAK1 mutation, or due to the ABL1/JAK2 gene fusion, have been identified, according to different studies, in 30 to $50 \%$ of clinical T-ALL cases [2]. The interest to identify these aberrations resides in the fact that they involve tyrosine kinases, for which specific inhibitors are known. These pathways are attractive candidates for a targeted therapy [51]. The AKT pathway plays a key role in the cell cycle progression and differentiation. Activation of AKT, either through PTEN loss-of-function mutations, activating mutations in the phosphatidyl inositol-3 kinase (PI3K) subunits, or AKT1 itself seem to be relatively common and occurs in nearly half of the (adult) T-ALL cases [52].

Genetic abnormalities that cause leukemia should meet a special favorable microenvironment to be realized. In pathways upregulated in the T-ALL, many functional elements depend directly or indirectly on the $\mathrm{Ca}^{2+}$ signaling (Figure 2). 


\section{TCR and $\mathrm{Ca}^{2+}$ Signaling in the T Cell Physiology}

In resting healthy $\mathrm{T}$ cells, the concentration of free intracellular $\mathrm{Ca}^{2+}\left(\left[\mathrm{Ca}^{2+}\right]_{\mathrm{i}}\right)$ is kept about $100-200 \mathrm{~nm}$ [53]. Changes in concentration of $\left[\mathrm{Ca}^{2+}\right]_{\mathrm{i}}$ represent ubiquitous signaling mechanism that regulates different phases of $\mathrm{T}$ cell physiology, including the proliferation, lineage decision in the maturation, and antigen activation [53-55]. To be able to maintain low $\left[\mathrm{Ca}^{2+}\right]_{\mathrm{i}}$ in resting cell or generate $\mathrm{Ca}^{2+}$ signal of a particular frequency and amplitude, time course, and intracellular location, every cell possesses the unique set of components, involved in this regulation, a so-called $\mathrm{Ca}^{2+}$ toolkit [56]. $\mathrm{Ca}^{2+}$ toolkit includes external sensors (plasma membrane receptors), signal transducers (such as $\mathrm{G}$ proteins and phospholipase $\mathrm{C}$ isoforms), signal-generating $\mathrm{Ca}^{2+}$ permeable ion channels, selective $\mathrm{K}^{+}$channels that hyperpolarize plasma membrane and generate a driving force for $\mathrm{Ca}^{2+}$, ER-localized $\mathrm{Ca}^{2+}$ storage proteins (such as calreticulin and calsequestrin), signal terminators that serve to return intracellular $\mathrm{Ca}^{2+}$ levels to prestimulation levels, such as the ER- and plasma membrane-localized $\mathrm{Ca}^{2+}$ pumps (SERCA and PMCA, resp.), plasma membrane exchangers, mitochondria and cytosolic buffer proteins, and $\mathrm{Ca}^{2+}$ sensors and effectors such as calmodulin (CaM) and its downstream targets, including CaM kinase (CaMK) and $\mathrm{Ca}^{2+} /$ calmodulindependent serine/threonine phosphatase calcineurin $(\mathrm{Cn})$ and protein kinase $\mathrm{C}$ (PKC). The $\mathrm{Ca}^{2+}$ toolkit may be modified during every developmental stage according to the changes in signaling events or may be remodeled in tumor cells to sustain the proliferation and avoid the cell death [56].

4.1. Mature T Cells. Antigen recognition through TCR receptor is a key event in the T lymphocyte physiology, leading to cell activation, clone expansion, and differentiation to effector cells (reviewed in [57]). Binding of the TCR to the MHC-Ag results in the assembly of the TCR/CD3 (TCR $\alpha \beta / \mathrm{CD} 3 \gamma \varepsilon \delta \varepsilon \zeta 2)$ signaling complex, which is formed by membrane-resident molecules that are physically segregated in resting $\mathrm{T}$ cells. The TCR recognition module governs MHC-Ag recognition and the association of the protein tyrosine kinase (PTK) zeta-chain-associated protein kinase of $70 \mathrm{kDa}$ (ZAP70) with the intracellular immunoreceptortyrosine-based activation motifs (ITAMs) of CD3. ITAMs are phosphorylated by the Src family PTK lymphocytespecific protein tyrosine kinase (Lck). The Src kinase module is in charge of regulating the activity of the PTKs Lck and Fyn and ensures the TCR activation threshold. CD45 dephosphorylates inhibitory tyrosine of membrane-localized Src family kinases Fyn and Lck, previously recruited and activated by CD4 or CD8 co-receptors. Activated Fyn and Lck phosphorylates ITAMs on the $\mathrm{CD} 3 \zeta$ chains. This allows binding ZAP-70 to the ITAM, and activated ZAP-70 phosphorylates tyrosines on the adaptor protein LAT, which then attracts the phospholipase C (PLC- $\gamma)$. Phosphatidylinositol4,5-bisphosphate $\left(\mathrm{PIP}_{2}\right)$ is the substrate for PLC- $\gamma$. PLC- $\gamma$ hydrolyses the $\mathrm{PIP}_{2}$, generating two second messengers, inositol $(1,4,5)$ trisphosphate $\left(\mathrm{InsP}_{3}\right)$ and diacylglycerol (DAG).
Whereas DAG activates the RAS/PKC pathway, binding of $\mathrm{InsP}_{3}$ to the InsP3R Ca ${ }^{2+}$-permeable channel, located on the endoplasmic reticulum (ER) membrane, mediates the release of $\mathrm{Ca}^{2+}$ from this store. Depletion of $\mathrm{ER} \mathrm{Ca}^{2+}$ stores is sensed by the stromal interaction molecule 1 (STIM1) protein integrated in ER membrane, which in turn induces the opening of ORAI1 calcium release-operated calcium channels (CRAC) located in plasma membrane and $\mathrm{Ca}^{2+}$ influx [58, 59].

The process of conversion the $\mathrm{Ca}^{2+}$ signal into a biological response is assured by $\mathrm{Ca}^{2+}$-binding regulatory proteins, which together form an intricate network of feedback loops to control the location, amount, and effect of calcium influx. In $\mathrm{T}$ cells, CaM is considered as a major sensor and transducer of $\mathrm{Ca}^{2+}$ signals, and among CaM-binding signal traducers are $\mathrm{Cn}$ and $\mathrm{Ca}^{2+} / \mathrm{CaM}$-stimulated protein kinases II and IV (CaMKII and CsaMKIV) [60].

$\mathrm{Cn}$ activation is foremost dependent on the intracellular $\mathrm{Ca}^{2+}$ concentration (reviewed in [61]). The $\mathrm{Cn}$ complex is composed of a catalytic subunit $\mathrm{A}(\mathrm{CnA})$ and a regulatory subunit $\mathrm{B}(\mathrm{CnB})$, tightly associated at resting conditions. $\mathrm{CnB}$ possesses four $\mathrm{Ca}^{2+}$-binding sites, two of which are of low and another two of high affinity. High-affinity sites are often referred to as structural ones and bind $\mathrm{Ca}^{2+}$ at nanomolar range, stabilizing the heterodimeric $\mathrm{Cn}$ structure. Little or no phosphatase activity is observed at $\left[\mathrm{Ca}^{2+}\right]_{\mathrm{i}}$ about $100 \mathrm{nM}$ in resting cells. The low affinity sites with $\mathrm{K}_{\mathrm{d}} \mathrm{s}$ in the micromolar range are considered as $\mathrm{Ca}^{2+}$ sensors. During signaling events causing a Ca${ }^{2+}$ rise, binding of $\mathrm{Ca}^{2+}$ ions to these sites results in sequential conformational changes (partially active form), dissociation of the CaM-binding region, binding of CaM, and displacement of the autoinhibitory inhibitory peptide from the active site (fully active form). Additionally, Cn activity is regulated by $\mathrm{Ca}^{2+}$-independent endogenous inhibitor calcipressin [62].

In T cells, NFAT is considered as a major substrate for the Cn [63]. NFAT activity is regulated by its phosphorylation status. Under resting conditions, NFAT is highly phosphorylated. During activating events, dephosphorylation of multiple sites by $\mathrm{Cn}$ causes a conformational switch of NFAT protein that allows its translocation to the nucleus. Once inside the nucleolus, NFAT cooperates with multiple transcriptional partners and binds to specific DNA response elements to regulate the transcriptional program, which is specific for every cell type and for the stimulation pattern $[64,65] . \mathrm{Ca}^{2+} / \mathrm{Cn} / \mathrm{NFAT}$ signaling was initially described in mature $\mathrm{T}$ cells as a critical regulator of the TCR-induced IL2 gene transcription [66-68]. Later it was shown that this pathway regulates the expression of numerous genes, including cytokines, as well as genes, encoding proteins involved in the regulation of survival and proliferation, apoptosis, and cell cycle $[64,65]$.

It was estimated that $75 \%$ of all activation-regulated genes in $\mathrm{T}$ cells demonstrate dependence on the $\mathrm{Ca}^{2+}$ influx [53]. The changes in $\left[\mathrm{Ca}^{2+}\right]_{\mathrm{i}}$ have been detected as the cell grows and passes through G1, G1/S, and mitosis. $\mathrm{Ca}^{2+}$ not only operates upstream of the cell-cycle machinery by regulating 
the expression, activity, and/or location of the transcription factors that control expression of the G1 cyclins (FOS, JUN, MYC, CREB-ATF1 (activating transcription factor 1), and NFAT), but also acts more directly on the cyclins, CDKs, and/or their small protein inhibitors to regulate the assembly and activation of CDK complexes (reviewed in [56]).

Whereas initial $\mathrm{T}$ cell activation is related to short-term local $\left[\mathrm{Ca}^{2+}\right]_{\mathrm{i}}$ raise, subsequent events related to a new gene expression all require a sustained $\mathrm{Ca}^{2+}$ influx to maintain $\left[\mathrm{Ca}^{2+}\right]_{\mathrm{i}}$ at level higher than basal one in resting cells. In addition to CRAC channels, other $\mathrm{Ca}^{2+}$-permeable channels have been found in $\mathrm{T}$ lymphocytes and proposed as $\mathrm{Ca}^{2+}$ influx pathways during different physiological events (as discussed below).

4.2. Maturing Thymocytes. TCR signaling coordinates thymocytes maturation as well [6]. The survival of "correctly" developed thymocytes in the thymus depends crucially on the signaling trough pre-TCR [6]. The process of $\beta$ selection is the first critical checkpoint related to the pre-TCR signaling [69]. Only DN3 cells that have productively rearranged a TCR $\beta$ chain, which can assemble with the invariant pre-T $\alpha$ and CD3 molecules to form the pre-TCR complex, are selected for further differentiation [70]. Expression of the functional preTCR in the DN3 promotes survival and proliferation (DN4) and following differentiation to the DP stage. Remarkably, transition of the DN to the DP demonstrates apparent independence of the pre-TCR on the ligand. The ligandindependent nature of pre-TCR signaling has been attributed to its localization closely to other signaling molecules in lipid rafts and to the relatively low signaling threshold of pre-T cells $[71,72]$. Notchl is considered as a probable candidate for this signaling molecule, because the interaction between Notch and its Delta-like ligand expressed at stromal cells indeed plays an essential role in enabling the autonomous signaling capacity of the pre-TCR complex $[17,73]$. These findings provided a functional basis for the observed pattern of the Notch receptor expression and activation in developing thymocytes, since several reports have showed that levels of Notch1 and Notch3 expression and activity are significantly higher in the DN than in the DP thymocytes [10, 74-76].

$\mathrm{T}$ cell development from immature DP thymocytes to the mature $\mathrm{CD}^{+}$or $\mathrm{CD}^{+} \mathrm{SP}$ stage is also coordinated by the TCR signaling. The current working model suggests that the interaction strength between the TCR and the self-MHC complex determinates the destiny of maturated thymocyte. Little-or-none signal means that this thymocyte is unable to recognize self-MHC and will undergo death by neglect. A too strong signal will lead to a negative selection to avoid a generalized T cell aggression toward self-tissues. Only signals of intermediate range will culminate in survival (positive selection) [6].

TCR engagement activates the Cn/NFAT signaling not only during the activation of mature $\mathrm{T}$ lymphocytes, but also at the specific steps of thymocytes development (revised in [77]). By Cn inactivating during haematopoietic development, it was demonstrated that this signaling pathway plays an important, nonredundant role in the regulation of lymphocyte developmental checkpoints, in contrast to development of myeloid lineages [78]. More specifically, absolute requirement for $\mathrm{Cn}$ in positive but not in negative selection was demonstrated [79]. Early studies using a Cn inhibitor cyclosporine A (CsA) showed an impaired development of the DP thymocytes into SP $[80,81]$. NFAT is upregulated during the T cells maturation $[18,19]$. Disruption of NFAT in the DP thymocytes results in fewer SP cells and is associated with defects in the expression of the antiapoptosis protein Bcl-2 by DP cells [82]. Since NFAT activation is strongly dependent on the $\mathrm{Ca}^{2+}$ rise, involvement of transport systems in regulation of thymocyte maturation should be expected. Nevertheless, there are still few studies on this subject.

In experiments with mouse models, it was shown that the constitutive pre-TCR signaling induces the NFAT and NF- $\kappa \mathrm{B}$ activation, associated with an increased rate of the $\mathrm{Ca}^{2+}$ influx through the CRAC channels. Herewith, the biphasic nature of the cytosolic $\mathrm{Ca}^{2+}$ rise was observed, which differentially modulated the activities of the transcription factors NF- $\kappa \mathrm{B}$ and NFAT in developing T cells [28].

Recently, Lo and colleagues have investigated the $\mathrm{Ca}^{2+}$ signaling during positive and negative selection in the $\mathrm{CD} 4^{+}$ MHCII-restricted T cells [83]. They demonstrated that negative selection induced a strong $\mathrm{Ca}^{2+}$ flux, and such a high $\mathrm{Ca}^{2+}$ peak might play a key role in inhibiting channel activity and decreasing transcript expression. On the other hand, a weaker yet more sustained $\mathrm{Ca}^{2+}$ flux was observed during positive selection. It was suggested that it may activate the $\mathrm{Cn}$ - and Erk-dependent pathways, leading to the survival and maturation. The authors consider that a sustained character rather than the magnitude of $\mathrm{Ca}^{2+}$ flux is the key function to support the positive selection. They identified a voltagegated $\mathrm{Na}^{+}$channel (VGSC), essential for a positive selection of $\mathrm{CD}^{+} \mathrm{T}$ cells. Pharmacological inhibition of the VGSC activity inhibited sustained $\mathrm{Ca}^{2+}$ influx induced by positiveselecting ligands and in vitro positive selection of $\mathrm{CD} 4^{+}$but not $\mathrm{CD}^{+} \mathrm{T}$ cells.

Interestingly, there are indications that the positive selection of $\mathrm{CD}^{+}$T cells may involve somewhat more intense and long-lasting signals that are required for the positive selection of $\mathrm{CD}^{+} \mathrm{T}$ cells [84]. Melichar and colleagues reported a distinct temporal pattern of the $\mathrm{T}$ cell receptor signals during positive versus negative selection in $\mathrm{CD}^{+}$cells in situ [85]. However, in contrast with studies carried out on $\mathrm{CD} 4^{+}$cells [84], they found that brief serial signaling events, which were separated by migratory periods and low cytosolic $\mathrm{Ca}^{2+}$, correlated with the positive selection of MHCI-restricted thymocytes, whereas sustained signaling and arrest of thymocytes were associated with negative selection [85].

It is widely accepted that $\mathrm{Ca}^{2+}$ entry through CRAC channels is the main pathway to increase intracellular $\mathrm{Ca}^{2+}$ concentration in the peripheral blood T cells [58]. But CRAC seems not to play a central role in $\mathrm{Ca}^{2+}$ signaling during $\mathrm{T}$ cell maturation because $\mathrm{T}$ cell positive selection is normal in multiple separate knockouts of STIM and ORAI [86]. Loss-of-function STIM1 mutations were also reported in human patients [87]. Clinically, they demonstrated severe immunodeficiency with susceptibility to viral and bacterial 
infections, but practically normal $\mathrm{T}$ cell repertoire. The latter clearly indicates that the $\mathrm{T}$ cell maturation was not greatly affected. But, as expected, their T cells were unable to generate $\mathrm{Ca}^{2+}$ rise in response to antigenic stimuli.

Thus, regulation of multiple decision steps in thymocyte development is coupled to a complex modulation of $\mathrm{Ca}^{2+}$ fluxes, but CRAC channels do not seem to necessarily play the central role. It was proposed that nonstore operated $\mathrm{Ca}^{2+}$ channel(s) which might operate independently of STIM and ORAI may be involved, or alternatively, CRAC channels play an important but redundant role $[83,88]$. There are some evidences in favor of this hypothesis. For example, deletion of TRPM7 $\mathrm{Ca}^{2+} / \mathrm{Mg}^{2+}$-permeable channel with an intrinsic kinase activity results in a block in thymocyte development at the DN stage [89]. Thereby the presence of "unusual" ion channels reported in leukemic cell lines may reflect both normal developmental thymic events and leukemogenesis.

4.3. T-ALL. It was the subject of long time debate, whether the contribution of $\mathrm{Ca}^{2+}$ signaling is imperative for the tumor growth progression. Conventional view supported the idea that malignant cells are much less dependent on $\mathrm{Ca}^{2+}$ during the proliferation than healthy cells, and even loss of proliferative dependency on $\mathrm{Ca}^{2+}$ was considered as a hallmark of malignant transformation (reviewed in [56]). Although relative independence on $\mathrm{Ca}^{2+}$ may occur in some type of cancers, the situation in general is much more complex. The question rather should be discussed in terms of the $\mathrm{Ca}^{2+}$ signaling deregulation, where some elements of the $\mathrm{Ca}^{2+}$ toolkit in transformed cells are downregulated whereas others are upregulated. Monteith and colleagues have undertaken a thorough analysis of available data, concerning variations in the expression and activity of some $\mathrm{Ca}^{2+}$ channels and pumps in tumors and cancer cell lines. They did not reveal any uniform profile characteristic for cancerous cells [90]. Rather, they point out to some potentially predictable consequences of the trends. They also provided available data on the aberrant location of $\mathrm{Ca}^{2+}$ channels in many types of tumors, which could change the nature of the $\mathrm{Ca}^{2+}$ signal and a subsequent biological response.

$\mathrm{Ca}^{2+}$ homeostasis controls various cellular processes, which are relevant to the tumorigenesis, such as proliferation, apoptosis, gene transcription, and angiogenesis (see for review [90]). $\mathrm{Ca}^{2+}$ is a key regulator of proteins, implicated in the cell cycle regulation: Ras, immediate early genes in $\mathrm{G} 0 / \mathrm{G} 1$ transition, retinoblastoma $(\mathrm{Rb})$ protein in $\mathrm{G} 2$. In addition to cell cycle regulation, $\mathrm{Ca}^{2+}$ is implicated in cellular motility, which in turn contributes to the tumor invasion and metastasis. $\mathrm{Ca}^{2+}$ was shown to be an important regulator of genomic stability and transcription, critic events in leukemogenesis. There are limited studies that specifically address possible alterations in different elements of $\mathrm{Ca}^{2+}$ toolkit and $\mathrm{Ca}^{2+}$ signaling in tumorigenesis. Therefore it looks that question about these kinds of alterations should be addressed specifically for every type of tumors.

Taking into account that the TCR signaling related to the $\mathrm{Ca}^{2+}$ rise and $\mathrm{Cn}$ activation is a central coordinator of $\mathrm{T}$ cell physiology, we will analyze the possibility of contribution of this pathway to $\mathrm{T}$ cell malignancy.
Proliferation of leukemic cells is obviously antigenindependent. But being derived from the T-lymphoid precursors, arrested at different early stages of the development, T-ALLs demonstrate an astonishing heterogeneity in their TCR/CD3 phenotypes [91, 92]. Apropos, T-ALL classification by EGIL (European Group for the Immunological Classification of Leukemias), is based on the presence of CD3 and TCR chains [93]. The cytoplasmic and then membrane expression of CD3 is an early event in the T cell ontogeny [94]. Then the presence of CD3, either at the surface (sCD3) or in the cytoplasm (cCD3), is a determinative feature of these malignances [94]. TCR genes rearrangements are found in a majority of the T-ALL; the presence of TCR chains at the surface or in cytoplasm is mostly characteristic for mature stages [95]. Accordantly, T-ALLs are distributed in five immunophenotypic subtypes: pro-T-ALL (TI), pre-TALL (TII), cortical-T-ALL (TIII), and mature $\alpha \beta$ or mature $\gamma \delta$ (TIV) [93, Figure 2].

TI leukemias do not possess the TCR chains [2]. In some animal models like E2A-deficient mice, defects that prevent the pre-T cell antigen receptor expression even tend to accelerate the Notch-dependent lymphomagenesis [96]. Then the question arises, whether the pre-TCR or TCR is involved in the neoplastic transformation in other more mature T progenitors. It seems logical that the pre-TCR/TCR requirement for leukemogenesis greatly depends on the context and other signaling pathways involved in process. Accordingly, the role for the pre-TCR/TCR was studied in diverse mouse models, where leukemogenesis was provoked by abnormalities in different signaling pathways. It has been observed that the pre-TCR assists leukemogenesis, driven by the Notch activation [97-99], c-Myc overexpression [100], or Ikaros deficiency [101]. In contrast, other T cell leukemia mouse models, such as eg Trp53- or ATM-deficient mice, do not show such pre-TCR dependency $[102,103]$. Some of these studies are described in more detail below.

Bellavia and colleagues used transgenic mice with upregulated constitutively active intracellular domain of the Notch3, which is ordinarily downregulated as thymocytes maturate [97]. The mice developed early and aggressive T cell neoplasias with features of immature thymocytes, including expression of the $\mathrm{pT} \alpha$, a defining component of the pre$\mathrm{T}$ cell receptor, known to be a potent signaling complex provoking thymocyte survival, proliferation, and activation. Deletion of the pT $\alpha$ in Notch3 transgenic mice abrogates tumor development, indicating a crucial role for the $\mathrm{pT} \alpha$ in the $\mathrm{T}$ cell leukemogenesis. In addition, the analysis of 30 samples, derived from children with T-ALL, demonstrated expressions of Notch3 and its target gene HES-1, as well as of pT $\alpha$ transcripts. Remarkably, the expression of all these genes was dramatically reduced or absent in the remission. In another clinical report, SCL overexpression was invariably associated with a high TCR expression in childhood T-ALL [1].

Similarly, pre-TCR expression was demonstrated to cooperate with TEL-Jak2 to transform thymocytes and induce rapid T-ALL [99]. However, in the pre-TCR-deficient TELJAK2 mice, the T cell leukemogenesis was only delayed but not canceled [104]. In Notch-dependent T-ALL, pre-TCR 
signaling was required to condition mice for the Notchdependent transformation but it was not required to sustain the malignant growth of the T-ALL [98]. Since the pre-TCR signaling is associated with a proliferative burst of thymocytes, accompanying differentiation stages [28], it was suggested that the pre-TCR-assisted proliferation in preleukemic cells increases the probability to acquire secondary oncogenic events, ultimately leading to a clonal disease [99]. Importantly, TCR expression induces the leukemic cell expansion in secondary lymphoid organs indicating the importance of the TCR-related signaling for the motility of leukemic cells [99].

Further studies of the pre-TCR signaling in leukemogenesis were designed to reveal the importance of the associated CD3 molecules for the leukemogenesis. The experiments were based on the fact that the pre-TCR and TCR require association with the $\mathrm{Cd} 3 \varepsilon$ for signaling [105]. Therefore, the $\mathrm{Cd} 3 \varepsilon$-deficient cells have nonfunctional pre-TCR/TCRs. As it was shown, the absence of the $\mathrm{pT} \alpha$ chain only slightly delays the appearance of the TAL1/LMO1-induced T-ALL in mice, while $C D 3 \varepsilon$-deficient mice do not develop the TAL1/LMO1induced T-ALL [106]. Then it was concluded that $\mathrm{pT} \alpha$ chain seems to play a minor role, but the $C D 3 \varepsilon$-mediated signal transduction pathway is essential for the transformation process. Similar results were obtained with another, namely, SCL/LMO1-induced T-ALL, using transgenic mice as a model [33]. They show that mice with SCL/LMO1 upregulation developed the Notchl activation and T-ALL with a $100 \%$ penetrance, whereas, in strain with an additional $\mathrm{Cd} 3 \varepsilon$ deficiency, the penetrance of the disease was decreased by $48 \%$ and the median survival significantly increased. It was suggested that SCL, LMO1, and Notchl together with an active pre-TCR/CD3 might represent the minimum set of complementing events for the transformation of susceptible thymocytes [33].

Immunophenotyping of frequently used T cell leukemia cell lines revealed high heterogeneity in the TCR expression [91]. It was suggested to consider the particular differentiation stage of each individual cell line, while using the T-cell leukemia lines as models for malignant or normal $\mathrm{T}$ cells.

Altogether the data available to the moment indicate that the pre-TCR/CD3 signaling accelerates the T cell leukemogenesis, being involved in the proliferation and in the expansion of leukemic cells to secondary lymphoid organs.

$\mathrm{Cn}$ is sustainably activated in T lymphoid malignances, both in animal models and biopsies from human lymphomas [43, 107-109]. The role of Cn activity in the pathogenesis of T-ALL was demonstrated in well-designed experiments with the usage of two different mouse models, related to human $\mathrm{T}$ leukemias [43]. In one model, bone marrow cells were retrovirally transduced with a construct, encoding the activating intracellular Notch1 domain. In a second model, transgenic mice expressed the TEJ/JAK2 fusion protein. In both models, mice developed the T-ALL, with a constitutive dephosphorylation of the NFAT in leukemic cells, indicating an aberrant $\mathrm{Cn}$ activation. Mice treatment with the $\mathrm{Cn}$ inhibitors CsA and FK506 resulted in disease remission with the hematopoiesis restoration [43].

Increased Cn/NFAT activity by the Notch signaling was shown to involve a downregulation of calcipressin through the Hes1-dependent mechanism [110]. As far as the Hes-1 is upregulated in T leukemias through the Notch1, this mechanism was proposed to be involved in the leukemogenesis [62, Figure 2]. Few reports have described different mechanisms of a sustained $\mathrm{Cn}$ activation due to the gain-of-function mutation in the $C n A$ in $\mathrm{T}$ or $\mathrm{B}$ lymphoma-derived cell lines $[111,112]$. In the EL4 murine T lymphoma cells, a missense mutation changed an evolutionary conserved aspartic acid to the asparagine within the autoinhibitory domain of the $C n A \alpha$ gene [111]. This substitution leads to the generation of a mutant $\mathrm{CnA} \alpha$, hypersensitive to $\mathrm{Ca}^{2+}$ [111]. But still, the elevated $\left[\mathrm{Ca}^{2+}\right]_{\mathrm{i}}$ is an indispensable factor to maintain the $\mathrm{Cn}$ activity, since mutations resulting in a persistent $\mathrm{Cn}$ activation, independent of $\mathrm{Ca}^{2+}$, were never reported.

As was already mentioned earlier, the NFAT activation is a hallmark of the T-ALL. While activated mutations of NFAT genes have been never observed in human cancers, the aberrant NFAT signaling in tumors was suggested to involve either its overexpression and/or hyperactivity (reviewed in [113]). NFAT hyperactivity in the T-ALL is likely to be related to the Notch-dependent Cn upregulation (Figure 2). NFATc1 nuclear localization or dephosphorylation of both NFATc1 and NFATc2 were found in primary tumor samples and cell lines, derived from a patient with an aggressive T-cell lymphoma. Moreover treatment of these cell lines with CsA triggered the cell cycle inhibition and induced apoptosis [43].

\section{Neglected Pathway in the T Cell Physiology: Lymphoid Cholinergic System Is Upregulated in Leukemias}

Calcium mobilization, following the TCR ligation during the T cell activation is essential but is not the only way of the $\mathrm{Ca}^{2+}$ rise generation in $\mathrm{T}$ lymphocyte. Less considered pathway is related to a nonneuronal lymphoid cholinergic system. Lymphocytes possess all components of independent cholinergic system that include the acetylcholine (ACh), choline acetyltransferase (ChAT), its synthesizing enzyme, and both muscarinic (mAChR, M1-M5) and nicotinic (nAChR) ACh receptors [114-116]. Human T lymphocytes produce a small quantity of Ach and up-regulate the ChAT and $\mathrm{mAChR}$ mRNA expression in a response to the TCR activation. Ligand binding to the PLC-coupled M1, M3, and M5 mAChRs induces rapid increases in $\left[\mathrm{Ca}^{2+}\right]_{\mathrm{i}}$ with $\mathrm{Ca}^{2+}$ oscillation via the $\mathrm{IP}_{3}$-evoked $\mathrm{Ca}^{2+}$ rise from the intracellular store. This pathway was suggested as an amplification mechanism to increase the IL2 and IL2R production [117] and the c-fos expression [116] during the TCR stimulation. In addition, M1 is known to play a critical role in the differentiation of $\mathrm{CD}^{+}$cells into the CTL [118]. Emerging evidence indicates that mAChRs may be implicated in the regulation of the cell proliferation and cancer progression in leukemogenesis [119]. As for the T cell leukemias, the Ach production was shown to be drastically increased in different T-ALL-derived cell lines, when compared to the resting mononuclear cells [120]. It could be suggested that a sustained $\mathrm{Ca}^{2+}$ influx in leukemic cells may be maintained by elevated Ach production and autocrine stimulation through the mAChRs ligation. 


\section{What Do We Know about the Relationship between T Leukemia-Related Mutations/Pathways and Ion Channel Expression and Activity?}

Taking into account the purpose of the present review, we have undertaken the bibliographic search of the data on possible involvement of transcriptional elements, misregulated in the T-ALL, in the ion channel expression and activity.

To identify TAL1 direct target genes, Palomero and colleagues have undertaken the chromatin immunoprecipitation experiments with antibodies raised against the TAL1 in Jurkat $\mathrm{CD}^{+}$cell line as a model [121]. It was shown that the TAL1 binds to promoters of 71 target genes, encoding proteins important for many vital cellular processes. The list of target genes includes receptor and surface molecules, intracellular signal transduction elements, transcription factors, and DNA-associated proteins, proteins that participate in the DNA reparation, vesicular trafficking, drug resistance, secreted molecules and growth factors, ion channels, and transporters. Among ion channels and transporters which represent a significant portion of direct targets for the TAL1 the authors specifically indicated the CHRNA5 (subunit alpha-5 of the nicotinic acetylcholine receptor), ACCN2 (Amiloride-sensitive cation channel 2), CACNG4 (gamma4 subunit of the L-type voltage-dependent calcium channel), KCNJ9 (G protein-activated inward rectifier potassium channel 3), SLC4A11 (sodium bicarbonate transporter-like protein 11), and OKB1 (organic cation transporter). The presence of other transcriptional factors as TAL1 target proteins suggests the existence of a very complex TAL1-dependent transcriptional network in the T-ALL with aberrant expression of a number of proteins implicated in different cell processes. Importantly, it was shown that TAL may act as an activator or as a repressor for target genes. Further experiments with other T leukemic lines (MOLT) and primary T-ALL samples demonstrated high levels of variation in the expression profiles of TAL1 target genes.

Notch 1 activation, being a hallmark of many types of the T-ALL, is also involved in the pathophysiology of other cancers. Then we undertook a search for data on the possible relationship between the Notchl activation and ion channel expression. For example, aggressive and malignant state of glioblastoma multiforme (GBM), the most frequent and incurable type of the brain tumor of adults, was shown to be related to an increased activation of the Notch1 provoked by hypoxia [122]. Notchl activation in turn induced the expression of transient receptor potential 6 (TRPC6) $\mathrm{Ca}^{2+}$-permeable channels in primary samples and cell lines derived from GBM. Functionally, TRPC6 caused a sustained elevation of the intracellular $\mathrm{Ca}^{2+}$ coupled to the activation of the calcineurin-related NFAT pathway. TRPC6 was shown to be required for the development of the aggressive tumor phenotype, because a knockdown of the TRPC6 inhibited the glioma growth, invasion, and angiogenesis. Notch-dependent transcription of the TRPC6 was reported in pheochromocytoma PC12 cells [123]. Interestingly, TRPC6 mRNA was also found in the T-ALL cell line Jurkat, in contrast to T cells obtained from healthy donors, but the question about its relation to aberrant activation of Notch1 and NFAT was not addressed yet [124].

\section{Nondifferentially Expressed Genes in T-ALL Signaling: Ion Channels May Be Involved}

Traditionally, the T-ALL diagnostics and corresponding therapeutic strategies are based on the differential expression (DE) of genes, that occurred in the T-ALL patients as compared to healthy persons. However, as it was recently pointed out by Maiorov and colleagues (2013), the expression of some genes might not vary in the T-ALL, but, instead, these genes may be interconnected with highly differentially expressed ones [125]. They have proposed a network-based approach instead of the expression-based one for better understanding and management of the T-ALL and identified 19 significant subnetworks that represent clusters of functionally related, both DE and non-DE, genes. So non-DE genes code the proteins that in pathologic conditions may be involved in signaling networks different from those they normally belong to. It was proposed that non-DE genes could be essential in the interconnection of numerous DE genes and play important roles in malignant transformation of the precursor T cells. Purinergic receptor P2RX7, complement component C9, plasminogen, $\mathrm{Ca}^{2+}$-binding protein $\mathrm{CHGA}$, and peptide hydrolase MEPIA were pointed out among the non-DE genes in T-ALL.

\section{Ion Channels in T Cell Physiology}

Tumor cells survival and proliferation, activation, differentiation and malignant progression, invasiveness/migration (via volume regulation, polarization, cytoskeleton, and extracellular matrix reorganization), and, at last but not the least, the resistance to anticancer therapies, all these critically depend on the function of ion channels. T lymphocytes and leukemic $\mathrm{T}$ cells bear authentic orchestras of $\mathrm{K}^{+}$-selective, $\mathrm{Ca}^{2+}$-selective, and nonselective cation and anion channels. Wherein, their local combinations one with another and with other signaling components form a highly specific microenvironment, essential for cellular performance. The first purpose of this chapter is to give an overview of ion channels, expressed in T-cells, along with their known functions and giving emphasis to those, which are differentially expressed in healthy and leukemic cells. The second purpose is to revise the channel-to-channel functional communications, especially those related to a formation of specific $\mathrm{Ca}^{2+}$ signal. The third is to present, whenever it is possible, the structural and functional view on membrane signaling complexes, involving an ion channel as a core element.

Potassium- $\left(\mathrm{K}^{+}-\right)$selective channels reported up to the date in healthy or neoplastic lymphoid cells belong to several families: voltage-gated $\left(\mathrm{K}_{\mathrm{v}}\right), \mathrm{Ca}^{2+}$-activated $\left(\mathrm{K}_{\mathrm{Ca}}\right)$, and tandem-pore domain $(\mathrm{K} 2 \mathrm{P})$ channels. $\mathrm{K}^{+}$channels may act via their ionotropic function or via noncanonical nonconducting mechanisms, that is, via direct interaction with other membrane or cytosolic proteins. Channels' mediated $\mathrm{K}^{+}$ 
transport causes a change of membrane voltage, affects a driving force for $\mathrm{Ca}^{2+}$ influx, and, via changes of intracellular $\mathrm{K}^{+}$, regulates the cell volume (in parallel with the activity of anion channels, see below) and, more specifically, affects the activity of the intracellular machinery, for example, activation of caspases in the course of apoptosis [126-128]. Membrane potential affects the cell cycle progression. Whereas G1/S transition is associated with a hyperpolarization (high $\mathrm{K}^{+}$conduction), the $\mathrm{G} 2 / \mathrm{M}$ one occurs with a depolarization and low $\mathrm{K}^{+}$ conductance [129]. Blockers of $\mathrm{K}^{+}$channels cause $\mathrm{Gl}$ arrest [130]. Also volume changes during cell cycle, for example, volume decrease during the $\mathrm{M}$-phase prior to cytokinesis, requires a $\mathrm{K}^{+}$efflux via voltage-gated (e.g., $\mathrm{K}_{\mathrm{V}} 10.2$ ) $\mathrm{K}^{+}$ channels [131]. G1/S progression and G2/M transition also require $\mathrm{Ca}^{2+}$ bursts. The former includes activation of CDKs and culminates through phosphorylation of Rbl in activation of E2F transcription factors. During progression of the G1 phase several processes like expression of AP1 (JUN and FOS) and CREB transcription factors, as well as regulation of cyclins, are calmodulin dependent, whereas transport of the transcription factor NFAT to nucleus requires the calcineurin-mediated dephosphorylation [56]. In T cells the $\mathrm{Ca}^{2+}$ signaling is critically dependent on the activity of partner $\mathrm{K}^{+}$channels as will be discussed below.

8.1. $K_{\mathrm{v}} 1.3 . \mathrm{K}_{\mathrm{v}} 1.3$ is the only one of 40 of the $\mathrm{K}_{\mathrm{v}}$ family members known in mammals [136], which is expressed in healthy human $\mathrm{T}$ cells; in murine $\mathrm{T}$ cells, $\mathrm{K}_{\mathrm{v}} 3.1, \mathrm{~K}_{\mathrm{v}} 1.1, \mathrm{~K}_{\mathrm{v}} 1.2$, and $\mathrm{K}_{\mathrm{v}} 1.6$ were found in addition [126]. $\mathrm{K}_{\mathrm{v}} 1.3$ is steeply activated by a depolarization with a half-activation at about $-30 \mathrm{mV}$ and inactivates up to by $95 \%$ in even more steeply voltage-dependent process, with a midpoint around $-50 \mathrm{mV}$. At resting membrane potentials $(-40--50 \mathrm{mV})$ only a tiny fraction of $\mathrm{K}_{\mathrm{v}} 1.3$ channels remains open at a steady state [137-139]. Thus, lower membrane potentials down to $\mathrm{K}^{+}$ equilibrium, which are observed at the G1/S transition in the cell cycle, require the activity of some voltage-independent $\mathrm{K}^{+}$(e.g., $\mathrm{K}_{\mathrm{Ca}}$ or $\mathrm{K} 2 \mathrm{P}$ ) channel(s), open at this voltage range. $\mathrm{K}_{\mathrm{v}} 1.3$ channel at its C-terminus forms a functional complex with the $\beta 1$-integrin, the PDZ-domain protein SAP97, linked to the p56Lck kinase and an adapter ZIP protein; the $\mathrm{N}$-terminus in turn could bind a $\mathrm{K}_{\mathrm{v}} \beta 2$ subunit (redox sensing), which may eventually interact with ZIP protein [140, Figure 3(a)]. Channel opening, provoked by membrane depolarization, stimulates functional and physical interactions between $\mathrm{K}_{\mathrm{v}} 1.3$ and $\beta 1$-integrin moieties and activates the integrin function, adhesion, and migration, whereas specific $\mathrm{K}_{\mathrm{v}} 1.3$ channel blockage prevents the integrin signaling [141]. Functions of the $K_{v} 1.3$ in $T$ cells include but not restricted to (1) control of membrane potential against a depolarization challenge, depending on the $\mathrm{T}$ cells subset [142, 143]; (2) regulatory volume decrease (RVD), together with VSOR [144, 145], and apoptotic volume decrease (AVD) [146, 147]; (3) support of a sustained $\mathrm{Ca}^{2+}$ influx by CRAC, generation of $\mathrm{Ca}^{2+}$ oscillations (together with $\mathrm{K}_{\mathrm{Ca}} 3.1$ and TRPM4). A sustained, lasting over hours, $\mathrm{Ca}^{2+}$ increase, which is primordial for new gene expression, is triggered in $\mathrm{T}$ cells via the $\mathrm{Ca}^{2+} /$ calcineurin/NFAT pathway [55]. A block of both
$\mathrm{K}_{\mathrm{v}} 1.3$ and $\mathrm{K}_{\mathrm{Ca}} 3.1$ tends to abolish $\mathrm{Ca}^{2+}$ oscillations, with an impact on $\mathrm{T}$ cells proliferation [148]. In Jurkat leukemic $\mathrm{T}$ cells, selective inhibition of $\mathrm{K}_{\mathrm{v}} 1.3$ abolished oscillations of the CRAC-mediated $\mathrm{Ca}^{2+}$ entry but not the average $\mathrm{Ca}^{2+}$ entry [149], which likely depends more on the $\mathrm{K}_{\mathrm{Ca}}$ channels activity (see below). Obviously, CRAC and $\mathrm{K}_{\mathrm{Ca}} 3.1$ activities are linked in a feedforward manner, so that the activation of $\mathrm{K}_{\mathrm{Ca}} 3.1$ by $\mathrm{Ca}^{2+}$ influx via CRAC will hyperpolarize the membrane, increasing CRAC-mediated $\mathrm{Ca}^{2+}$ influx, and so forth. To reverse this $\mathrm{Ca}^{2+}$ increase, additional mechanisms are required which may be CRAC inactivation by $\mathrm{Ca}^{2+}[150]$ and/or membrane depolarization, caused by unique $\mathrm{Ca}^{2+}$ impermeable member of the TRP family, the TRPM4 (see below). Kv1.3 is a predominant (several hundred copies per cell) $\mathrm{K}^{+}$channel in naïve human $\mathrm{T}$ cells, which functionally express just few $\mathrm{K}_{\mathrm{Ca}} 3.1 . \mathrm{K}_{\mathrm{v}} 1.3$ plays a very essential role in the lymphocyte activation and associated $\mathrm{Ca}^{2+}$ signaling and IL-2 production. Upon the activation, differential behavior is observed in diverse $\mathrm{T}$ cell subsets. In activated $\mathrm{T}_{\mathrm{EM}}$ (effector memory) cells $\mathrm{K}_{\mathrm{v}} 1.3$ is selectively upregulated (highK $\mathrm{V}_{\mathrm{v}} 1.3$ : lowK $\mathrm{Ca}_{\mathrm{Ca}} 3.1$ phenotype); on the contrary, in $\mathrm{T}_{\mathrm{CM}}$ (central memory) cells, Kv1.3 only modestly upregulated, whereas $\mathrm{K}_{\mathrm{Ca}} 3.1$ dramatically (by 1.5 order of magnitude increase), producing lowK $\mathrm{K}_{\mathrm{v}} 1.3$ : highK $\mathrm{Ca} 3.1$ phenotype [151154]. Accordingly, specific inhibition or silencing of the $K_{v} 1.3$ decreases the proliferation of $\mathrm{T}_{\mathrm{EM}}$ without significant effect on $\mathrm{T}_{\mathrm{CM}}$ and naïve cell population [155]. Immunosuppression can be achieved via the Kv1.3 specific inhibition and resulting depolarization, which attenuates the $\mathrm{Ca}^{2+}$ influx via CRAC. Selective $\mathrm{K}_{\mathrm{v}} 1.3$ suppression was only efficient upon $\mathrm{Ca}^{2+}$ dependent lymphocyte activation and not in the cases of CD28 or IL-2-induced activation, which is independent on the intracellular $\mathrm{Ca}^{2+}$ rise [156]. Curiously, when expressed in heterologous system, $\mathrm{K}_{\mathrm{v}} 1.3$-mediated cells proliferation was unaffected in a poreless mutant (albeit sensitive to supposedly sole open-pore blockers, MgTx and PAP-1) but abolished in a mutant with altered voltage gating [157]. It appears then that the conformational change of $\mathrm{K}_{\mathrm{v}} 1.3$ protein upon the channel opening may be sufficient for an efficient signaling, without involving a $\mathrm{K}^{+}$flux or membrane polarization. Such conformational coupling may be mediated by a close association of Kv1.3 channels with $\beta 1$-integrin $[141,158]$.

Comparison of the $\mathrm{K}_{\mathrm{v}} 1.3$ channels density in human peripheral blood resting $\mathrm{T}$ cells $[137,138,141,153,159-163]$ and Jurkat lymphoblasts [139, 147, 149, 164-167] gives mean values of 380 and 215 active $K_{v} 1.3$ copies per cell, respectively. In activated $\mathrm{T}$ cells, depending on subpopulation, the number of $\mathrm{K}_{\mathrm{v}} 1.3$ channels could increase, modestly or very significantly, up to 1800 copies per cell [153]. Taking an approximately 3-fold larger membrane surface in Jurkat lymphoblasts into account, the $\mathrm{K}_{\mathrm{v}} 1.3$ density, expressed as number of channels per unit area, is substantially lower in Jurkat cells. Yet, bearing in mind a complex Kv1.3 regulation within a signalosome, with all or some of interacting proteins involved [140] one may wonder, should such regulation be equally or more important than just a variation of the $K_{v} 1.3$ copies numbers. Signaling complex, presented in Figure 3(a), exists within an immunological synapse. Thus, 


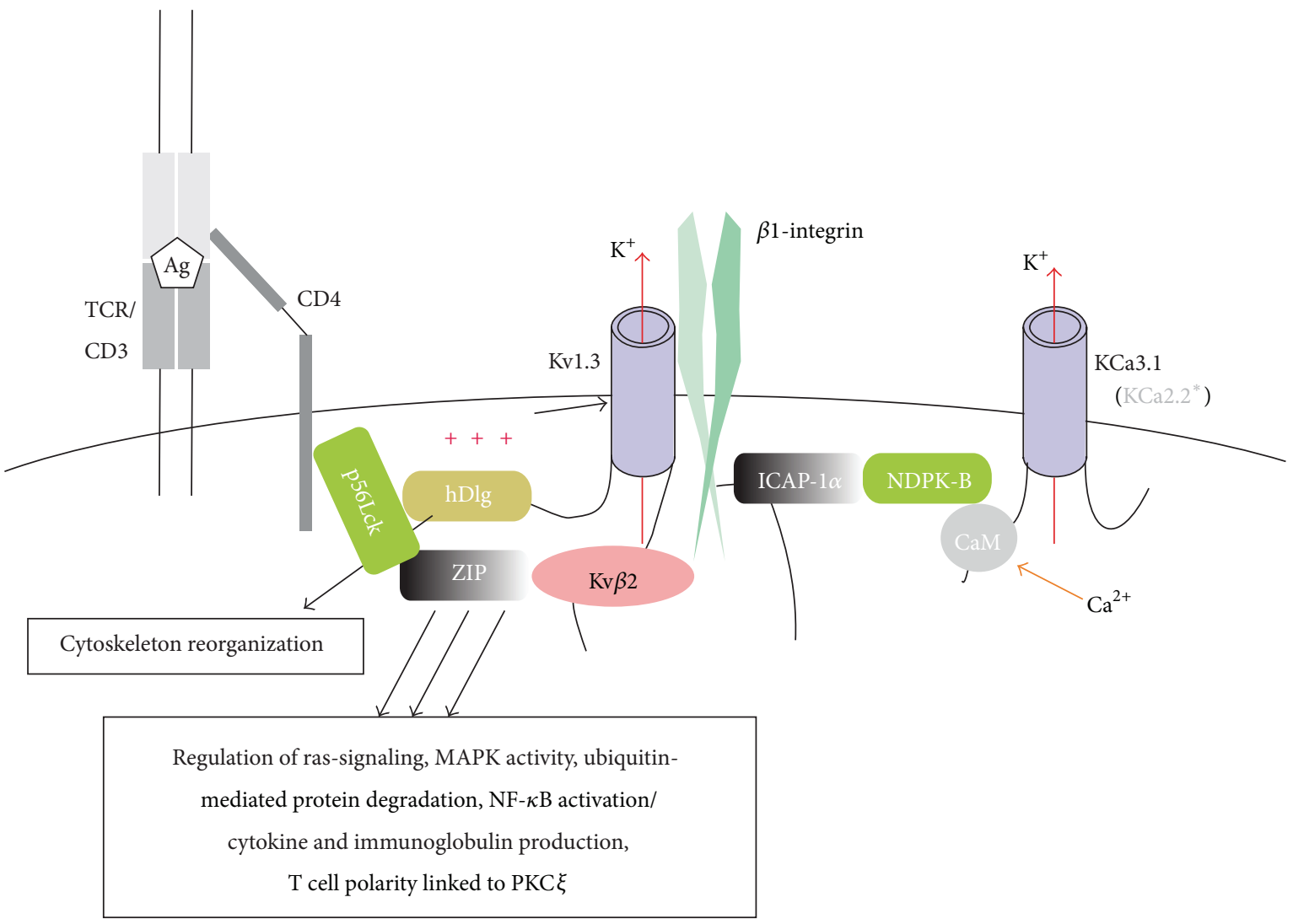

(a)

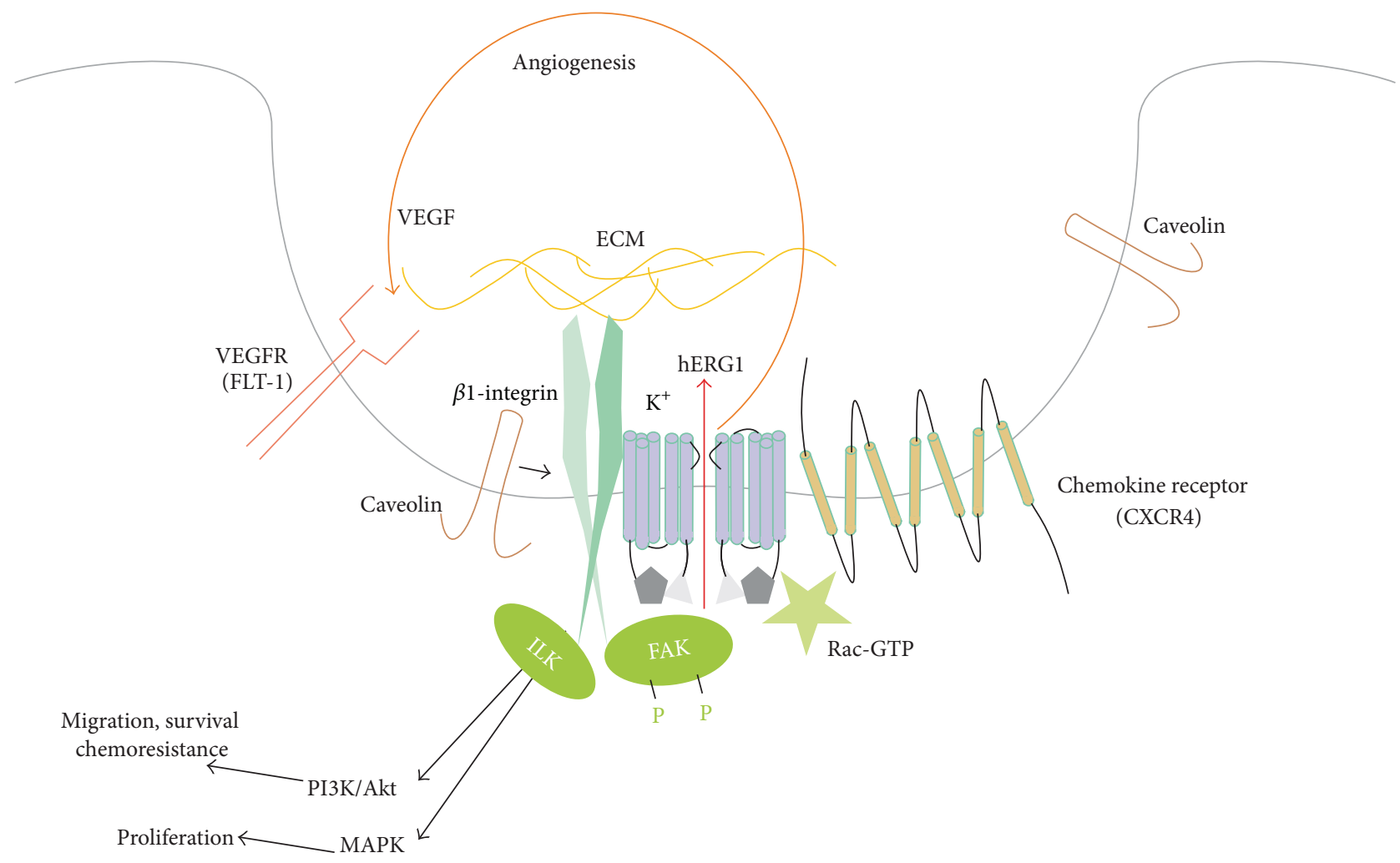

(b)

FIgUre 3: Continued. 


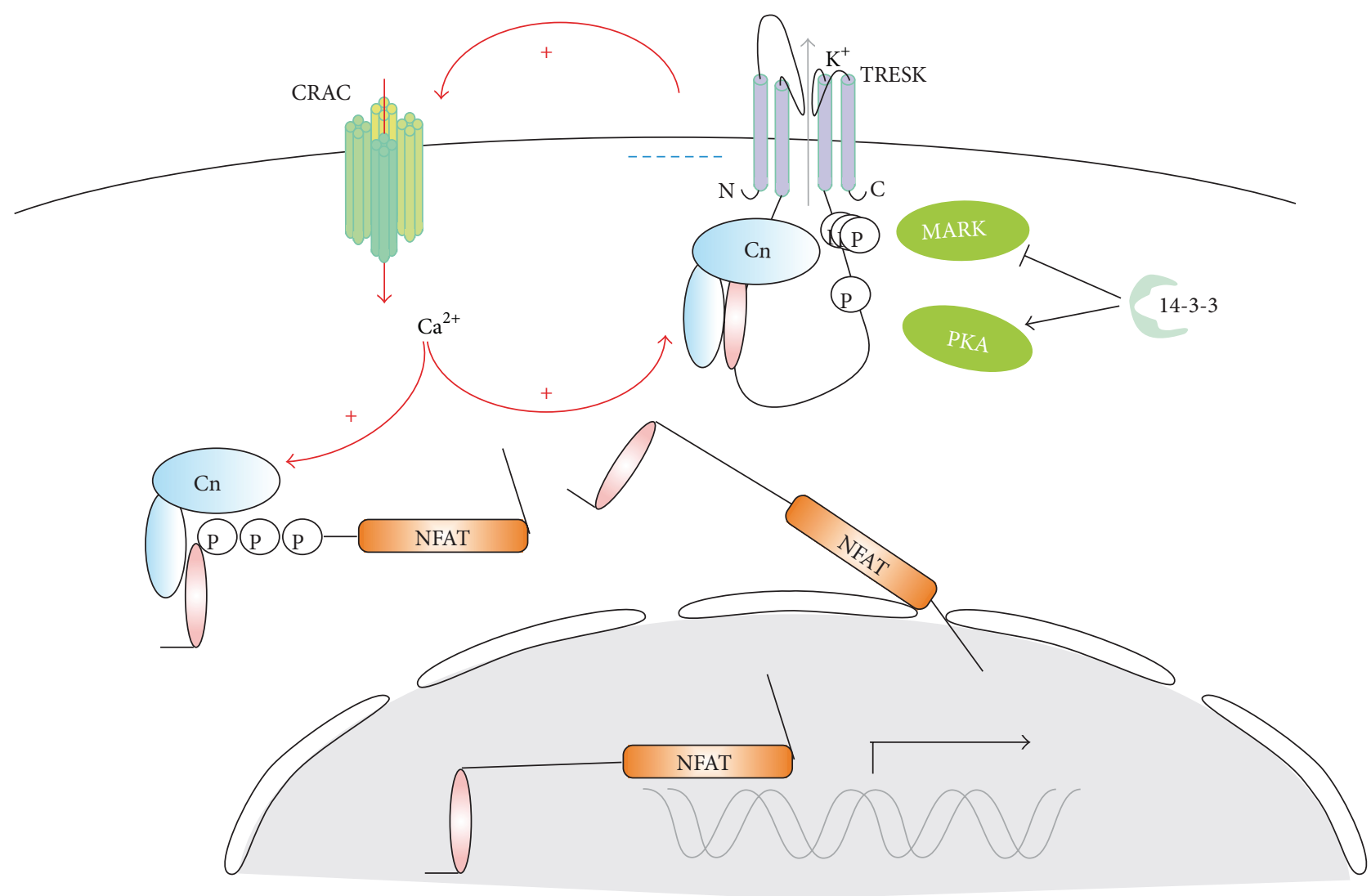

(c)

FIGURE 3: $\mathrm{K}^{+}$channels and their partners in the plasma membrane of T-cells. (a) Kv1.3 channels are activated and inactivated by the membrane depolarization. Its cytosolic $\mathrm{N}$ terminus binds to auxiliary, $\mathrm{NADP}$ binding $\beta$-subunit $\mathrm{Kv} \beta 2$, possessing oxidoreductase activity, and sensing cell metabolism and redox state. It also mediates trafficking of members of Kvl subfamily to plasma membrane. Beta-subunit via multifunctional adapter protein ZIP is linked to p56Lck, phosphotyrosine kinase in a phosphotyrosine-independent way. ZIP regulates a variety of intracellular processes as indicated. In turn, p56Lck is connected via PDZ-domain (hDlg) to the last three residues at the C-terminus; binding of hDlg to a kinesin motor protein (GAKIN) and provoking cortical cytoskeleton reorganization. Open state Kvl.3 conformation favors its binding to $\beta$ 1-integrin and the latter via integrin cytoplasmic domain associated protein (ICAP1-1a) and nucleoside diphosphate kinase NDPK-B (activating KCa3.1 via phosphorylation) communicates to intermediate conductance $\mathrm{Ca}^{2+}$-activated $\mathrm{K}^{+}$channel KCa3.1 (substituted for small conductance KCa2.2 in Jurkat cells). Kv1.3 can promote clustering of all aforementioned interacting proteins plus CD4 in the immunological synapse. A colocalization of Kv1.3, KCa3.1, and CRAC channels is essential for synapse stability, via local $\mathrm{K}^{+}\left(\mathrm{K}^{+}\right.$accumulation in the cleft, membrane depolarization) and $\mathrm{Ca}^{2+}$ signaling (for a further discussion, see [127]). Linking of Kvl.3 to integrin allows a bidirectional signaling, when $\mathrm{K}^{+}$channel gating transmits to cell adhesion (inside-out signaling) and, vice versa, integrin-mediated external signal (outside-in) may be traduced to intracellular events via Kv1.3 and its interacting proteins. (b) hERG1 channels physically interact with $\beta 1$-integrin receptors and are concentrated in caveolas, a type of lipid rafts, enriched of caveolins. Binary complexes of hERG1 with $\beta 1$-integrin are typical for cancer cells. "Outside-in" signaling: hERG1 activation links $\beta$ 1-integrin adhesion to fibronectin (in the extracellular matrix, ECM) to the tyrosine phosphorylation of FAK and activation of small GTPase (Rac); both are coprecipitated with the channel protein. Caveolin association with $\beta 1$-integrin promotes the channel activation [132]. FAK and ILK are primary targets for integrin-mediated cell adhesion, which transmits to the activation of MAPK, PI3K, and small GTPases. In leukemias trimolecular complexes can be also formed. In AML the third partner may be VEGF receptor, with an autocrine (hERG1-dependent) mechanism via VEGF secretion [133]. In ALL cells, hERG1/ $\beta 1$-integrin complex interacts with 7-TM domain (CXCR4, chemokine) receptors, stimulating signaling via ILK to Akt. Activation of this complex can be achieved via integrin engagement or CXCR4 chemical activation; ILK activity is suppressed by hERG1 specific block [134]. FAK (focal adhesion kinase), PI3K (phosphoinositide-3 kinase), VEGF (vascular endothelial growth factor), ILK (integrin linked kinase), and Akt (protein kinase B). (c) Tandem-pore domain $\mathrm{K}^{+}$channel TRESK is activated by dephosphorylation by calcineurin $(\mathrm{Cn})$ and suppressed by a phosphorylation of certain serine residues within the cytosolic loop between transmembrane domains II and III by protein kinase A (PKA) and a second kinase, likewise MARK, or microtubule affinity-regulating kinase [135]. $\mathrm{Cn}$ is activated either directly by $\mathrm{Ca}^{2+}, \mathrm{Ca}^{2+}-\mathrm{CaM}$ or $\mathrm{Ca}^{2+}-\mathrm{CaM}^{-}$ dependent kinase. $\mathrm{Ca}^{2+}$ influx in T-cells is mainly mediated by CRAC. Thus, TRESK and CRAC potentiate the activity of each other: TRESK generates driving force for $\mathrm{Ca}^{2+}$ influx by CRAC via membrane hyperpolarization, and CRAC shifts TRESK phosphorylation status to the dephosphorylated active form via $\mathrm{Ca}^{2+}-\mathrm{Cn}$. Sustained increase of $\mathrm{Ca}^{2+}$ via $\mathrm{Cn}$ dephosphorylates NFAT and allows its entrance through a nuclear pore, hence activating genes transcription. Both TRESK and NFAT contain a characteristic Cn-docking site (PQIVID for TRESK and PxIxIT for NFAT), thus coupling the $\mathrm{Ca}^{2+}$ signal positive feedback loop to genes expression via $\mathrm{Cn}$ activity. 14-3-3 protein docking to the phosphorylated S264 protects it from the dephosphorylation; additionally, 14-3-3 protein inhibits the second kinase. 
in case of leukemic cells, another question is whether there are alternative regulatory proteins, which interact with $\mathrm{K}_{\mathrm{v}} 1.3$ in these cells and what is the outcome of such interaction. Regulation of $\mathrm{K}_{\mathrm{v}} 1.3$ by p56Lck kinase $[164,165]$ as well as a colocalization with TCR/CD3 [168] is preserved in Jurkat cells. We are not aware, however, of any evidence pro or contra the functional interaction of $\mathrm{K}_{\mathrm{v}} 1.3$ with integrins in leukemic $\mathrm{T}$ cells. It should be noted that p56Lck kinase mediates oxygen sensing by $\mathrm{K}_{\mathrm{v}} 1.3$; hypoxia is a common condition within a tumor tissue and tends to suppress the $\mathrm{K}_{\mathrm{v}} 1.3$ channel activity, thus, T-cell proliferation under conditions of $\mathrm{O}_{2}$ deprivation [169]. Healthy human leucocytes and Jurkat cells express a second type of $\beta$-subunit, KCNE ( 1 to 5 ). KCNE 4 but not 2 physically interacts and substantially modifies the Kv1.3 gating, decreases the channel surface expression, and impairs channel's targeting to lipid rafts [170]. Upon Jurkat activation with fetal bovine serum (FBS), KCNEs 2 and 4 were upregulated, but the same KCNEs were downregulated upon Jurkat activation by PHA [171]. Voltage gating of Kv1.3 was differentially modulated by the lipid rafts disintegration in healthy T cells [138] and Jurkat cells [139], suggesting a different microenvironment.

Here we will mainly discuss the roles, played by plasma membrane ion channels. However, several intracellular channels and transporters, expressed in nuclear, ER, and mitochondrial membranes, especially the latter, play important roles in cancer cells proliferation and survival [172]. In particular, some $\mathrm{K}^{+}$channels have dual expression, in the plasma and intracellular membranes. $\mathrm{K}_{\mathrm{v}} 1.3$ channel, discussed above, is expressed both in plasma and inner mitochondrial membranes. Plasma membrane $\mathrm{K}_{\mathrm{v}} 1.3$ may be selectively blocked by membrane-impermeable toxins, whereas mitochondrial $\mathrm{K}_{\mathrm{v}} 1.3$ is only blocked by membrane-permeable drugs; blockage in the latter case induced apoptosis in cancer cells, including leukemic ones [172]. In addition, mitoK $_{\mathrm{v}} 1.3$ interacts directly with Bax in Jurkat cells. This gives rise to a sequence of events, including the hyperpolarization of the inner mitochondrial membrane, ROS generation, and cytochrome c release from mitochondria, thus, promoting the intrinsic apoptotic pathway [173].

8.2. hERG1. hERG1 (human ether-a-go-go-related gene, Kv11.1) channels are normally expressed in excitable cells, primarily, in neurons and heart [174]. In heart it encodes a rapid delayed rectifier $\left(\mathrm{I}_{\mathrm{Kr}}\right) \mathrm{K}^{+}$current, activating at membrane depolarization and mediating action potential repolarization. It has very peculiar biophysical properties, possessing a rapid inactivation at positive potentials and a rapid relief of inactivation at negative ones. Therefore, the steady-state I/V relationship for this channel is bell-shaped, with a peak around $-10 \mathrm{mV}$, where also the channel's open probability reached its maximum. Yet, channel's deactivation (a process of the reversal of activation) at negative potentials is slow (hundreds of milliseconds). Thus, at the peak and plateau of the action potential hERG1 conductance is greatly reduced due to the inactivation; it started to increase and reached its maximum at phase 3 repolarization [175]. In conclusion, hERG1 channels need to open first upon the action potential firing (depolarization), but they act (contribute) mainly on the way back, when a rapid relief from the inactivation followed by a slow deactivation allows a large $\mathrm{K}^{+}$efflux, promoting further repolarization. However, the midpoint of the hERG1 activation is around $-30 \mathrm{mV}$, so that it possesses a significant activity down to $-40 \mathrm{mV}$, which is close to resting potential in some nonexcitable cells, including lymphocytes. hERG1 is undetectable or expressed at very low levels in healthy immune cells. But it is frequently abnormally overexpressed in many cancer types, in particular, in acute lymphoblastic as well as in chronic lymphocytic (CLL) and both in acute and chronic myeloid (AML and CML) leukemias [134, 176-178]. hERG1 was found in selfrenewing population of leukemic stem cells [179] and also in healthy precursor $\mathrm{CD} 34^{+}$cells from peripheral blood, but only after cytokine stimulation [176]. Importantly, unlike in healthy cells, in tumors hERG1 is often found in functionally binary complexes with $\beta 1$-integrin, or even in triple protein complexes (Figure 3(b)), thus linking external to intracellular signaling and vice versa $[127,180]$. hERG1 can increase oncogenic potential in leukemias by affecting one of several ways facilitating leukemogenesis: (1) balance between proliferation and cell death; (2) invasiveness, depending on the fine balance between adhesion and motility, the latter being in turn dependent on polarized volume changes; (3) resistance to chemotherapy $[127,180]$; (4) angiogenesis, via secretion of vascular endothelial growth factor (VEGF) and positively feedbacked microvesicles release [181, 182]. hERG1 surface expression depends on the interaction of different isoforms; presence of $h E R G_{u s o}$, which form heterotetramers with other hERG1 isoforms that resulted in an arrest of hERG1 in endoplasmic reticulum, with a further degradation, thus, substantial decreasing hERG1-mediated currents across the plasma membrane [183]. Cancer cells, including leukemias, often express a truncated hERGlb isoform, lacking the oxygensensing domain. It forms heterotetramers with full length isoform hERG1 and the higher is hERG1/hERG1b ratio, the lower is voltage threshold for the channel activation, and more hyperpolarized is the membrane potential. Upregulation of hERG1b during the S-phase consequently resulted in more depolarized membrane potential thus, assisting the cell cycle progression. On the other hand, at hypoxic conditions, which are typical for tumor progression, increase of hERG1/hERG1b ratio could hyperpolarize membrane potential, reducing $\mathrm{K}^{+}$ loss, thus handicapping AVD and the apoptosis [184]. Although there is specific pharmacology against hERG1, its usage to treat hERG1 in leukemias is handicapped by the fact that cardiac hERG1 may be also affected, producing long QT-syndrome, which can eventually cause a fatal fibrillation. Yet, drugs only affecting the open channel state may be given a preference compared to blockers, acting also in the inactivated state, in case of hERG1 R-roscovitine and E4031, respectively [174]. In heart, hERG1 opens only shortly, at phase 3, whereas most of time hERG1 is either deactivated (at resting potential) or inactivated (at depolarized potentials). However, to properly address anti-hERG1 therapy to T-ALL treatment more studies on this type of leukemia are required. Except a single report on CEM cell line [177], hERG1 function and signaling were investigated on all types of leukemias but not on T-ALL. In particular, we and others were unable to 
detect any measurable hERG1-mediated currents in Jurkat cells.

8.3. $K_{\mathrm{Ca}}$ 3.1. $\mathrm{K}_{\mathrm{Ca}}$ 3.1 (IKCal), intermediate conductance $\mathrm{K}_{\mathrm{Ca}}$ channel, is voltage independent and is activated by $\mathrm{Ca}^{2+}$ CaM (CaM bound to C-terminus) with an apparent $\mathrm{K}_{\mathrm{d}}=$ $300 \mathrm{nM}$ [126]. $\mathrm{K}_{\mathrm{Ca}} 3.1$ also requires the phosphatidylinositol-3 (PI(3)P) for its activity, albeit it is not clear how this activation achieved; the effect on the channel is indirect [185]. Downstream to the PI(3)P is a reversible phosphorylation of channel's tyrosine 358; silencing of respective kinase (nucleoside diphosphate kinase B or NDPK-B) or phosphatase (histidine phosphatase PHPT-1) caused a suppression or activation of the $\mathrm{K}_{\mathrm{Ca}} 3.1$ current and efficiently modulates, in opposite way by NDPK-B or PHPT, $\mathrm{Ca}^{2+}$ influx and $\mathrm{CD}^{+}{ }^{+} \mathrm{T}$ cells proliferation after stimulation $[186,187]$. The activation of $\mathrm{K}_{\mathrm{Ca}}$ provokes a stable hyperpolarization down to equilibrium potential for $\mathrm{K}^{+}, \mathrm{E}_{\mathrm{K}}$ [188]. This hyperpolarization is indispensable for $\mathrm{T}$ cells, apparently lacking depolarization $\mathrm{Ca}^{2+}$ channels (see below), where CRAC (SOCE) is believed to be a central $\mathrm{Ca}^{2+}$ influx channel. Although resting $\mathrm{T}$ cells express only few copies of $\mathrm{K}_{\mathrm{Ca}} 3.1$, it is rapidly upregulated upon the activation and its expression level rises about 25 -fold [189]. $\mathrm{K}_{\mathrm{Ca}} 3.1$ channel is involved in various cellular processes, namely, activation via TCR-engagement and stabilization of the immunological synapse; control of membrane potential, RVD, cell migration, and tumor-related angiogenesis [126, $150,190] . \mathrm{K}_{\mathrm{Ca}} 3.1$ interacts functionally with $\mathrm{K}_{\mathrm{v}} 1.3$ and CRAC $[126,190]$.

8.4. $K_{\mathrm{Ca}} 2.2$. $\mathrm{K}_{\mathrm{Ca}} 2.2(\mathrm{SKCa} 2)$, small conductance $\mathrm{K}_{\mathrm{Ca}}$ channel, is expressed in a variety of healthy tissues, including brain and muscle [191]. It was also described in Jurkat leukemic cells, where its functional expression channels were high, comparable to the $\mathrm{K}_{\mathrm{Ca}} 3.1$ expression in activated healthy $\mathrm{T}$ cells $[189,192,193] . \mathrm{K}_{\mathrm{Ca}} 2.2$ is activated by $\mathrm{Ca}^{2+}$ with an apparent $\mathrm{K}_{\mathrm{d}}=700 \mathrm{nM}$ and is upregulated by p56Lck [192]. It has a higher expression in $G_{0} / G_{1}$ compared to $G 2 / M$ phase, supporting a sustained $\mathrm{Ca}^{2+}$ influx [194]. In Jurkat, $\mathrm{K}_{\mathrm{Ca}} 2.2$ silencing but not $\mathrm{K}_{\mathrm{v}} 1.3$ inhibition suppresses the $\mathrm{Ca}^{2+}$ entry; it can be restored by the ectopic expression of $\mathrm{K}_{\mathrm{Ca}} 3.1$ [193]. This study obviously argues that $\mathrm{K}_{\mathrm{Ca}} 2.2$ and $\mathrm{K}_{\mathrm{Ca}} 3.1$ may be interchangeable, but it is not clear to which extent. It should be noted that in Jurkat the functional expression of $\mathrm{K}_{\mathrm{Ca}} 2.2$ channels is constitutively high and can be compared to the $\mathrm{K}_{\mathrm{Ca}} 3.1$ expression in activated healthy $\mathrm{T}$ cells $[189,193]$. Remarkably, mitogenic stimulation instead of increase causes a 2-3-fold decrease of the $\mathrm{K}_{\mathrm{Ca}} 2.2$ expression both at mRNA and functional expression in the membrane levels [192].

8.5. Tandem-Pore Domain (K2P) Channels. K2P represents $\mathrm{K}^{+}$selective channels, genetically unrelated to the former two families $\left(\mathrm{K}_{\mathrm{Ca}}\right.$ and $\left.\mathrm{K}_{\mathrm{V}}\right)$. Each channel subunit possesses two pore domains, and a minimal number of transmembrane segments, two per pore, as compared to the 6-TM subunit structure of $\mathrm{K}_{\mathrm{Ca}}$ and $\mathrm{K}_{\mathrm{V}}$. Consequently, functional $\mathrm{K} 2 \mathrm{P}$ channels are dimers; functional heterodimers were reported only for closely related TASK1 and TASK3, and the rest of active K2P channels are homodimers. There are 14 members of K2P family discovered in mammals (see [135] for a review). The activity of K2P channels is practically independent of the membrane voltage; rather, they are regulated by a variety of metabolic and physical factors. First reports on the functional expression of TASK1 and 3 in T cells [195] and of TRESK in Jurkat leukemic T cells $[196,197]$ in human models came relatively recently. Further on, TASK2 was found to be constitutively expressed in human T cells, but not in B or NK cells. Within $\mathrm{T}$ cells the relative expression was dependent on the T cells subset; TASK2 was strongly upregulated in $\mathrm{CD}^{+}$and $\mathrm{CD}^{+}$cells of patients with multiple sclerosis [198]. Later on it was shown that TASK2 expression in $\mathrm{CD}^{+} \mathrm{T}$ cells strongly correlates with rheumatoid arthritis disease activity [199]. Mechanistic explications of both correlations are still lacking. However, roles of TASK1 and TASK3 in $\mathrm{T}$ cells function seem to be clearer. TASK1 and 3 belong to acid-sensitive K2P, which are inhibited by low external $\mathrm{pH}$; for TASK1 and TASK1/3 heterodimer apparent $\mathrm{pK}$ is 7.3 and TASK3 homodimer displays $\mathrm{pH}$-sensitivity outside the physiological range; intracellular $\mathrm{pH}$ changes were inefficient for both channels [200]. TASK channels are directly inhibited by anandamide and some synthetic cannabinoides. They are also inhibited by the stimulation of $\mathrm{G}_{\mathrm{q}}$-coupled receptors, possibly via the breakdown of $\mathrm{PIP}_{2}$, with TASK1 and TASK1/3 heterodimer being more sensitive than TASK3 homodimer [135]. According to the data of Meuth and coworkers (2008) TASK channels may account for up to $40 \%$ of the outward $\mathrm{K}^{+}$ current in human T cells; their inhibition caused a significant decrease in production of cytokines and cells proliferation [195]. In addition, the role of TASK2 and TRESK in the RVD is comparable to that of $K_{v} 1.3$, whereas TASK-3 shows a lower contribution, which was somewhat higher in activated T cells [145]. TASK-3 is often amplified in different types of cancer; it is also expressed in mitochondrial inner membrane, which likely underlies its role in apoptosis. Yet its impact on the oncogenesis may be not necessarily negative and in some cases its high expression correlates with a better prognosis [128]. No studies of TASK expression in T-ALL are available to date. With TRESK the situation is different. Normally, it not only is abundantly expressed in neurons of dorsal ganglia, but also is reported in spleen and thymus in murine models [201]. Yet TRESK is strongly upregulated in several leukemic cell lines as well as in patients with T-ALL [197]. In vivo real time $\mathrm{K}^{+}$flux measurements and concurrent patch-clamp data on Jurkat cells revealed that both TRESK and $\mathrm{K}_{\mathrm{v}} 1.3$ mediate AVD in the intrinsic apoptosis pathway, yet TRESK is transiently upregulated by apoptotic stimulus (staurosporine) and then completely inactivated in a half of hour, causing a strong membrane depolarization, whereas the $\mathrm{K}_{\mathrm{v}} 1.3$ contribution to the $\mathrm{K}^{+}$efflux was more constant in time [147]. TRESK, which does not have close homologues, is unique among $\mathrm{K} 2 \mathrm{P}$ channels, because its principle way of activation is $\mathrm{Ca}^{2+}$-dependent (Figure 3(c)). TRESK possesses a large cytosolic loop between transmembrane segments 2 and 3, which harbors, similar to NFAT, the Cn docking site (the NFAT-like domain) and several phosphorylation sites. Phosphorylation by MARK and PKA in the two distinct sites caused TRESK inhibition. On the contrary, binding of $\mathrm{Ca}^{2+}$ calcineurin to NFAT-like domain and dephosphorylation at 
both sites provoked the TRESK activation [202]. This is a very important point, as activation of the NFAT-pathway by calcineurin at prolonged $\mathrm{Ca}^{2+}$ increase would cause also the TRESK activation. TRESK activation may be not only the consequence of a prolonged $\mathrm{Ca}^{2+}$ increase, but also its cause, due to a feedback support of the $\mathrm{Ca}^{2+}$ influx via the TRESKmediated membrane hyperpolarization (Figure 3(c)). TRESK dependence on $\mathrm{Ca}^{2+}$ is different from that of $\mathrm{K}_{\mathrm{Ca}}$ channels. $\mathrm{K}_{\mathrm{Ca}}$ are directly activated by $\mathrm{Ca}^{2+}$ increase and immediately deactivated after $\mathrm{Ca}^{2+}$ removal. TRESK in contrast, once activated via dephosphorylation by calcineurin, could maintain its activity for a longer period after the $\mathrm{Ca}^{2+}$ removal. Thus, TRESK could be directly involved in the gene expression in T-ALL and may be considered as a plausible target for the immunomodulation $[203,204]$. Yet, it is a general problem with $\mathrm{K} 2 \mathrm{P}$ channels, and there are no specific blockers of any of mammal K2P channels, which handicaps studies of their roles in vivo as well as $\mathrm{K} 2 \mathrm{P}$-targetted therapies. However, recent advances in studies of low-molecular weight modulators for $\mathrm{K} 2 \mathrm{P}$ are promising. In particular, antihistamine loratadine appears to block TRESK with a high affinity and does not display drastic collateral effects [205].

8.6. SOCE/CRAC (Orail-STIM1). $\mathrm{Ca}^{2+}$ signaling in $\mathrm{T}$ cells differs greatly from those in excitable cells, which mainly rely on the voltage-dependent (depolarization-activated) $\mathrm{Ca}^{2+}$ channels of the plasma membrane. In lymphocytes, contrary to this, $\mathrm{Ca}^{2+}$ rise in cytosol is mediated by the store-operated $\mathrm{Ca}^{2+}$ entry (SOCE), named also CRAC, for $\mathrm{Ca}^{2+}$ releaseactivated $\mathrm{Ca}^{2+}$ current, that is, $\mathrm{Ca}^{2+}$-selective current of the plasma membrane, activated by the $\mathrm{Ca}^{2+}$ depletion in the ER. It is extremely (factor $>1000$ ) selective for $\mathrm{Ca}^{2+}$ over monovalent cations and has extremely low single channel conductance for $\mathrm{Ca}^{2+}$ (30 fS), which is compensated by a very high channels density (ca. 100 channels $/ \mu \mathrm{m}^{2}$ ). Due to its intrinsic inward rectification, $\mathrm{Ca}^{2+}$ influx via CRAC is strongly potentiated by membrane hyperpolarization, whereas depolarization reduces $\mathrm{Ca}^{2+}$ entry in lymphocytes [126]. For a long time it was thought that CRAC is mediated by members of TRPC subfamily (see below). Of course, these relatively weakly selective channels alone may not be responsible for a strongly $\mathrm{Ca}^{2+}$-selective CRAC, but now there is also an ample evidence that TRPCs and CRAC are functionally and physically separated [206]. Crucial for molecular identification of CRAC was a study of severe combined immune deficiency (SCID), which was characterized by nonfunctional CRAC in T cells from some patients. In such a way, Orail was discovered as a poreforming protein of CRAC, as single mutation in Orail from SCID patients was responsible for a defective CRAC function [207]. Orai does not relate to any known ion channel. In humans, three different isoforms form very similar CRAC channels, but in lymphocytes only Orail seems to be of functional importance [208]. Store depletion is communicated to Orai via STIM (stromal interaction molecule) proteins, located in the ER-membrane. In $\mathrm{Ca}^{2+}$ replete stores STIM proteins are randomly distributed at the membrane surface, and store depletion causes oligomerization of STIM in special contact areas with plasma membrane, where cytosolically exposed STIM domain directly interacted with both $\mathrm{N}$ - and $\mathrm{C}$ termini of Orail, thus, causing CRAC activation (Figure 4, see also [208] for a recent review). There are two STIM isoforms in $\mathrm{T}$ cells, and both are important for CRAC, yet in murine models STIM1 or STIM2 deficiency caused a complete or partial abolishment of CRAC, respectively [209]. CRAC plays a central role in cytokines production, firstly, via $\mathrm{Ca}^{2+}$ activation of the NFAT transcription factor; conversely, it does not play a very significant role in the antibodies production by B cells (see [208] and references therein). Orail displays Orail displays two-time lower current density in Jurkat lymphoblasts as compared to resting T-cells; no significant difference in STIM1 expression was revealed between these two cellular models [210]. Relatively modest changes in the CRAC expression per se may not underlie changes in $\mathrm{Ca}^{2+}$ signaling in activated and malignant $\mathrm{T}$ cells. More likely, differences in the expression and regulation of "partner" $\mathrm{K}^{+}$channels, especially those activated by intracellular $\mathrm{Ca}^{2+}$ rise, may be more important for the modulation of the CRAC function (Figure 4). As CRACmediated $\mathrm{Ca}^{2+}$-influx is inhibited by inflowing $\mathrm{Ca}^{2+}[211]$ and membrane depolarization, its activity may be further modulated by TRPs. TRPs differ greatly not only in the modes of their activation and expression in leukemic T-cells (see below), but also by their $\mathrm{Ca}^{2+} / \mathrm{Na}^{+}$selectivity, hence differentially affecting membrane depolarization and $\mathrm{Ca}^{2+}$ signal. Figure 4 represents possible cross-talks between plasma membrane cation channels, including a feedback, provided by their differential dependence on the cytosolic $\mathrm{Ca}^{2+}$. More scenarios, exploiting TRP and ORAI competition for STIM1, physical interactions, affecting ORAI surface expression and membrane localization, or existence of hybrid SOCE channels are discussed in the recent review by Saul and coworkers (2014) [212].

8.7. TRP (Transient Receptor Potential) Family Channels. TRP channels (currently, 28 described in mammals) are cationic, mostly nonselective and $\mathrm{Ca}^{2+}$-permeable ones; they resemble by transmembrane topology but distantly are related to voltage-gated (e.g., $\mathrm{K}_{\mathrm{v}}$ ) channels $[213,214]$. They are subdivided into TRPC (canonical), TRPM (melastatin), TRPV (vanilloid), TRPA (ankyrin), TRPML (mucolipin), and TRPP (polycystin) subfamilies. TRPA, TRPP, and TRPML detection in lymphocytes was not addressed. However, TRPA may have a relatively restricted expression, mainly in sensory neurons, whereas TRPML forms intracellular channels [213].

TRPC 1, 3, and 6 were reported in PBL and Jurkat cells, Jurkat expresses additionally TRPC 4 and 5 [124]. All above channels are weakly selective $\left(\mathrm{P}_{\mathrm{Ca}} / \mathrm{P}_{\mathrm{Na}}=1-5\right)$, with linear or dual-rectifying I/V relation [215]. TRPC channels at cytosolic C-terminus contain two specific $\mathrm{Ca}^{2+}$-binding sites, a EFhand and CIRB, a calmodulin/IP3R-binding domain and may be directly regulated by intracellular $\mathrm{Ca}^{2+}$ [213]. Mostly, they are inhibited via $\mathrm{Ca}^{2+} / \mathrm{CaM}$ pathway [216]. According to their properties, TRPC can be subdivided into TRPC1/4/5 and TRPC3/6/7 (trpc2 is a pseudogene in humans) subgroups. A common property of the latter subgroup is their activation by DAG (or its membrane permeable form OAG), whereas 


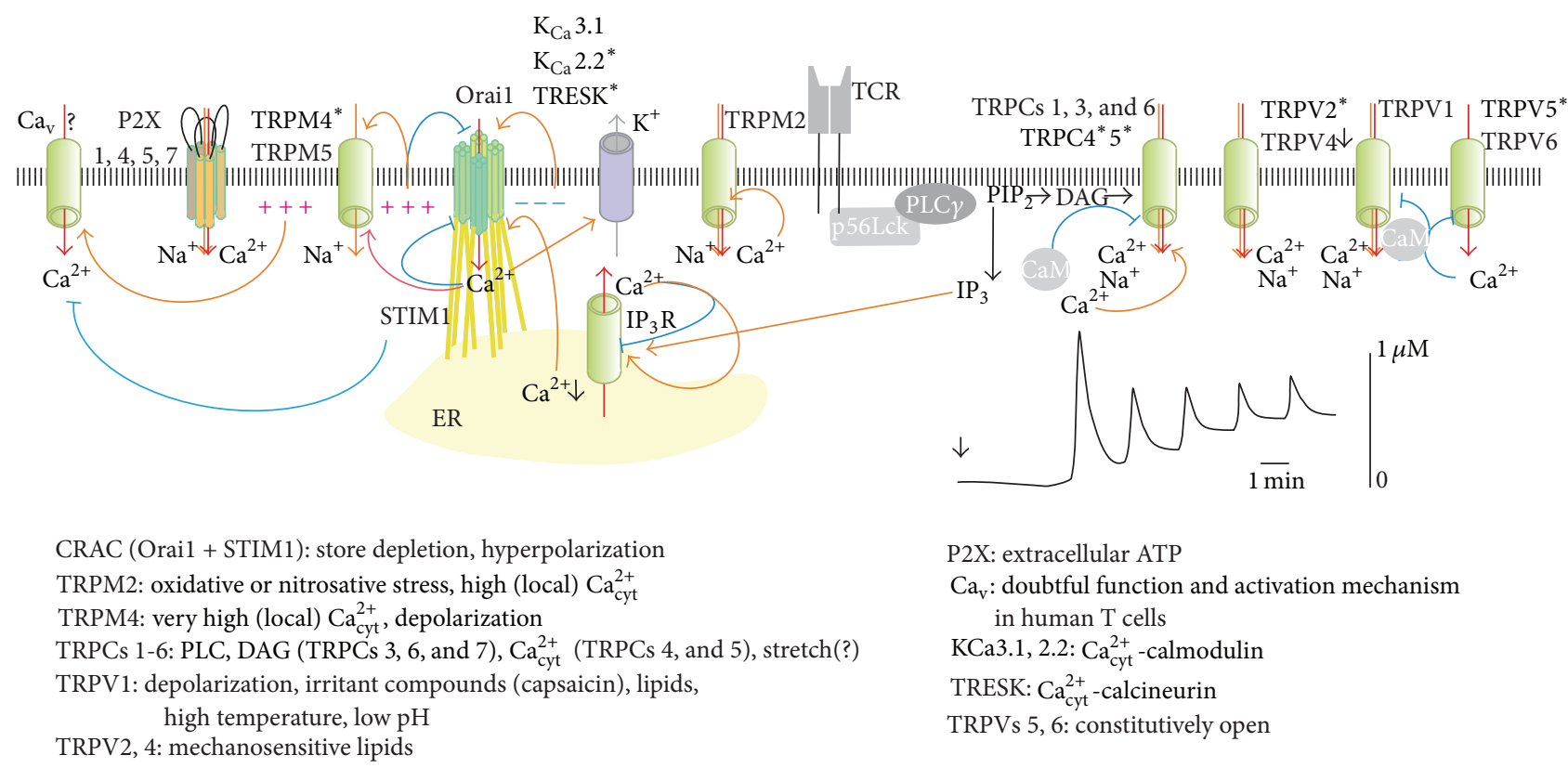

Figure 4: $\mathrm{Ca}^{2+}$ influx network in T cells. Channels, marked with asterisks, are overexpressed or present exclusively in T-ALL. Central is activation of CRAC- (Orail+STIM1) mediated $\mathrm{Ca}^{2+}$ influx. Activation of PLC (e.g., via the $\mathrm{T}$ cell receptor) causes cleavage of PIP ${ }_{2}$ with the production of DAG and soluble $\mathrm{IP}_{3}$; the latter activates $\mathrm{IP}_{3}$-receptor $\mathrm{Ca}^{2+}$ release channels of the endoplasmic reticulum. $\mathrm{Ca}^{2+}$ store depletion is sensed by specialized transmembrane sensors (STIM1), which oligomerize and move to special contact zones of ER with the plasma membrane, where they physically interact with the channel-forming proteins (Orai), forcing them to form active $\mathrm{Ca}^{2+}$ selective channel (CRAC), which mediates $\mathrm{Ca}^{2+}$ influx. Operation of CRAC is further modulated by the activity of other channels, which affects the membrane polarization and intracellular $\mathrm{Ca}^{2+}$. Voltage-independent $\mathrm{Ca}^{2+}$-dependent $\mathrm{K}^{+}$channels potentiate $\mathrm{CRAC}$-mediated $\mathrm{Ca}^{2+}$ influx, lowering the membrane potential, thus increasing the driving force for $\mathrm{Ca}^{2+}$ uptake. Conversely, channels with a predominant $\mathrm{Na}^{+}$permeability (TRPM4) cause membrane depolarization and abrogation of the $\mathrm{Ca}^{2+}$ influx. Depending on the channel selectivity high Ca ${ }^{2+}$ (e.g., TRPV5) or indiscriminate $\mathrm{Ca}^{2+} / \mathrm{Na}^{+}$(e.g., TRPC) as well as (when applicable) on the nature of the feedback (positive or negative, see respective loops) via $\mathrm{Ca}^{2+}$ and on the context (differential ways for the activation of particular ion channel), overall $\mathrm{Ca}^{2+}$ signal can be positively or negatively modulated. An idealized $\mathrm{Ca}^{2+}$ response to a mitogen stimulation, which contains both oscillatory and monotonous increase components, evidencing a feedback regulation via $\mathrm{Ca}^{2+}$, is given as an example. Ways of the channels' activation are summarized below. From the left to the right: $\mathrm{Ca}_{\mathrm{v}}$ (voltage-dependent $\mathrm{Ca}^{2+}$ channels), P2X (purinergic ionotropic receptors), TRP (transient receptor potential channels), OraiSTIM1 (CRAC, $\mathrm{Ca}^{2+}$ release-activated $\mathrm{Ca}^{2+}$ channel), $\mathrm{K}_{\mathrm{Ca}}\left(\mathrm{Ca}^{2+}\right.$-activated $\mathrm{K}^{+}$channels), TRESK (TWIK-like spinal cord $\mathrm{K}^{+}$channel), and CaM (calmodulin).

TRPC1/4/5, albeit being dependent on the PLC activity, are not responding to DAG [217]. OAG-activated current mediated the influx of $\mathrm{Ca}^{2+}, \mathrm{Ba}^{2+}$, and $\mathrm{Sr}^{2+}$ into Jurkat and PBLs; on the contrary, in case of SOCE (CRAC) activation cation influx was $\mathrm{Ca}^{2+}$-selective, without measurable $\mathrm{Ba}^{2+}$ component [218]. In HPB-ALL, acute T lymphoid leukemia only TRPC1 was expressed at detectable levels among TRPCs 1 to 7 , as compared to Jurkat, expressing TRPCs 1,3 , and 6 and more (see below). $\mathrm{Ca}^{2+}$ influx, induced in HPB-ALL cells by $\Delta^{9}$-tetrahydrocannabinol, was less sensitive to SOCE and, based on pharmacological evidence, was mediated by TRPC1 via CBD-2 receptors and DAG [219]. Yet there are some doubts that TRPC1 could form functional homomeric channels, whereas it definitely can form heteromeric channels with all others TRPCs, including 4 and 5 [220] as well as with TRPV4 [221]; in the latter case translocation of TRPC1/TRPV4 complex to plasma membrane requires store depletion and STIM1 involvement. TRPCs 4 and 5, which are not present in PBLs, are robustly expressed in Jurkat cells [124]. Importantly, homomeric TRPC 5 or heteromeric
TRPCs 4 and 5 act as a positive loop for the NO production: channel's nitrosylation provokes a formation of disulphide bond between neighboring cysteine residues, locking the channel in the open conformation, thus, promoting $\mathrm{Ca}^{2+}$ influx and $\mathrm{Ca}^{2+}$-dependent $\mathrm{NO}$ production [222]. It remains to be elucidated whether such mechanism may operate in leukemic T cells. Partial silencing of TRPC 3 in $\mathrm{CD} 4^{+}$caused a reduction of intracellular $\mathrm{Ca}^{2+}$ only under limiting external $\mathrm{Ca}^{2+}(<0.1 \mathrm{mM})$ and slightly $(<20 \%)$ decreased the proliferation of activated cells [124]. However, specific TRPC3 blocker, Pyr-3, strongly reduced the late phase of $\mathrm{Ca}^{2+}$ entry induced by anti-CD3 antibodies in Jurkat cells [223], confirming the TRPC3 role in $\mathrm{Ca}^{2+}$ signaling.

TRPM2 form nonrectifying channels, almost equally permeable to $\mathrm{K}^{+}, \mathrm{Na}^{+}$, and $\mathrm{Ca}^{2+}$ [224] and slightly less to $\mathrm{Mg}^{2+}$ [225]. TRPM2 is known as "chanzyme" because its dual function of ion channel and C-terminal enzyme domain [226]. (TRPM2) mRNA was highly abundant in CD $34^{+}$precursors and in hematologic malignant cell lines of different 
lineages, like Jurkat cells (T-ALL), K562 (erythromyeloblastoid leukemia), AML-193 (acute monocytic leukemia), U937ecoR (monocytic leukemia), and TF-1 (erythroleukemia) $[224,227,228]$. TRPM2 is activated by reactive oxygen species, and this way may be the principle route of TRPM2 activation in Jurkat cells, whereas intracellular ligands, like cADPR, appear to be inefficient for this model system [229]. The combination of channels responsible for $\mathrm{Ca}^{2+}$ influx varied depending on the method of stimulation. In Jurkat cells, activation by ConA led to late $\mathrm{Ca}^{2+}$ influx via TRPM2 without CRAC involvement, whereas TRPC (TRPC3?) channels were responsible for anti-CD3-activated $\mathrm{Ca}^{2+}$ influx [223]. In $\mathrm{CD} 4^{+} \mathrm{T}$ cells of healthy donors, stimulation by antiCD3/anti-CD28, caused a transient increase of the TRPM2 expression [124]. TRPM2 mediates apoptosis upon the oxidative stress [227]. Overexpression of TRPM2 increases tumor susceptibility to oxidative stress, favoring the mitochondrial $\mathrm{Ca}^{2+}$ overload and triggering the intrinsic pathway of apoptosis, so TRPM2 is considered as a tumor suppressing factor [230].

TRPM4 encodes an intrinsically voltage-dependent outwardly-rectifying [231] monovalent cation channel, equally permeable to $\mathrm{Na}^{+}$and $\mathrm{K}^{+}$[232]. It requires high (micromolar) cytosolic $\mathrm{Ca}^{2+}$ for its activation [231]. Wenning et al. (2011) reported nondetectable levels of TRPM4 mRNA in naïve $\mathrm{T}$ cells, but a consistent expression both in Jurkat and effector $\mathrm{CD} 4^{+}$cells; TRPM5 was expressed in stimulated and nonstimulated PBLs and Jurkat. TRPM4 and TRPM5 possess similar biophysical characteristics and are unique among TRP superfamily, which are virtually $\mathrm{Ca}^{2+}$ impermeable [124]. Thus, under physiological conditions TRPM4 mediates $\mathrm{Na}^{+}$influx, producing membrane depolarization [232]. This tends to reduce the CRAC-mediated $\mathrm{Ca}^{2+}$ influx. Indeed, suppression of TRPM4 in Jurkat transforms PHA-induced $\mathrm{Ca}^{2+}$ signal from oscillations to a higher sustained $\mathrm{Ca}^{2+}$ increase, resulting in a higher IL-2 production [232]. Similarly to TRPM4, TRPM5 is activated by high intracellular $\mathrm{Ca}^{2+}$, but, in contrast to the former, it is strongly suppressed by external acidification [233], which may be relevant physiological situation under hypoxia in lesions. Analysis of polymorphisms in TRPM5 genes revealed correlation of childhood leukemia with certain genotypes [234]. Interestingly, TRPM5 gene is located in the human chromosome 11, which frequently shows aberrations for a number of hematological malignancies, including ALL [235]. In addition, on the protein level TRPM5 is conservatively regulated by residual proteins, formed in the Notch pathway, which in turn is important pathway associated with T-ALL [236]. However, in contrast to TRPM4, direct experimental demonstration of the TRPM5 channels activity in T cells is lacking so far.

TRPM7 is another, in addition to TRPM2, "chanzyme," consisting of ionotropic divalent cation-permeable channel and kinase, linked to cytosolic C-terminus [237]. It is ubiquitously expressed, but normally at relatively low levels [213]. In vivo current, generated by TRPM7 channels, is strongly outwardly rectifying, due to a blockage by cytosolic $\mathrm{Mg}^{2+}$ and, possibly, some additional internal factor [213]. $\mathrm{Mg}^{2+}$ block of TRPM7 channel and a role of a very similar TRPM6 channel in $\mathrm{Mg}^{2+}$ homeostasis led to a hypothesis that TRPM7 could equally participate in sensing and control of the intracellular $\mathrm{Mg}^{2+}$. Yet, current experimental evidence is more against that in favor of this hypothesis $[208,213]$. TRPM7 expression is higher in Jurkat as compared to healthy T cells [124]. Importantly, cell-specific TRPM7 deletion arrests $\mathrm{T}$ cells differentiation at the DN stage [89]. Although TRPM7 is the only channel up to date with an approved role in the lymphocyte development, it is not known, whether this role is mediated by $\mathrm{Mg}^{2+}$ or $\mathrm{Ca}^{2+}$ influx through its pore, kinase domain activity, or a combination of these factors. Interestingly, TRPM8, a crucial motor element for cell migration in glioblastomas [238] but oppositely acting in other tumor types (see [230] for a review), is expressed neither in healthy PBLs nor in Jurkat lymphoblasts [124].

There are two subgroups in the TRPV family: TRPV1/4 and highly $\mathrm{Ca}^{2+}$-selective TRPV5/6 ones. TRPV1 (vanilloid receptor), the founding member, represents an outwardrectifying voltage-gated channel, which is upregulated by different physical factors (external $\mathrm{pH}$, heat) and a great variety of unrelated chemical compounds (Figure 4) and is modulated by protein phosphorylation by PKA and PKC [239]. Its pore is flexible and the channel selectivity changes upon the activation and it depends also on the activation factor [216, 240]. TRPV1 is modestly selective for $\mathrm{Ca}^{2+}$ over $\mathrm{Na}^{+}$, given values between 10 for capsaicin and 4 for heat [241]. Thus, the fraction of $\mathrm{Ca}^{2+}$ current inflowing the cell via TRPV1 counts only a few percent of the total current, mainly carried by $\mathrm{Na}^{+}$. Yet, this $\mathrm{Ca}^{2+}$ influx is sufficient to cause the TRPV1 desensitization, which likely is caused by $\mathrm{Cn}$-mediated dephosphorylation of several sites [216]. TRPV1/4 can be also considered as chemosensors; among the agonists for TRPV1, 2 and 4, cannabinoids should be mentioned [216, 242].

TRPV1 and TRPV2 are the most expressed among TRPV1/4 channels in human peripheral blood and leukocytes, with the TRPV2 mRNA being more abundant than that of TRPV1 by a factor of 150 and 20, respectively [243, 244]. TRPV2 is relatively poor expressed in other tissues (except smooth muscle and lung) but in blood [245]. TRPV2 is expressed in lymphoma and leukemic cell lines, including TALL, Jurkat, and MOLT-4 [124, 245, 246]. On note, TRPV2 activation by cannabidiol in some tumors increased their sensitivity to anticancer drugs, by increasing drugs uptake and stimulating cell death $[235,247]$. TRPV2 was also detected in the intracellular (endosomal) membrane, where it mediates $\mathrm{Ca}^{2+}$ release [248]. There are two splicing variants of TRPV2: full-length and poreless short (s-TRPV2) ones. STRPV2 is more typical for tumor cells including leukemic ones; it is localized in cytosol, and it inhibits full TRPV2 translocation to the cell membrane [246]. TRPV2 is probably one of the least understood TRP channels when it comes to its regulation. It has a bipolar current-voltage dependence and similar permeability for $\mathrm{Ca}^{2+}$ and $\mathrm{Na}^{+}$[249]. In humans, in contrast to rats, TRPV2 appears to be not activated by noxious heat [250]. It is thought that the main way of its activity regulation is the mobilization from the ER to the 
plasma membrane, for example, by growth factors [246, 251]. However, in murine aortic myocytes and neurons, TRPV2 is activated by membrane stretch and mediated a $\mathrm{Ca}^{2+}$ influx $[252,253]$. Activation by mechanical stretch and hypotonicity was demonstrated also for TRPV2-like channels, expressed in human mast-cell line [254]. Our own study on Jurkat cells revealed that the properties of major mechanosensitive channel in their plasma membrane are indistinguishable from TRPV2 by its voltage dependence, cation selectivity, and pharmacological profile (Pottosin et al., unpublished). Properties of mechanosensitive currents in Jurkat were clearly distinct from TRPV1 and 3 but may be confused with those generated by TRPV4 [255], albeit the latter channel shows a somewhat higher $\mathrm{Ca}^{2+}$ over $\mathrm{Na}^{+}$selectivity. TRPV4 channel is also proved to be mechano- and osmosensing element in different tissues [256-258]. It is regulated by intracellular $\mathrm{Ca}^{2+}$ in a complex way, via CaM binding to $\mathrm{C}$ - and $\mathrm{N}$ termini; it activates at moderate intracellular $\mathrm{Ca}^{2+}$ increase and inactivates at higher $(>800 \mathrm{nM}) \mathrm{Ca}^{2+}$ levels [256]. It is still a matter of debate, whether this activation may be direct or mediated by mechanosensitive phospholipase A2 activity, which metabolizes the arachidonic acid and produced epoxyeicosatrienoic acid, which in turn activates the TRPV4 [213]. We give lesser preference to TRPV4 versus TRPV2 due to their very low expression in Jurkat cells [124], but this point requires further exploration. Emerging evidence is accumulated that TRPV2 could colocalize within a network of $\mathrm{K}_{\mathrm{v}} 1.3, \mathrm{~K}_{\mathrm{Ca}} 3.1$, and CRAC, thus contributing to a variety of vital $\mathrm{T}$ cells functions by modulation of the $\mathrm{Ca}^{2+}$ signaling [245]. In Jurkat cells and mouse thymocytes, the $\mathrm{RVD}$ in response to hypotonic treatment is a $\mathrm{Ca}^{2+}$-dependent process, unlike mature peripheral lymphocytes, either mouse or human, where hypotonic stress does not provoke any intracellular $\mathrm{Ca}^{2+}$ change [150]. About respective $\mathrm{Ca}^{2+}$ signal it is known that it is mediated by the plasma membrane nonselective channels (TRPs?), which are 100-time less sensitive to $\mathrm{Gd}^{3+}$ as compared to the CRAC. Likewise, in immature $\mathrm{T}$ cells and T-ALL the volume regulation is controlled by a mechanosensitive TRP, which, in accordance with our data, could be the TRPV 2 .

TRPV5 and 6 are inwardly rectifying and the only highly $\mathrm{Ca}^{2+}$-selective $\left(\mathrm{P}_{\mathrm{Ca}} / \mathrm{P}_{\mathrm{Na}}>100\right)$ members of the TRP family $[213,215]$. Both TRPV5 and TRPV6 channels could be found in resting human PBL and Jurkat cells, as transcripts and, functionally, based on the different sensitivity of measured single-channel currents to ruthenium red (RR). However, TRPV6 expression in Jurkat cells and PHA-activated PBLs is much higher as compared to resting cells, implying a stimulating role of TRPV in the proliferation. Indeed, inhibition of TRPV currents by RR arrested the progression of the cell cycle in activated PBLs or Jurkat in G0/G1 and S or G2/M phases, respectively [259]. TRPV6 in Jurkat may physically interact with or even contribute to the CRAC/SOCE [260].

8.8. Purinoreceptors (P2X). P2X forms nonselective $\mathrm{Ca}^{2+}$ permeable channels, activated by external ATP [261]. First evidence that peripheral blood $\mathrm{T}$ cells bear $\mathrm{P} 2 \mathrm{X}$, whose activation by ATP produces depolarization and $\mathrm{Ca}^{2+}$ influx, was obtained by Baricordi and coworkers (1996). It was demonstrated that $\mathrm{P} 2 \mathrm{X}$ may contribute to T cell proliferation, induced by mitogenic stimulation [262]. There are seven P2X subtypes (P2X1-7), of which mainly P2X1, P2X4, and P2X7 were expressed in primary $\mathrm{CD}^{+}$and Jurkat cells [263, 264]. T cell activation was shown to induce ATP release and considerable augment of P2X1, P2X4 [264], and P2X7 [263] expression. In turn, stimulation by ATP contributes to $\mathrm{Ca}^{2+}$ rise and enhances IL-2 production [263, 264]. Silencing or chemical inhibition of $\mathrm{P} 2 \mathrm{X}$ receptors strongly impair $\mathrm{Ca}^{2+}$ influx, NFAT activation, and interleukin production [263, 264]. Therefore P2X along with STIM1 and Orail was suggested to contribute to $\mathrm{Ca}^{2+}$ entry, providing an amplification mechanism for TCR signaling [263, 264]. ATP release required for $\mathrm{P} 2 \mathrm{X}$ stimulation may be achieved by exocytosis, or from dying cells, but also from intact $\mathrm{T}$ cells [265] via some wide-pore channels, like pannexin 1 [266] or, notably, through P2X7 themselves. Importantly, stimulation of T cells or Jurkat causes a rapid (within minutes) translocation and clustering of $\mathrm{P} 2 \mathrm{X} 1$ and $\mathrm{P} 2 \mathrm{X} 4$, but there are no changes in the P2X7 distribution [264]. The same is true for the immunological synapse, where in addition pannexin 1 is rapidly recruited. It is hypothesized that such a colocalization may produce a strong positive purinergic feedback, with a further amplification due to the concentration of ATP in the synaptic cleft, thus, allowing sensation of just few presented antigens [261]. Additionally, P2X7 seems to interact with apoptotic pathways: prolonged activation of this receptor by extracellular ATP released by neighboring apoptotic cells promotes overall apoptotic process [267].

Remarkably, the evidences emerged, which link P2X7 with leukemogenesis. Bone marrow samples obtained from patients with different types of leukemias, mainly AML and CLL, show a substantially higher level of P2X7 mRNA expression as compared to normal donor group [268]. Quite a few samples from ALL patients were analyzed in this study, and, although they showed increased level of P2X7, it was not indicated if there were B-ALL or T-ALL cells. In contrast, recent study on identification of interconnected markers for T-ALL, which included 173 T-ALL patients, revealed P2X7 as non-DE gene [125]. As was mentioned earlier, non-DE genes may be involved in signaling networks, upregulated during leukemogenesis.

8.9. $\mathrm{Cl}^{-}$Currents. Any osmotic or volume adjustment (e.g., RVD or AVD) requires a massive transport of solute across the plasma membrane. Such a massive transport is possible only when it occurs in electroneutral manner, so that cations (e.g., $\mathrm{K}^{+}$) transport needs to be accompanied by a parallel transport of anions via anion channels. In ALL (T-ALL) the expression of $\mathrm{ClC} 2-5$ was detected by PCR; ClC-3 is robustly expressed in healthy PBL and leukemias, whereas ClC-2 is mainly in leukemias [269]. $\mathrm{ClC} 2$ and $\mathrm{ClC} 3$ play roles in volume regulation, whereas there are $\mathrm{ClC} 2$ and $\mathrm{ClC} 4$ - in $\mathrm{pH}$ homeostasis. Activator-induced proliferation of healthy $\mathrm{T}$ cells involved DIDS-sensitive NPPB-insensitive $\mathrm{Cl}^{-}$channels, whereas in case of leukemic cells (Daudi, Jurkat, and H-60) it is mediated by DIDS-insensitive NPPB-sensitive ones (but 
not ClC-2, as evidenced by silencing experiment) [269, 270]. VSOR $\left(\mathrm{Cl}_{\text {swell }}\right)$ (volume sensitive outward rectifying $\mathrm{Cl}^{-}$current, activated by swelling) was first discovered in peripheric human T cells [271-273]. Identical biophysical properties (intrinsically outward-rectifying) $\mathrm{Cl}^{-}$current for CFTR (cystic fibrosis transmembrane conductance regulator) cAMP-activated [274] and volume-regulated [273] currents were reported also for leukemic Jurkat cells. VSOR may also require lck-kinase (p56 ${ }^{\text {lck }}$ ) activity: the inhibition of this kinase blocks swelling-induced $\mathrm{Cl}^{-}$current, whereas addition of p56 ${ }^{\text {lck }}$ to excised patches caused the current activation [275]. Once activated, VSOR may stay extremely long time in open state (several minutes) without transitions to closed state. Yet more careful inspection revealed close-open events. At physiological ionic conditions and zero membrane voltage unitary conductance of VSOR is about $40 \mathrm{pS}$ [274-276]; single channel current displays a strong outward rectification, which mimics the voltage dependence of the whole cell VSOR. Likewise, VSOR is encoded by CFTR, unique member of ABC-transporter family, encoding $\mathrm{Cl}^{-}$channel and not a pump. Transfection of the CFTRdefective B cells and lymphoblasts with wild-type CFTR cDNA resulted in a restoration of a cell-cycle-dependent (maximal expression in the G1 phase, low expression in the S-phase) cAMP-activated outward rectifying $\mathrm{Cl}^{-}$current $[277,278]$. It was shown that the outward rectifying $\mathrm{Cl}^{-}$ current can be activated in a triple manner: transiently by cAMP and steadily by either hypotonic stress or intracellular $\mathrm{Ca}^{2+}$ increase; only the activation by cAMP was abolished by genetic defect in CFTR [279]. In addition, CFTR deficient mice have shown a higher NFAT to nucleus translocation and higher interleukin and immunoglobulin E production by $\mathrm{T}$ cells due to altered (elevated) intracellular $\mathrm{Ca}^{2+}$ increase in response to $\mathrm{T}$ cell receptor activation. This may be a depolarization, caused by outward-rectifying $\mathrm{Cl}^{-}$current which normally moderates $\mathrm{Ca}^{2+}$ influx via CRAC [280]. Summarizing, all aforementioned $\mathrm{Cl}^{-}$channels are expressed in normal lymphocytes and lymphoblasts. Whereas in case of $\mathrm{ClC}$ channels direct demonstration of respective currents is lacking, in case of VSOR its molecular identity remains to be revealed. Preliminary pharmacological analysis suggests differential dominant $\mathrm{Cl}^{-}$currents in normal and malignant lymphocytes.

8.10. Other Channels. Nicotinic AchR forms nonselective cation channel, with important roles in neoplastic progression, both via conducting and nonconducting signaling mechanisms. There is circumvent evidence for nAchR expression in lymphocytes and nicotine affects hematopoiesis [281, 282]. Yet functional roles of $n A c h R$ and cholinergic signaling in healthy lymphocytes and leukemias remain to be elucidated. Both human $\mathrm{T}$ and leukemic Jurkat cells appear to express ionotropic glutamate receptors of AMPA and NMDA types. Their activation by respective ligands promoted cell adhesion and migration [283,284]. NMDA receptor antagonists decreased proliferation of $\mathrm{T}$ and Jurkat cells, but in a different manner. In Jurkat cells this reduction was associated with Gl-S transition arrest and increased apoptosis; neither phenomenon was associated with a decrease of proliferation in healthy $\mathrm{T}$ cells $[284,285]$. In early studies one may find the notion that a few percent of $\mathrm{T}$ cells from human peripheric blood express functional voltage-dependent $\mathrm{Na}^{+}$ channels [159], but their role in nonexcitable cells remains obscure. Expression of $\alpha$-subunits of voltage-dependent Ltype $\mathrm{Ca}^{2+}$ channels $\left(\mathrm{Ca}_{\mathrm{v}} 1\right)$ as well as interacting $\beta$-subunits is consistently reported in human healthy $\mathrm{T}$ and Jurkat cells. However, up to now neither depolarization-activated $\mathrm{Ca}^{2+}$ selective currents nor significant $\mathrm{Ca}^{2+}$ influx evoked by a depolarization was detected in human $\mathrm{T}$ cells $[126,208]$. However, on murine models, typical L-type $\mathrm{Ca}^{2+}$ currents, which disappeared upon $\mathrm{Ca}_{\mathrm{v}} 1.4$ silencing, were reported in a single study [286]. Furthermore, mice with mutant $\beta$-subunits or Cavl.4-deficient mice, or mice with knockdown $\mathrm{Ca}_{\mathrm{v}} 1.2$ and/or $\mathrm{Ca}_{\mathrm{v}} 1.3$ display clear immunopathological phenotypes (see $[208,287]$ for a recent update). Yet no immunopathological phenotypes were demonstrated in humans. The situation may be even more complicated due to the fact that STIM1, activating CRAC, inhibits the L-type $\mathrm{Ca}^{2+}$ channel activity [288], so that CRAC dominance in T cells implies a suppression of the $\mathrm{Ca}_{\mathrm{V}}$ activity. In the latter study, authors were able to show a depolarization-activated $\mathrm{Ca}^{2+}$ increase in mutant STIM1-deficient Jurkat cells, transfected with $\mathrm{Ca}_{\mathrm{v}} 1.2$ along with $\beta 1 \mathrm{~b}$ and $\alpha 2 \delta 1$ subunits; yet without such a transfection no significant depolarizationactivated $\mathrm{Ca}^{2+}$ influx was detected, which questions again the functional role of background $\mathrm{Ca}_{\mathrm{v}} 1$ channels. It was speculated that instead of activation by large depolarization, hardly attainable in T-cells, $\mathrm{Ca}_{\mathrm{v}}$ channels may be activated due to their clustering and interaction with PKC [287].

\section{Targeting Ion Channels for the T-ALL Treatment}

Although an impressive progress has been made in the treatment of T-ALL, it is still a disease with enormous need for innovation in the therapeutic field. Undoubtedly, the concept of total chemotherapy has been a milestone in the history of the treatment of this disease. The stage of differentiation, at which the proliferative arrest occurs, denotes not only the degree of maturation of the leukemic cell, but also its clinical behavior and response to a particular treatment. Early $\mathrm{T}$ leukemias, regarding the mature $\mathrm{T}$ cell neoplasias, are more chemoresistant and, therefore, demonstrate lower rates of complete remission and overall survival. The current therapeutic strategy is based on a combination of chemotherapeutic agents targeting DNA and protein synthesis (methotrexate, L-asparaginase, doxorubicin, cyclophosphamide, cytarabine, and nelarabine), or inducing apoptosis (dexamethasone). Allogeneic bone marrow transplantation has been shown to be beneficial in a selected population in this leukemia subtype. Although the leukemia-free survival has significantly improved in the last decades, being reported in some series in children up to $85 \%$ at 5 years [289], traditional antileukemic drugs demonstrate numerous shortand long-term toxic side effects, which may lead to significant morbidity. More than $50 \%$ of pediatric cancer survivors 
will develop long-term complications, including cardiovascular, gonadal, and gastrointestinal/hepatic dysfunction, neurocognitive sequelae, auditory complications, and decline in growth, with approximately $25 \%$ of cases being severe [290]. Additionally, long-term toxicities of these antineoplastics include the possibility of a future secondary malignancy.

Among novel molecular targets FLT3, JAK1/JAK3 and Notch were proposed [291]. Some FLT3 inhibitors as lestaurtinib currently have been studied in the phase III clinical trials, showing in vitro apoptosis induction capability in LLA cells lines that express high levels of FLT3 and interacting synergistically with multiple chemotherapeutic agents. JAK inhibitors are currently in varying stages of development and they have only been in adult trials. Notch inhibitors are under development. Though, in animal models and in the phase I clinical trials, serious gastrointestinal toxicity has been shown, which can be reversed by concomitant use of glucocorticoids, subsequent additions have been few and mainly restricted to the advent of some new chemotherapeutic drugs (clofarabine, nelarabine), the use of monoclonal antibodies such as alemtuzumab, and more recently drugs able to impact molecular targets (see for review [292]). Sustained activation of Cn/NFAT pathway is a hallmark of the T-ALL $[43,107,108]$. However, this pathway is ubiquitous not only in malignant, but in many healthy tissues as well. As a result, although administration of the $\mathrm{Cn}$ inhibitors showed an antileukemic effect $[43,77]$, it was associated with a number of undesirable offtarget effects [293].

Leukemias show altered expression of a variety of ion channels (for review see [127] and this review). Even if the profile of channel expression is not changed, as was shown for nondifferentially expressed genes, it may be involved in newly upregulated signaling network [125]. However it is unlikely that these alterations by themselves launch the leukemic scenario. Rather, ion channels represent important components, which ensure homeostatic conditions favorable for the migration, proliferation, and leukemic survival, or facilitate the expression of oncogenes, involved in the leukemogenesis. Almost all signaling pathways, upregulated in the T-ALL, show a dependence on the $\mathrm{Ca}^{2+}$ signaling. Channels may be involved in the cell motility and tumor metastasis. These phenomena may provide the basis for the targeting ion channel in leukemogenesis.

For example, TRESK channels are abnormally expressed in some types of T leukemias [197]. As was mentioned, this channel is activated through $\mathrm{Cn}$-dependent mechanism and is involved in a positive feedback regulation of the $\mathrm{Ca}^{2+}$ entry. Thus, TRESK inhibition could result in a downregulation of the $\mathrm{Cn}$. However, the issue is much more complex than it might seem. First of all, TRESK is normally expressed in some healthy tissues [201], foremost in the central nervous system where it is related to the migraine pathology [294]. Next, no specific blockers for the TRESK are known so far. To resolve a similar problem related to the $\mathrm{K}_{\mathrm{v}} 10.1$ channel, specific functional antibodies were designed [295]. Although it is possible that an antibody actively crosses the blood-brain barrier, the concentrations efficient for tumors are likely lower than those required to reach the brain parenchyma and to cause massive side effects [295]. Another classical example is $\mathrm{K}_{\mathrm{v}} 11.1$, aberrantly expressed in many tumor types [127]. The difficulty lies in the fact that $\mathrm{K}_{\mathrm{v}} 11.1$ normal localization is the cardiac tissue, where it contributes in the repolarization phase of the cardiac action potential [175]. Although specific blockers of this channel are available, its inhibition can retard the repolarization and prolong QT interval leading to the ventricular arrhythmia, with a possible fatal fibrillation [296]. Therefore, $\mathrm{K}_{\mathrm{v}} 11.1$ is generally considered as an undesired pharmacological target. To overcome this issue, it was proposed to consider different blocking mechanisms and target a particular conformational state of leukemic ion channels, as well as bipolar antibodies, raised against the complex of the channel and one of its auxiliary proteins, characteristic for tumors [127].

Yet another very important point should be taken into consideration, namely, hierarchical tumor development, its genetic instability, and heterogeneity of the T-ALL population. Obviously, LSC and T-ALL clones, representing the same clinical case, differ in their "gene expression signatures" and, accordingly, in their sensitivity/resistance to chemotherapy. Chemotherapeutic agents, used nowadays, successfully eradicate the blast cells in many patients; however, they have very little if any effect at the level of the blast progenitor cell, namely, LSC, which is biologically distinct from most of the cells found in a typical patient [297]. Then LSCs that survived chemotherapeutic attack finally cause the chemoresistance and relapse. Additionally, some therapeutic targets may be present only in a few nondominant clones, which does cause unresponsiveness to the treatment. Targeting the LSC was suggested as the Holy Grail of leukemia therapy [298]. Then, considering ion channels as a possible target, the search for ion channels expressed specifically in LSC would be of a special advantage. We suggest that the experiments with primary blast cells or cell lines derived from patients in relapse may give some important information.

\section{Conclusions}

Tumor-specific expression of a certain ion channel is a relatively rare phenomenon. However, changes in the expression (including its variation during cell cycle) and subcellular localization, splicing of channels (and relative expression of different variants), role of heteroligomerization, of $\beta$ subunits, and of other auxiliary proteins (especially integrins), and modification of the channel protein, as well as every aspect of microenvironment and metabolic regulation and signaling pathways context, affecting the channel's activity, may be of potential importance for the tumor progression. Here, the integration of the channels function and their crosstalks, most apparently via cell membrane polarization and intracellular $\mathrm{Ca}^{2+}$ changes, needs to be considered.

\section{Conflict of Interests}

The authors report no conflict of interests. The authors alone are responsible for the content of the paper.

\section{Authors' Contribution}

Oxana Dobrovinskaya and Igor Pottosin had an equal contribution. 


\section{Acknowledgments}

This study was supported by CONACyT, Grant 12897, to Oxana Dobrovinskaya. The authors are thankful to Mr. Scott Hayes for his indispensible help in editing the paper for English language and style.

\section{References}

[1] A. A. Ferrando, D. S. Neuberg, J. Staunton et al., "Gene expression signatures define novel oncogenic pathways in T cell acute lymphoblastic leukemia," Cancer Cell, vol. 1, no. 1, pp. 75-87, 2002.

[2] C. Graux, J. Cools, L. Michaux, P. Vandenberghe, and A. Hagemeijer, "Cytogenetics and molecular genetics of T-cell acute lymphoblastic leukemia: from thymocyte to lymphoblast," Leukemia, vol. 20, no. 9, pp. 1496-1510, 2006.

[3] J. Kang and D. H. Raulet, "Events that regulate differentiation of $\alpha \beta \mathrm{TCR}^{+}$and $\gamma \delta \mathrm{TCR}+\mathrm{T}$ cells from a common precursor," Seminars in Immunology, vol. 9, no. 3, pp. 171-179, 1997.

[4] I. Ferrero, S. J. C. Mancini, F. Grosjean, A. Wilson, L. Otten, and H. R. MacDonald, "TCR $\gamma$ silencing during $\alpha \beta$ T cell development depends upon pre-TCR-induced proliferation," Journal of Immunology, vol. 177, no. 9, pp. 6038-6043, 2006.

[5] J. A. Owen, J. Punt, and S. A. Stranford, KUBY Immunology, W. H. Freeman, 7th edition, 2009.

[6] A. C. Carpenter and R. Bosselut, "Decision checkpoints in the thymus," Nature Immunology, vol. 11, no. 8, pp. 666-673, 2010.

[7] E. S. Hoffman, L. Passoni, T. Crompton et al., "Productive T-cell receptor $\beta$-chain gene rearrangement: coincident regulation of cell cycle and clonality during development in vivo," Genes \& Development, vol. 10, no. 8, pp. 948-962, 1996.

[8] B. L. Brady and C. H. Bassing, "Differential regulation of proximal and distal $\mathrm{V} \beta$ segments upstream of a functional VDJ $\beta 1$ rearrangement upon $\beta$-selection," The Journal of Immunology, vol. 187, no. 6, pp. 3277-3285, 2011.

[9] H. T. Petrie, F. Livak, D. Burtrum, and S. Mazel, “T cell receptor gene recombination patterns and mechanisms: cell death, rescue, and T cell production," The Journal of Experimental Medicine, vol. 182, no. 1, pp. 121-127, 1995.

[10] M. Mingueneau, T. Kreslavsky, D. Gray et al., "The transcriptional landscape of $\alpha \beta$ T cell differentiation," Nature Immunology, vol. 14, no. 6, pp. 619-632, 2013.

[11] E. R. Andersson, R. Sandberg, and U. Lendahl, "Notch signaling: simplicity in design, versatility in function," Development, vol. 138, no. 17, pp. 3593-3612, 2011.

[12] A. Bigas, À. Robert-Moreno, and L. Espinosa, "The Notch pathway in the developing hematopoietic system," The International Journal of Developmental Biology, vol. 54, no. 6-7, pp. 1175-1188, 2010.

[13] P. K. Thompson and J. C. Zúñiga-Pflücker, "On becoming a T cell, a convergence of factors kick it up a Notch along the way," Seminars in Immunology, vol. 23, no. 5, pp. 350-359, 2011.

[14] K. Hozumi, C. Mailhos, N. Negishi et al., "Delta-like 4 is indispensable in thymic environment specific for T cell development," The Journal of Experimental Medicine, vol. 205, no. 11, pp. 2507-2513, 2008.

[15] U. Koch, E. Fiorini, R. Benedito et al., "Delta-like 4 is the essential, nonredundant ligand for Notchl during thymic T cell lineage commitment," Journal of Experimental Medicine, vol. 205, no. 11, pp. 2515-2523, 2008.
[16] M. Dose, I. Khan, Z. Guo et al., "c-Myc mediates pre-TCRinduced proliferation but not developmental progression," Blood, vol. 108, no. 8, pp. 2669-2677, 2006.

[17] M. Ciofani, T. M. Schmitt, A. Ciofani et al., "Obligatory role for cooperative signaling by pre-TCR and Notch during thymocyte differentiation," Journal of Immunology, vol. 172, no. 9, pp. 52305239, 2004.

[18] Y. Amasaki, E. S. Masuda, R. Imamura, K.-I. Arai, and N. Arai, "Distinct NFAT family proteins are involved in the nuclear NFAT-DNA binding complexes from human thymocyte subsets," The Journal of Immunology, vol. 160, no. 5, pp. 2324-2333, 1998.

[19] R. E. Voll, E. Jimi, R. J. Phillips et al., "NF-kappaB activation by the pre-T cell receptor serves as a selective survival signal in $\mathrm{T}$ lymphocyte development," Immunity, vol. 13, no. 5, pp. 677-689, 2000.

[20] T. Naito, H. Tanaka, Y. Naoe, and I. Taniuchi, "Transcriptional control of T-cell development," International Immunology, vol. 23, no. 11, pp. 661-668, 2011.

[21] E. M. Gallo, M. M. Winslow, K. Canté-Barrett et al., "Calcineurin sets the bandwidth for discrimination of signals during thymocyte development," Nature, vol. 450, no. 7170, pp. 731-735, 2007.

[22] A. A. Yarilin and I. M. Belyakov, "Cytokines in the thymus: production and biological effects," Current Medicinal Chemistry, vol. 11, no. 4, pp. 447-464, 2004.

[23] C. S. Tremblay and D. J. Curtis, "The clonal evolution of leukemic stem cells in T-cell acute lymphoblastic leukemia," Current Opinion in Hematology, vol. 21, no. 4, pp. 320-325, 2014.

[24] B. Cauwelier, N. Dastugue, J. Cools et al., "Molecular cytogenetic study of 126 unselected T-ALL cases reveals high incidence of TCR $\beta$ locus rearrangements and putative new Tcell oncogenes," Leukemia, vol. 20, no. 7, pp. 1238-1244, 2006.

[25] F. J. T. Staal and A. W. Langerak, "Signaling pathways involved in the development of T-cell acute lymphoblastic leukemia," Haematologica, vol. 93, no. 4, pp. 493-497, 2008.

[26] S. Chiaretti and R. Foà, "T-cell acute lymphoblastic leukemia," Haematologica, vol. 94, no. 2, pp. 160-162, 2009.

[27] M. D. Kraszewska, M. Dawidowska, T. Szczepański, and M. Witt, "T-cell acute lymphoblastic leukaemia: recent molecular biology findings," British Journal of Haematology, vol. 156, no. 3, pp. 303-315, 2012.

[28] I. Aifantis, E. Raetz, and S. Buonamici, "Molecular pathogenesis of T-cell leukaemia and lymphoma," Nature Reviews Immunology, vol. 8, no. 5, pp. 380-390, 2008.

[29] K. de Keersmaecker, P. J. Real, G. D. Gatta et al., "The TLX1 oncogene drives aneuploidy in T cell transformation," Nature Medicine, vol. 16, no. 11, pp. 1321-1327, 2010.

[30] S. Dadi, S. Le Noir, D. Payet-Bornet et al., “TLX homeodomain oncogenes mediate $\mathrm{T}$ cell maturation arrest in T-ALL via interaction with ETS1 and suppression of TCR $\alpha$ gene expression," Cancer Cell, vol. 21, no. 4, pp. 563-576, 2012.

[31] J. E. Haydu and A. A. Ferrando, "Early T-cell precursor acute lymphoblastic leukaemia," Current Opinion in Hematology, vol. 20, no. 4, pp. 369-373, 2013.

[32] J. O’Neil, J. Shank, N. Cusson, C. Murre, and M. Kelliher, "TAL1/SCL induces leukemia by inhibiting the transcriptional activity of E47/HEB," Cancer Cell, vol. 5, no. 6, pp. 587-596, 2004.

[33] M. Tremblay, C. S. Tremblay, S. Herblot et al., "Modeling T-cell acute lymphoblastic leukemia induced by the SCL and LMO1 
oncogenes," Genes and Development, vol. 24, no. 11, pp. 1093$1105,2010$.

[34] T. Sanda, L. N. Lawton, M. I. Barrasa et al., "Core transcriptional regulatory circuit controlled by the TAL1 complex in human T cell acute lymphoblastic leukemia," Cancer Cell, vol. 22, no. 2, pp. 209-221, 2012.

[35] R. O. Bash, S. Hall, C. F. Timmons et al., "Does activation of the TAL1 gene occur in a majority of patients with T-cell acute lymphoblastic leukemia? A pediatric oncology group study," Blood, vol. 86, no. 2, pp. 666-676, 1995.

[36] A. P. Weng, A. A. Ferrando, W. Lee et al., "Activating mutations of NOTCH1 in human T cell acute lymphoblastic leukemia," Science, vol. 306, no. 5694, pp. 269-271, 2004.

[37] T. Palomero, K. L. Wei, D. T. Odom et al., "NOTCH1 directly regulates $c$-MYC and activates a feed-forward-loop transcriptional network promoting leukemic cell growth," Proceedings of the National Academy of Sciences of the United States of America, vol. 103, no. 48, pp. 18261-18266, 2006.

[38] M. L. Sulis, O. Williams, T. Palomero et al., "NOTCH1 extracellular juxtamembrane expansion mutations in T-ALL," Blood, vol. 112, no. 3, pp. 733-740, 2008.

[39] M. J. Malecki, C. Sanchez-Irizarry, J. L. Mitchell et al., "Leukemia-associated mutations within the NOTCH1 heterodimerization domain fall into at least two distinct mechanistic classes," Molecular and Cellular Biology, vol. 26, no. 12, pp. 4642-4651, 2006.

[40] M. Y. Chiang, M. L. Xu, G. Histen et al., "Identification of a conserved negative regulatory sequence that influences the leukemogenic activity of NOTCH1," Molecular and Cellular Biology, vol. 26, no. 16, pp. 6261-6271, 2006.

[41] L. W. Ellisen, J. Bird, D. C. West et al., "TAN-1, the human homolog of the Drosophila Notch gene, is broken by chromosomal translocations in T lymphoblastic neoplasms," Cell, vol. 66, no. 4, pp. 649-661, 1991.

[42] T. Palomero, K. McKenna, J. O’Neil et al., “Activating mutations in NOTCH1 in acute myeloid leukemia and lineage switch leukemias," Leukemia, vol. 20, no. 11, pp. 1963-1966, 2006.

[43] H. Medyouf, H. Alcalde, C. Berthier et al., "Targeting calcineurin activation as a therapeutic strategy for T-cell acute lymphoblastic leukemia," Nature Medicine, vol. 13, no. 6, pp. 736-741, 2007.

[44] B. K. Robbs, A. L. S. Cruz, M. B. F. Werneck, G. P. Mognol, and J. P. B. Viola, "Dual roles for NFAT transcription factor genes as oncogenes and tumor suppressors," Molecular and Cellular Biology, vol. 28, no. 23, pp. 7168-7181, 2008.

[45] T. Palomero, M. L. Sulis, M. Cortina et al., "Mutational loss of PTEN induces resistance to NOTCH1 inhibition in T-cell leukemia," Nature Medicine, vol. 13, no. 10, pp. 1203-1210, 2007.

[46] C. Grabher, H. von Boehmer, and A. T. Look, "Notch 1 activation in the molecular pathogenesis of T-cell acute lymphoblastic leukaemia," Nature Reviews Cancer, vol. 6, no. 5, pp. 347-359, 2006.

[47] N. Chadwick, L. Zeef, V. Portillo et al., "Identification of novel Notch target genes in T cell leukaemia," Molecular Cancer, vol. 8, article 35, 2009.

[48] L. M. Sarmento, H. Huang, A. Limon et al., "Notch1 modulates timing of $\mathrm{G}_{1}$-S progression by inducing SKP2 transcription and p $27^{\text {Kip1 }}$ degradation," The Journal of Experimental Medicine, vol. 202, no. 1, pp. 157-168, 2005.

[49] T. Vilimas, J. Mascarenhas, T. Palomero et al., "Targeting the NF- $\kappa$ B signaling pathway in Notch1-induced T-cell leukemia," Nature Medicine, vol. 13, no. 1, pp. 70-77, 2007.
[50] W. S. Pear, J. C. Aster, M. L. Scott et al., "Exclusive development of $\mathrm{T}$ cell neoplasms in mice transplanted with bone marrow expressing activated Notch alleles," The Journal of Experimental Medicine, vol. 183, no. 5, pp. 2283-2291, 1996.

[51] A. Hagemeijer and C. Graux, "ABLI rearrangements in T-cell acute lymphoblastic leukemia," Genes Chromosomes and Cancer, vol. 49, no. 4, pp. 299-308, 2010.

[52] J. P. Meijerink, "Genetic rearrangements in relation to immunophenotype and outcome in T-cell acute lymphoblastic leukaemia," Best Practice and Research: Clinical Haematology, vol. 23, no. 3, pp. 307-318, 2010.

[53] S. Feske, "Calcium signalling in lymphocyte activation and disease," Nature Reviews Immunology, vol. 7, no. 9, pp. 690-702, 2007.

[54] R. S. Lewis, "Calcium signaling mechanisms in T lymphocytes," Annual Review of Immunology, vol. 19, pp. 497-521, 2001.

[55] M. Oh-Hora, "Calcium signaling in the development and function of T-lineage cells," Immunological Reviews, vol. 231, no. 1, pp. 210-224, 2009.

[56] H. L. Roderick and S. J. Cook, " $\mathrm{Ca}^{2+}$ signalling checkpoints in cancer: remodelling $\mathrm{Ca}^{2+}$ for cancer cell proliferation and survival," Nature Reviews Cancer, vol. 8, no. 5, pp. 361-375, 2008.

[57] G. Fu, V. Rybakin, J. Brzostek, W. Paster, O. Acuto, and N. R. J. Gascoigne, "Fine-tuning T cell receptor signaling to control T cell development," Trends in Immunology, vol. 35, no. 7, pp. 311-318, 2014.

[58] M. D. Cahalan, "STIMulating store-operated $\mathrm{Ca}^{2+}$ entry," Nature Cell Biology, vol. 11, no. 6, pp. 669-677, 2009.

[59] P. G. Hogan, R. S. Lewis, and A. Rao, "Molecular basis of calcium signaling in lymphocytes: STIM and ORAI," Annual Review of Immunology, vol. 28, pp. 491-533, 2010.

[60] J. O. Liu, "Calmodulin-dependent phosphatase, kinases, and transcriptional corepressors involved in T-cell activation," Immunological Reviews, vol. 228, no. 1, pp. 184-198, 2009.

[61] H. Li, A. Rao, and P. G. Hogan, "Interaction of calcineurin with substrates and targeting proteins," Trends in Cell Biology, vol. 21, no. 2, pp. 91-103, 2011.

[62] R. V. Parry and C. H. June, "Calcium-independent calcineurin regulation," Nature Immunology, vol. 4, no. 9, pp. 821-823, 2003.

[63] C. B. Klee, H. Ren, and X. Wang, "Regulation of the calmodulinstimulated protein phosphatase, calcineurin," The Journal of Biological Chemistry, vol. 273, no. 22, pp. 13367-13370, 1998.

[64] P. G. Hogan, L. Chen, J. Nardone, and A. Rao, "Transcriptional regulation by calcium, calcineurin, and NFAT," Genes and Development, vol. 17, no. 18, pp. 2205-2232, 2003.

[65] F. Macian, "NFAT proteins: key regulators of T-cell development and function," Nature Reviews Immunology, vol. 5, no. 6, pp. 472-484, 2005.

[66] P. G. McCaffrey, J. Jain, C. Jamieson, R. Sen, and A. Rao, “A T cell nuclear factor resembling NF-AT binds to an NF- $\kappa$ B site and to the conserved lymphokine promoter sequence "cytokine-1"', The Journal of Biological Chemistry, vol. 267, no. 3, pp. 1864-1871, 1992.

[67] P. G. McCaffrey, C. Luo, T. K. Kerppola et al., "Isolation of the cyclosporin-sensitive T cell transcription factor NFATp," Science, vol. 262, no. 5134, pp. 750-754, 1993.

[68] J.-P. Shaw, P. J. Utz, D. B. Durand, J. J. Toole, E. A. Emmel, and G. R. Crabtree, "Indentification of a putative regulator of early T cell activation genes," Science, vol. 241, no. 4862, pp. 202-205, 1988. 
[69] H. von Boehmer, I. Aifantis, J. Feinberg et al., "Pleiotropic changes controlled by the pre-T-cell receptor," Current Opinion in Immunology, vol. 11, no. 2, pp. 135-142, 1999.

[70] A. M. Michie and J. C. Zúñiga-Pflücker, "Regulation of thymocyte differentiation: Pre-TCR signals and $\beta$-selection," Seminars in Immunology, vol. 14, no. 5, pp. 311-323, 2002.

[71] C. Saint-Ruf, M. Panigada, O. Azogul, P. Debey, H. Von Boehmer, and F. Grassi, "Different initiation of pre-TCR and $\gamma \delta$ TCR signalling," Nature, vol. 406, no. 6795, pp. 524-527, 2000.

[72] M. C. Haks, S. M. Belkowski, M. Ciofani et al., "Low activation threshold as a mechanism for ligand-independent signaling in pre-T cells," The Journal of Immunology, vol. 170, no. 6, pp. 28532861, 2003.

[73] T. M. Schmitt and J. C. Zúñiga-Pflücker, "Induction of T cell development from hematopoietic progenitor cells by delta-like1 in vitro," Immunity, vol. 17, no. 6, pp. 749-756, 2002.

[74] M. P. Felli, M. Maroder, T. A. Mitsiadis et al., "Expression pattern of Notch1, 2 and 3 and Jagged 1 and 2 in lymphoid and stromal thymus components: distinct ligand-receptor interactions in intrathymic T cell development," International Immunology, vol. 11, no. 7, pp. 1017-1025, 1999.

[75] E. Y. Huang, A. M. Gallegos, S. M. Richards, S. M. Lehar, and M. J. Bevan, "Surface expression of Notch1 on thymocytes: correlation with the double-negative to double-positive transition," Journal of Immunology, vol. 171, no. 5, pp. 2296-2304, 2003.

[76] M. L. Deftos, E. Huang, E. W. Ojala, K. A. Forbush, and M. J. Bevan, "Notch1 signaling promotes the maturation of CD4 and CD8 SP thymocytes," Immunity, vol. 13, no. 1, pp. 73-84, 2000.

[77] S. Gachet and J. Ghysdael, "Calcineurin/NFAT signaling in lymphoid malignancies," General Physiology and Biophysics, vol. 28, pp. F47-F54, 2009.

[78] E. M. Gallo, L. Ho, M. M. Winslow, T. L. Staton, and G. R. Crabtree, "Selective role of calcineurin in haematopoiesis and lymphopoiesis," EMBO Reports, vol. 9, no. 11, pp. 1141-1148, 2008.

[79] J. R. Neilson, M. M. Winslow, E. M. Hur, and G. R. Crabtree, "Calcineurin B1 is essential for positive but not negative selection during thymocyte development," Immunity, vol. 20, no. 3, pp. 255-266, 2004.

[80] M. K. Jenkins, R. H. Schwartz, and D. M. Pardoll, "Effects of cyclosporine A on T cell development and clonal deletion," Science, vol. 241, no. 4873, pp. 1655-1658, 1988.

[81] E. K. Gao, D. Lo, R. Cheney, O. Kanagawa, and J. Sprent, "Abnormal differentiation of thymocytes in mice treated with cyclosporin A," Nature, vol. 336, no. 6195, pp. 176-179, 1988.

[82] M. Oukka, I.-C. Ho, F. Charles de la Brousse, T. Hoey, M. J. Grusby, and L. H. Glimcher, "The transcription factor NFAT4 is involved in the generation and survival of T cells," Immunity, vol. 9, no. 3, pp. 295-304, 1998.

[83] W.-L. Lo, D. L. Donermeyer, and P. M. Allen, "A voltage-gated sodium channel is essential for the positive selection of CD4 ${ }^{+} \mathrm{T}$ cells," Nature Immunology, vol. 13, no. 9, pp. 880-887, 2012.

[84] K. A. Hogquist, "Signal strength in thymic selection and lineage commitment," Current Opinion in Immunology, vol. 13, no. 2, pp. 225-231, 2001.

[85] H. J. Melichar, J. O. Ross, P. Herzmark, K. A. Hogquist, and E. A. Robey, "Distinct temporal patterns of $\mathrm{T}$ cell receptor signaling during positive versus negative selection in situ," Science Signaling, vol. 6, no. 297, article ra92, 2013.

[86] N. Beyersdorf, A. Braun, T. Vögtle et al., "STIM1-independent T cell development and effector function in vivo," Journal of Immunology, vol. 182, no. 6, pp. 3390-3397, 2009.
[87] C. Picard, C.-A. McCarl, A. Papolos et al., "STIM1 mutation associated with a syndrome of immunodeficiency and autoimmunity," The New England Journal of Medicine, vol. 360, no. 19, pp. 1971-1980, 2009.

[88] M. Vig and J. P. Kinet, "Calcium signaling in immune cells," Nature Immunology, vol. 10, no. 1, pp. 21-27, 2009.

[89] J. Jin, B. N. Desai, B. Navarro, A. Donovan, N. C. Andrews, and D. E. Clapham, "Deletion of Trpm7 disrupts embryonic development and thymopoiesis without altering $\mathrm{Mg}^{2+}$ homeostasis," Science, vol. 322, no. 5902, pp. 756-760, 2008.

[90] G. R. Monteith, D. McAndrew, H. M. Faddy, and S. J. RobertsThomson, "Calcium and cancer: targeting $\mathrm{Ca}^{2+}$ transport," Nature Reviews Cancer, vol. 7, no. 7, pp. 519-530, 2007.

[91] R. Burger, T. E. Hansen-Hagge, H. G. Drexler, and M. Gramatzki, "Heterogeneity of T-acute lymphoblastic leukemia (TALL) cell lines: suggestion for classification by immunophenotype and T-cell receptor studies," Leukemia Research, vol. 23, no. 1, pp. 19-27, 1999.

[92] V. Asnafi, K. Beldjord, E. Boulanger et al., "Analysis of TCR, $\mathrm{pT} \alpha$, and RAG-1 in T-acute lymphoblastic leukemias improves understanding of early human T-lymphoid lineage commitment," Blood, vol. 101, no. 7, pp. 2693-2703, 2003.

[93] M. C. Bene, G. Castoldi, W. Knapp et al., "Proposals for the immunological classification of acute leukemias," Leukemia, vol. 9, no. 10, pp. 1783-1786, 1995.

[94] D. Campana, J. S. Thompson, P. Amlot, S. Brown, and G. Janossy, "The cytoplasmic expression of CD3 antigens in normal and malignant cells of the T lymphoid lineage," The Journal of Immunology, vol. 138, no. 2, pp. 648-655, 1987.

[95] T. Szczepański, V. H. J. van der Velden, T. Raff et al., "Comparative analysis of T-cell receptor gene rearrangements at diagnosis and relapse of T-cell acute lymphoblastic leukemia (TALL) shows high stability of clonal markers for monitoring of minimal residual disease and reveals the occurence of second T-ALL," Leukemia, vol. 17, no. 11, pp. 2149-2156, 2003.

[96] I. Engel and C. Murre, "Disruption of pre-TCR expression accelerates lymphomagenesis in E2A-deficient mice," Proceedings of the National Academy of Sciences of the United States of America, vol. 99, no. 17, pp. 11322-11327, 2002.

[97] D. Bellavia, A. F. Campese, S. Checquolo et al., "Combined expression of $\mathrm{pT} \alpha$ and Notch3 in T cell leukemia identifies the requirement of preTCR for leukemogenesis," Proceedings of the National Academy of Sciences of the United States of America, vol. 99, no. 6, pp. 3788-3793, 2002.

[98] A. F. Campese, A. I. Garbe, F. Zhang, F. Grassi, I. Screpanti, and H. Von Boehmer, "Notchl-dependent lymphomagenesis is assisted by but does not essentially require pre-TCR signaling," Blood, vol. 108, no. 1, pp. 305-310, 2006.

[99] N. R. dos Santos, D. S. Rickman, A. de Reynies et al., "Pre-TCR expression cooperates with TEL-JAK2 to transform immature thymocytes and induce T-cell leukemia," Blood, vol. 109, no. 9, pp. 3972-3981, 2007.

[100] D. P. Smith, M. L. Bath, A. W. Harris, and S. Cory, "T-cell lymphomas mask slower developing B-lymphoid and myeloid tumours in transgenic mice with broad haemopoietic expression of MYC," Oncogene, vol. 24, no. 22, pp. 3544-3553, 2005.

[101] S. Winandy, L. Wu, J.-H. Wang, and K. Georgopoulos, "Pre-T cell receptor (TCR) and TCR-controlled checkpoints in T cell differentiation are set by Ikaros," The Journal of Experimental Medicine, vol. 190, no. 8, pp. 1039-1048, 1999.

[102] M.-J. Liao, X.-X. Zhang, R. Hill et al., "No requirement for $\mathrm{V}(\mathrm{D}) \mathrm{J}$ recombination in p53-deficient thymic lymphoma," 
Molecular and Cellular Biology, vol. 18, no. 6, pp. 3495-3501, 1998.

[103] L. K. Petiniot, Z. Weaver, C. Barlow et al., "Recombinaseactivating gene (RAG) 2-mediated $\mathrm{V}(\mathrm{D}) \mathrm{J}$ recombination is not essential for tumorigenesis in Atm-deficient mice," Proceedings of the National Academy of Sciences of the United States of America, vol. 97, no. 12, pp. 6664-6669, 2000.

[104] C. Carron, F. Cormier, A. Janin et al., “TEL-JAK2 transgenic mice develop T-cell leukemia," Blood, vol. 95, no. 12, pp. 38913899, 2000.

[105] M. Malissen, A. Gillet, L. Ardouin et al., "Altered T cell development in mice with a targeted mutation of the CD3- $\varepsilon$ gene," The EMBO Journal, vol. 14, no. 19, pp. 4641-4653, 1995.

[106] M. Fasseu, P. D. Aplan, M. Chopin et al., "p6INK4A tumor suppressor gene expression and $\mathrm{CD} 3 \varepsilon$ deficiency but not preTCR deficiency inhibit TAL1-linked T-lineage leukemogenesis," Blood, vol. 110, no. 7, pp. 2610-2619, 2007.

[107] T. Marafioti, M. Pozzobon, M. L. Hansmann et al., “The NFATc1 transcription factor is widely expressed in white cells and translocates from the cytoplasm to the nucleus in a subset of human lymphomas," British Journal of Haematology, vol. 128, no. 3, pp. 333-342, 2005.

[108] A. Akimzhanov, L. Krenacs, T. Schlegel et al., "Epigenetic changes and suppression of the nuclear factor of activated $\mathrm{T}$ cell 1 (NFATC1) promoter in human lymphomas with defects in immunoreceptor signaling," The American Journal of Pathology, vol. 172, no. 1, pp. 215-224, 2008.

[109] S. Gachet, E. Genescà, D. Passaro et al., "Leukemia-initiating cell activity requires calcineurin in T-cell acute lymphoblastic leukemia," Leukemia, vol. 27, no. 12, pp. 2289-2300, 2013.

[110] C. Mammucari, A. T. di Vignano, A. A. Sharov et al., "Integration of notch 1 and calcineurin/NFAT signaling pathways in keratinocyte growth and differentiation control," Developmental Cell, vol. 8, no. 5, pp. 665-676, 2005.

[111] D. A. Fruman, S.-Y. Pai, S. J. Burakoff, and B. E. Bierer, "Characterization of a mutant calcineurin A $\alpha$ gene expressed by EL4 lymphoma cells," Molecular and Cellular Biology, vol. 15, no. 7, pp. 3857-3863, 1995.

[112] K. L. Gross, E. A. Cioffi, and J. G. Scammell, "Increased activity of the calcineurin-nuclear factor of activated T cells pathway in squirrel monkey B-Lymphoblasts identified by Power-Blot," In Vitro Cellular \& Developmental Biology. Animal, vol. 40, no. 1-2, pp. 57-63, 2004.

[113] M. R. Müller and A. Rao, "NFAT, immunity and cancer: a transcription factor comes of age," Nature Reviews Immunology, vol. 10, no. 9, pp. 645-656, 2010.

[114] T. Fujii, T. Tsuchiya, S. Yamada et al., "Localization and synthesis of acetylcholine in human leukemic T-cell lines," Journal of Neuroscience Research, vol. 44, no. 1, pp. 66-72, 1996.

[115] T. Fujii and K. Kawashima, "Calcium signaling and c-Fos gene expression via M3 muscarinic acetylcholine receptors in human T- and B-cells," Japanese Journal of Pharmacology, vol. 84, no. 2 , pp. 124-132, 2000.

[116] T. Fujii, Y. Takada-Takatori, and K. Kawashima, "Basic and clinical aspects of non-neuronal acetylcholine: expression of an independent, non-neuronal cholinergic system in lymphocytes and its clinical significance in immunotherapy," Journal of Pharmacological Sciences, vol. 106, no. 2, pp. 186-192, 2008.

[117] H. Fujino, Y. Kitamura, T. Yada, T. Uehara, and Y. Nomura, "Stimulatory roles of muscarinic acetylcholine receptors on $\mathrm{T}$ cell antigen receptor/CD3 complex-mediated interleukin-2 production in human peripheral blood lymphocytes," Molecular Pharmacology, vol. 51, no. 6, pp. 1007-1014, 1997.

[118] J. C. Zimring, L. M. Kapp, M. Yamada, J. Wess, and J. A. Kapp, "Regulation of CD8+ cytolytic T lymphocyte differentiation by a cholinergic pathway," Journal of Neuroimmunology, vol. 164, no. 1-2, pp. 66-75, 2005.

[119] N. Shah, S. Khurana, K. Cheng, and J.-P. Raufman, "Muscarinic receptors and ligands in cancer," The American Journal of Physiology-Cell Physiology, vol. 296, no. 2, pp. C221-C232, 2009.

[120] K. Kawashima and T. Fujii, "Expression of non-neuronal acetylcholine in lymphocytes and its contribution to the regulation of immune function," Frontiers in Bioscience, vol. 9, pp. 2063-2085, 2004.

[121] T. Palomero, D. T. Odom, J. O’Neil et al., “Transcriptional regulatory networks downstream of TAL1/SCL in T-cell acute lymphoblastic leukemia," Blood, vol. 108, no. 3, pp. 986-992, 2006.

[122] S. Chigurupati, R. Venkataraman, D. Barrera et al., "Receptor channel TRPC6 is a key mediator of Notch-driven glioblastoma growth and invasiveness," Cancer Research, vol. 70, no. 1, pp. 418-427, 2010.

[123] G. A. Kyriazis, C. Belal, M. Madan, and eatl, "Stress-induced switch in numb isoforms enhances notch-dependent expression of subtype-specific transient receptor potential channel," The Journal of Biological Chemistry, vol. 285, no. 9, pp. 6811-6825, 2010.

[124] A. S. Wenning, K. Neblung, B. Strauss et al., "TRP expression pattern and the functional importance of TRPC3 in primary human T-cells," Biochimica et Biophysica Acta: Molecular Cell Research, vol. 1813, no. 3, pp. 412-423, 2011.

[125] E. G. Maiorov, O. Keskin, O. H. Ng, U. Ozbek, and A. Gursoy, "Identification of interconnected markers for T-cell acute lymphoblastic leukemia," BioMed research international, vol. 2013, Article ID 210253, 20 pages, 2013.

[126] M. D. Cahalan and K. G. Chandy, "The functional network of ion channels in T lymphocytes," Immunological Reviews, vol. 231, no. 1, pp. 59-87, 2009.

[127] A. Arcangeli, S. Pillozzi, and A. Becchetti, "Targeting ion channels in leukemias: a new challenge for treatment," Current Medicinal Chemistry, vol. 19, no. 5, pp. 683-696, 2012.

[128] L. A. Pardo and W. Stühmer, "The roles of $\mathrm{K}^{+}$channels in cancer," Nature Reviews Cancer, vol. 14, no. 1, pp. 39-48, 2014.

[129] D. Urrego, A. P. Tomczak, F. Zahed, W. Stühmer, and L. A. Pardo, "Potassium channels in cell cycle and cell proliferation," Philosophical Transactions of the Royal Society B: Biological Sciences, vol. 369, no. 1638, Article ID 20130094, 2014.

[130] S. Amigorena, D. Choquet, J.-L. Teillaud, H. Korn, and W. H. Fridman, "Ion channel blockers inhibit B cell activation at a precise stage of the G1 phase of the cell cycle. Possible involvement of K+ channels," The Journal of Immunology, vol. 144, no. 6, pp. 2038-2045, 1990.

[131] X. Huang, A. M. Dubuc, R. Hashizume et al., "Voltage-gated potassium channel EAG2 controls mitotic entry and tumor growth in medulloblastoma via regulating cell volume dynamics," Genes and Development, vol. 26, no. 16, pp. 1780-1796, 2012.

[132] A. Cherubini, G. Hofmann, S. Pillozzi et al., "Human ether-ago-go-related gene 1 channels are physically linked to $\beta 1$ integrins and modulate adhesion-dependent signaling," Molecular Biology of the Cell, vol. 16, no. 6, pp. 2972-2983, 2005. 
[133] S. Pillozzi, M. F. Brizzi, P. A. Bernabei et al., "VEGFR-1 (FLT1), $\beta_{1}$ integrin, and hERG $\mathrm{K}^{+}$channel for a macromolecular signaling complex in acute myeloid leukemia: role in cell migration and clinical outcome," Blood, vol. 110, no. 4, pp. 1238-1250, 2007.

[134] S. Pillozzi, M. Masselli, E. De Lorenzo et al., "Chemotherapy resistance in acute lymphoblastic leukemia requires hERG1 channels and is overcome by hERG1 blockers," Blood, vol. 117, no. 3, pp. 902-914, 2011.

[135] P. Enyedi and G. Czirják, "Molecular background of leak $\mathrm{K}^{+}$ currents: two-pore domain potassium channels," Physiological Reviews, vol. 90, no. 2, pp. 559-605, 2010.

[136] G. A. Gutman, K. G. Chandy, S. Grissmer et al., "International Union of Pharmacology. LIII. Nomenclature and molecular relationships of voltage-gated potassium channels," Pharmacological Reviews, vol. 57, no. 4, pp. 473-508, 2005.

[137] P. A. Pahapill and L. C. Schlichter, "Modulation of potassium channels in human T lymphocytes: effects of temperature," Journal of Physiology, vol. 422, pp. 103-126, 1990.

[138] P. Hajdú, Z. Varga, C. Pieri, G. Panyi, and R. Gáspár Jr., "Cholesterol modifies the gating of Kv1.3 in human T lymphocytes," Pflügers Archiv: European Journal of Physiology, vol. 445, no. 6, pp. 674-682, 2003.

[139] I. I. Pottosin, G. Valencia-Cruz, E. Bonales-Alatorre, S. N. Shabala, and O. R. Dobrovinskaya, "Methyl- $\beta$-cyclodextrin reversibly alters the gating of lipid rafts-associated Kv1.3 channels in Jurkat T lymphocytes," Pflugers Archiv European Journal of Physiology, vol. 454, no. 2, pp. 235-244, 2007.

[140] C. Beeton, H. Wulff, N. E. Standifer et al., "Kv1.3 channels are a therapeutic target for T cell-mediated autoimmune diseases," Proceedings of the National Academy of Sciences of the United States of America, vol. 103, no. 46, pp. 17414-17419, 2006.

[141] M. Levite, L. Cahalon, A. Peretz et al., "Extracellular $\mathrm{K}^{+}$and opening of voltage-gated potassium channels activate $\mathrm{T}$ cell integrin function: physical and functional association between Kv1.3 channels and $\beta 1$ integrins," Journal of Experimental Medicine, vol. 191, no. 7, pp. 1167-1176, 2000.

[142] R. J. Leonard, M. L. Garcia, R. S. Slaughter, and J. P. Reuben, "Selective blockers of voltage-gated $\mathrm{K}^{+}$channels depolarize human T lymphocytes: mechanism of the antiproliferative effect of charybdotoxin," Proceedings of the National Academy of Sciences of the United States of America, vol. 89, no. 21, pp. 10094-10098, 1992.

[143] F. Mello de Queiroz, C. G. Ponte, A. Bonomo, R. ViannaJorge, and G. Suarez-Kurtz, "Study of membrane potential in T lymphocytes subpopulations using flow cytometry," $B M C$ immunology, vol. 9, article 63, 2008.

[144] C. Deutsch and L.-Q. Chen, "Heterologous expression of specific $\mathrm{K}+$ channels in $\mathrm{T}$ lymphocytes: functional consequences for volume regulation," Proceedings of the National Academy of Sciences of the United States of America, vol. 90, no. 21, pp. 10036-10040, 1993.

[145] J. Andronic, N. Bobak, S. Bittner et al., "Identification of two-pore domain potassium channels as potent modulators of osmotic volume regulation in human T lymphocytes," Biochimica et Biophysica Acta: Biomembranes, vol. 1828, no. 2, pp. 699707, 2013.

[146] B. Jürgen, I. Szabó, A. Jekle, and E. Gulbins, "Actinomycin D-induced apoptosis involves the potassium channel Kv1.3," Biochemical and Biophysical Research Communications, vol. 295, no. 2, pp. 526-531, 2002.
[147] G. Valencia-Cruz, L. Shabala, I. Delgado-Enciso et al., "K $\mathrm{K}_{b g}$ and Kv1.3 channels mediate potassium efflux in the early phase of apoptosis in Jurkat T lymphocytes," American Journal of Physiology: Cell Physiology, vol. 297, no. 6, pp. C1544-C1553, 2009.

[148] J. A. H. Verbeugen, F. Le Deist, V. Devignot, and H. Korn, "Enhancement of calcium signaling and proliferation responses in activated human $\mathrm{T}$ lymphocytes. Inhibitory effects of $\mathrm{K}^{+}$ channel block by charybdotoxin depend on the T cell activation state," Cell Calcium, vol. 21, no. 1, pp. 1-17, 1997.

[149] Y. R. Ren, F. Pan, S. Parvez et al., "Clofazimine inhibits human Kvl.3 potassium channel by perturbing calcium oscillation in $\mathrm{T}$ lymphocytes," PLoS ONE, vol. 3, no. 12, Article ID e4009, 2008.

[150] P. E. Ross and M. D. Cahalan, " $\mathrm{Ca}^{2+}$ influx pathways mediated by swelling or stores depletion in mouse thymocytes," The Journal of General Physiology, vol. 106, no. 3, pp. 415-444, 1995.

[151] S. Ghanshani, H. Wulff, M. J. Miller et al., "Up-regulation of the IKCal potassium channel during T-cell activation: molecular mechanism and functional consequences," The Journal of Biological Chemistry, vol. 275, no. 47, pp. 37137-37149, 2000.

[152] C. Beeton, H. Wulff, J. Barbaria et al., "Selective blockade of $\mathrm{T}$ lymphocyte $\mathrm{K}^{+}$channels ameliorates experimental autoimmune encephalomyelitis, a model for multiple sclerosis," Proceedings of the National Academy of Sciences of the United States of America, vol. 98, no. 24, pp. 13942-13947, 2001.

[153] H. Wulff, P. A. Calabresi, R. Allie et al., "The voltage-gated Kv1.3 $\mathrm{K}^{+}$channel in effector memory T cells as new target for MS," The Journal of Clinical Investigation, vol. 111, no. 11, pp. 1703-1713, 2003.

[154] Z. Varga, P. Hajdu, and G. Panyi, "Ion channels in T lymphocytes: an update on facts, mechanisms and therapeutic targeting in autoimmune diseases," Immunology Letters, vol. 130, no. 1-2, pp. 19-25, 2010.

[155] L. Hu, M. Pennington, Q. Jiang, K. A. Whartenby, and P. A. Calabresi, "Characterization of the functional properties of the voltage-gated potassium channel Kv1.3 in human $\mathrm{CD}^{4+} \mathrm{T}$ lymphocytes," Journal of Immunology, vol. 179, no. 7, pp. 45634570, 2007.

[156] C. S. Lin, R. C. Boltz, J. T. Blake et al., "Voltage-gated potassium channels regulate calcium-dependent pathways involved in human T lymphocyte activation," The Journal of Experimental Medicine, vol. 177, no. 3, pp. 637-645, 1993.

[157] P. Cidad, L. Jiménez-Pérez, D. García-Arribas et al., "Kv1.3 channels can modulate cell proliferation during phenotypic switch by an ion-flux independent mechanism," Arteriosclerosis, Thrombosis, and Vascular Biology, vol. 32, no. 5, pp. 1299-1307, 2012.

[158] L. K. Kaczmarek, "Non-conducting functions of voltage-gated ion channels," Nature Reviews Neuroscience, vol. 7, no. 10, pp. 761-771, 2006.

[159] M. D. Cahalan, K. G. Chandy, T. E. DeCoursey, and S. Gupta, "A voltage-gated potassium channel in human T lymphocytes," Journal of Physiology, vol. 358, pp. 197-237, 1985.

[160] I. Chung and L. C. Schlichter, "Criteria for perforated-patch recordings: ion currents versus dye permeation in human $\mathrm{T}$ lymphocytes," Pflugers Archiv European Journal of Physiology, vol. 424, no. 5-6, pp. 511-515, 1993.

[161] G. Panyi, G. Vámosi, Z. Bacsó et al., "Kv1.3 potassium channels are localized in the immunological synapse formed between cytotoxic and target cells," Proceedings of the National Academy of Sciences of the United States of America, vol. 101, no. 5, pp. 1285-1290, 2004. 
[162] T. Olamendi-Portugal, S. Somodi, J. A. Fernández et al., "Novel $\alpha$-KTx peptides from the venom of the scorpion Centruroides elegans selectively blockade Kvl.3 over IKCal $\mathrm{K}^{+}$channels of T cells," Toxicon, vol. 46, no. 4, pp. 418-429, 2005.

[163] A. Teisseyre and K. Michalak, "Genistein inhibits the activity of Kv1.3 potassium channels in human T lymphocytes," Journal of Membrane Biology, vol. 205, no. 2, pp. 71-79, 2005.

[164] I. Szabó, E. Gulbins, H. Apfel et al., “Tyrosine phosphorylationdependent suppression of a voltage-gated $\mathrm{K}^{+}$channel in $\mathrm{T}$ lymphocytes upon Fas stimulation," The Journal of Biological Chemistry, vol. 271, no. 34, pp. 20465-20469, 1996.

[165] E. Gulbins, I. Szabo, K. Baltzer, and F. Lang, "Ceramide-induced inhibition of T lymphocyte voltage-gated potassium channel is mediated by tyrosine kinases," Proceedings of the National Academy of Sciences of the United States of America, vol. 94, no. 14, pp. 7661-7666, 1997.

[166] A. Lampert, M. M. Müller, S. Berchtold et al., "Effect of dexamethasone on voltage-gated $\mathrm{K}^{+}$channels in Jurkat $\mathrm{T}$ lymphocytes," Pflügers Archiv-European Journal of Physiology, vol. 447, no. 2, pp. 168-174, 2003.

[167] N. M. Storey, M. Gómez-Angelats, C. D. Bortner, D. L. Armstrong, and J. A. Cidlowski, "Stimulation of Kv1.3 Potassium channels by death receptors during apoptosis in Jurkat $\mathrm{T}$ lymphocytes," Journal of Biological Chemistry, vol. 278, no. 35, pp. 33319-33326, 2003.

[168] G. Panyi, M. Bagdány, A. Bodnár et al., "Colocalization and nonrandom distribution of Kv1.3 potassium channels and CD3 molecules in the plasma membrane of human T lymphocytes," Proceedings of the National Academy of Sciences of the United States of America, vol. 100, no. 5, pp. 2592-2597, 2003.

[169] P. Szigligeti, L. Neumeier, E. Duke et al., "Signalling during hypoxia in human $\mathrm{T}$ lymphocytes - critical role of the src protein tyrosine kinase p56Lck in the $\mathrm{O}_{2}$ sensitivity of Kv1.3 channels," The Journal of Physiology, vol. 573, no. 2, pp. 357-370, 2006.

[170] L. Solé, M. Roura-Ferrer, M. Pérez-Verdaguer et al., "KCNE4 suppresses Kv1.3 currents by modulating trafficking, surface expression and channel gating," Journal of Cell Science, vol. 122, no. 20, pp. 3738-3748, 2009.

[171] L. Solé, A. Vallejo-Gracia, S. R. Roig et al., "KCNE gene expression is dependent on the proliferation and mode of activation of leukocytes," Channels, vol. 7, no. 2, pp. 85-96, 2013.

[172] L. Leanza, L. Biasutto, A. Managò, E. Gulbins, M. Zoratti, and I. Szabò, "Intracellular ion channels and cancer," Frontiers in Physiology, vol. 4, article 227, 2013.

[173] E. Gulbins, N. Sassi, H. Grassmè, M. Zoratti, and I. Szabò, "Role of Kv1.3 mitochondrial potassium channel in apoptotic signalling in lymphocytes," Biochimica et Biophysica ActaBioenergetics, vol. 1797, no. 6-7, pp. 1251-1259, 2010.

[174] A. Arcangeli and A. Becchetti, "New trends in cancer therapy: targeting ion channels and transporters," Pharmaceuticals, vol. 3, no. 4, pp. 1202-1224, 2010.

[175] M. C. Sanguinetti, "HERG1 channelopathies," Pflügers Archiv, vol. 460, no. 2, pp. 265-276, 2010.

[176] S. Pillozzi, M. F. Brizzi, M. Balzi et al., "HERG potassium channels are constitutively expressed in primary human acute myeloid leukemias and regulate cell proliferation of normal and leukemic hemopoietic progenitors," Leukemia, vol. 16, no. 9, pp. 1791-1798, 2002.

[177] G. A. M. Smith, H.-W. Tsui, E. W. Newell et al., "Functional upregulation of HERG $\mathrm{K}+$ channels in neoplastic hematopoietic cells," The Journal of Biological Chemistry, vol. 277, no. 21, pp. 18528-18534, 2002.

[178] M. S. Cavarra, S. M. del Mónaco, Y. A. Assef, C. Ibarra, and B. A. Kotsias, "HERG1 currents in native K562 leukemic cells," The Journal of Membrane Biology, vol. 219, no. 1-3, pp. 49-61, 2007.

[179] H. Li, L. Liu, L. Guo et al., "HERG K+ channel expression in $\mathrm{CD} 34^{+} / \mathrm{CD} 38^{-} / \mathrm{CD} 123$ high cells and primary leukemia cells and analysis of its regulation in leukemia cells," International Journal of Hematology, vol. 87, no. 4, pp. 387-392, 2008.

[180] A. Arcangeli, "Ion channels and transporters in cancer. 3. Ion channels in the tumor cell-microenvironment cross talk," American Journal of Physiology: Cell Physiology, vol. 301, no. 4, pp. C762-C771, 2011.

[181] F. Zheng, J. Li, W. Du, N. Wang, H. Li, and S. Huang, "Human ether-a-go-go-related gene $\mathrm{K}^{+}$channels regulate shedding of leukemia cell-derived microvesicles," Leukemia and Lymphoma, vol. 53, no. 8, pp. 1592-1598, 2012.

[182] J. J. Babcock and M. Li, "HERG channel function: beyond long QT,' Acta Pharmacologica Sinica, vol. 34, no. 3, pp. 329-335, 2013.

[183] L. Guasti, O. Crociani, E. Redaelli et al., "Identification of a posttranslational mechanism for the regulation of hERG1 $\mathrm{K}^{+}$ channel expression and hERG1 current density in tumor cells," Molecular and Cellular Biology, vol. 28, no. 16, pp. 5043-5060, 2008.

[184] O. Crociani, L. Guasti, M. Balzi et al., "Cell cycle-dependent expression of HERG1 and HERG1B isoforms in tumor cells," Journal of Biological Chemistry, vol. 278, no. 5, pp. 2947-2955, 2003.

[185] S. Srivastava, K. Ko, P. Choudhury et al., "Phosphatidylinositol3 phosphatase myotubularin-related protein 6 negatively regulates CD4 T cells," Molecular and Cellular Biology, vol. 26, no. 15, pp. 5595-5602, 2006.

[186] S. Srivastava, Z. Li, K. Ko et al., "Histidine phosphorylation of the potassium channel KCa3.1 by nucleoside diphosphate kinase B is required for activation of KCa3.1 and CD4 T cells," Molecular Cell, vol. 24, no. 5, pp. 665-675, 2006.

[187] S. Srivastava, O. Zhdanova, L. Di et al., "Protein histidine phosphatase 1 negatively regulates CD4 T cells by inhibiting the $\mathrm{K}^{+}$channel KCa3.1," Proceedings of the National Academy of Sciences of the United States of America, vol. 105, no. 38, pp. 14442-14446, 2008.

[188] S. Grinstein and J. D. Smith, "Calcium-independent cell volume regulation in human lymphocytes: Inhibition by charybdotoxin," The Journal of General Physiology, vol. 95, no. 1, pp. 97120,1990

[189] S. Grissmer, A. N. Nguyen, and M. D. Cahalan, "Calciumactivated potassium channels in resting and activated human $\mathrm{T}$ lymphocytes: expression levels, calcium dependence, ion selectivity, and pharmacology," The Journal of General Physiology, vol. 102, no. 4, pp. 601-630, 1993.

[190] A. Schwab, A. Fabian, P. J. Hanley, and C. Stock, "Role of ion channels and transporters in cell migration," Physiological Reviews, vol. 92, no. 4, pp. 1865-1913, 2012.

[191] A. D. Wei, G. A. Gutman, R. Aldrich, K. G. Chandy, S. Grissmer, and H. Wulff, "International Union of Pharmacology. LII. Nomenclature and molecular relationships of calcium-activated potassium channels," Pharmacological Reviews, vol. 57, no. 4, pp. 463-472, 2005.

[192] R. Desai, A. Peretz, H. Idelson, P. Lazarovici, and B. Attali, "Ca ${ }^{2+}$-activated $\mathrm{K}^{+}$channels in human leukemic Jurkat T cells," 
Journal of Biological Chemistry, vol. 275, no. 51, pp. 3995439963, 2000.

[193] C. M. Fanger, H. Rauer, A. L. Neben et al., "Calcium-activated potassium channels sustain calcium signaling in T lymphocytes. Selective blockers and manipulated channel expression levels," The Journal of Biological Chemistry, vol. 276, no. 15, pp. 1224912256, 2001.

[194] T. Morimoto, S. Ohya, H. Hayashi, K. Onozaki, and Y. Imaizumi, "Cell-cycle-dependent regulation of $\mathrm{Ca}^{2+}$-activated $\mathrm{K}^{+}$channel in Jurkat T-lymphocyte," Journal of Pharmacological Sciences, vol. 104, no. 1, pp. 94-98, 2007.

[195] S. G. Meuth, S. Bittner, P. Meuth, O. J. Simon, T. Budde, and $\mathrm{H}$. Wiendl, "TWIK-related acid-sensitive $\mathrm{K}^{+}$channel 1 (TASK1) and TASK3 critically influence T lymphocyte effector functions," The Journal of Biological Chemistry, vol. 283, no. 21, pp. 14559-14570, 2008.

[196] I. I. Pottosin, E. Bonales-Alatorre, G. Valencia-Cruz, M. L. Mendoza-Magaña, and O. R. Dobrovinskaya, "TRESK-like potassium channels in leukemic T cells," Pflügers ArchivEuropean Journal of Physiology, vol. 456, no. 6, pp. 1037-1048, 2008.

[197] D. S. Sánchez-Miguel, F. García-Dolores, M. Rosa FloresMárquez, I. Delgado-Enciso, I. Pottosin, and O. Dobrovinskaya, "TRESK potassium channel in human T lymphoblasts," Biochemical and Biophysical Research Communications, vol. 434, no. 2, pp. 273-279, 2013.

[198] S. Bittner, N. Bobak, A. M. Herrmann et al., "Upregulation of K2P5.1 potassium channels in multiple sclerosis," Annals of Neurology, vol. 68, no. 1, pp. 58-69, 2010.

[199] S. Bittner, N. Bobak, M. Feuchtenberger et al., "Expression of K2P5.1 potassium channels on CD4+ T lymphocytes correlates with disease activity in rheumatoid arthritis patients," Arthritis Research and Therapy, vol. 13, no. 1, article R21, 2011.

[200] D. P. Lotshaw, "Biophysical, pharmacological, and functional characteristics of cloned and native mammalian two-pore domain $\mathrm{K}^{+}$channels," Cell Biochemistry and Biophysics, vol. 47, no. 2, pp. 209-256, 2007.

[201] D. Kang, E. Mariash, and D. Kim, "Functional expression of TRESK-2, a new member of the tandem-pore $\mathrm{K}^{+}$channel family," Journal of Biological Chemistry, vol. 279, no. 27, pp. 28063-28070, 2004.

[202] P. Enyedi, G. Braun, and G. Czirják, “TRESK: the lone ranger of two-pore domain potassium channels," Molecular and Cellular Endocrinology, vol. 353, no. 1-2, pp. 75-81, 2012.

[203] J. Han and D. Kang, "TRESK channel as a potential target to treat T-cell mediated immune dysfunction," Biochemical and Biophysical Research Communications, vol. 390, no. 4, pp. 11021105, 2009.

[204] Z. Es-Salah-Lamoureux, D. F. Steele, and D. Fedida, "Research into the therapeutic roles of two-pore-domain potassium channels," Trends in Pharmacological Sciences, vol. 31, no. 12, pp. 587595, 2010.

[205] J. K. Bruner, B. Zou, H. Zhang, Y. Zhang, K. Schmidt, and M. Li, "Identification of novel small molecule modulators of K2P18.1 two-pore potassium channel," European Journal of Pharmacology, vol. 740, pp. 603-610, 2014.

[206] W. I. Dehaven, B. F. Jones, J. G. Petranka et al., “TRPC channels function independently of STIM1 and Orail," The Journal of Physiology, vol. 587, no. 10, pp. 2275-2298, 2009.

[207] S. Feske, Y. Gwack, M. Prakriya et al., "A mutation in Orail causes immune deficiency by abrogating CRAC channel function," Nature, vol. 441, no. 7090, pp. 179-185, 2006.
[208] S. Feske, E. Y. Skolnik, and M. Prakriya, "Ion channels and transporters in lymphocyte function and immunity," Nature Reviews Immunology, vol. 12, no. 7, pp. 532-547, 2012.

[209] M. Oh-Hora, M. Yamashita, P. G. Hogan et al., "Dual functions for the endoplasmic reticulum calcium sensors STIM1 and STIM2 in T cell activation and tolerance," Nature Immunology, vol. 9, no. 4, pp. 432-443, 2008.

[210] P. Thakur and A. F. Fomina, "Density of functional $\mathrm{Ca}^{2+}$ releaseactivated $\mathrm{Ca}^{2+}$ (CRAC) channels declines after T cell activation," Channels, vol. 5, no. 6, pp. 510-517, 2011.

[211] R. S. Lewis and M. D. Cahalan, "Mitogen-induced oscillations of cytosolic Ca2+ and transmembrane $\mathrm{Ca} 2+$ current in human leukemic T cells," Cell Regulation, vol. 1, no. 1, pp. 99-112, 1989.

[212] S. Saul, H. Stanisz, C. S. Backes, E. C. Schwarz, and M. Hoth, "How ORAI and TRP channels interfere with each other: interaction models and examples from the immune system and the skin," European Journal of Pharmacology, vol. 739, pp. 49-59, 2014.

[213] L.-J. Wu, T.-B. Sweet, and D. E. Clapham, "International union of basic and clinical pharmacology. LXXVI. Current progress in the mammalian TRP ion channel family," Pharmacological Reviews, vol. 62, no. 3, pp. 381-404, 2010.

[214] J. Zheng, "Molecular mechanism of TRP channels," Comprehensive Physiology, vol. 3, no. 1, pp. 221-242, 2013.

[215] G. Owsianik, K. Talavera, T. Voets, and B. Nilius, "Permeation and selectivity of TRP channels," Annual Review of Physiology, vol. 68, pp. 685-717, 2006.

[216] B. Nilius and A. Szallasi, "Transient receptor potential channels as drug targets: from the science of basic research to the art of medicine," Pharmacological Reviews, vol. 66, no. 3, pp. 676-814, 2014.

[217] K. Venkatachalam, F. Zheng, and D. L. Gill, "Regulation of canonical transient receptor potential (TRPC) channel function by diacylglycerol and protein kinase C," The Journal of Biological Chemistry, vol. 278, no. 31, pp. 29031-29040, 2003.

[218] A. Gamberucci, E. Giurisato, P. Pizzo et al., "Diacylglycerol activates the influx of extracellular cations in T-lymphocytes independently of intracellular calcium-store depletion and possibly involving endogenous TRP6 gene products," The Biochemical Journal, vol. 364, no. 1, pp. 245-254, 2002.

[219] G. K. Rao and N. E. Kaminski, "Induction of intracellular calcium elevation by $\Delta 9$ - tetrahydrocannabinol in $\mathrm{T}$ cells involves TRPC1 channels," Journal of Leukocyte Biology, vol. 79, no. 1, pp. 202-213, 2006.

[220] U. Storch, A.-L. Forst, M. Philipp, T. Gudermann, and M. Mederos Y Schnitzler, "Transient receptor potential channel 1 (TRPC1) reduces calcium permeability in heteromeric channel complexes," The Journal of Biological Chemistry, vol. 287, no. 5, pp. 3530-3540, 2012.

[221] X. Ma, J. Cao, J. Luo et al., "Depletion of intracellular $\mathrm{ca}^{2+}$ stores stimulates the translocation of vanilloid transient receptor potential 4-C1 heteromeric channels to the plasma membrane," Arteriosclerosis, Thrombosis, and Vascular Biology, vol. 30, no. 11, pp. 2249-2255, 2010.

[222] S. Yamamoto, N. Takahashi, and Y. Mori, "Chemical physiology of oxidative stress-activated TRPM2 and TRPC5 channels," Progress in Biophysics and Molecular Biology, vol. 103, no. 1, pp. 18-27, 2010.

[223] B. Pang, D. H. Shin, K. S. Park et al., "Differential pathways for calcium influx activated by concanavalin A and CD3 stimulation in Jurkat T cells," Pflügers Archiv European Journal of Physiology, vol. 463, no. 2, pp. 309-318, 2012. 
[224] Y. Sano, K. Inamura, A. Miyake et al., "Immunocyte $\mathrm{Ca}^{2+}$ influx system mediated by LTRPC2," Science, vol. 293, no. 5533, pp. 1327-1330, 2001.

[225] R. Xia, Z.-Z. Mei, H.-J. Mao et al., "Identification of pore residues engaged in determining divalent cationic permeation in transient receptor potential melastatin subtype channel 2," The Journal of Biological Chemistry, vol. 283, no. 41, pp. 2742627432, 2008.

[226] A. Sumoza-Toledo and R. Penner, "TRPM2: a multifunctional ion channel for calcium signalling," Journal of Physiology, vol. 589, no. 7, pp. 1515-1525, 2011.

[227] W. Zhang, X. Chu, Q. Tong et al., "A novel TRPM2 isoform inhibits calcium influx and susceptibility to cell death," The Journal of Biological Chemistry, vol. 278, no. 18, pp. 16222-16229, 2003.

[228] W. Zhang, I. Hirschler-Laszkiewicz, Q. Tong et al., "TRPM2 is an ion channel that modulates hematopoietic cell death through activation of caspases and PARP cleavage," American Journal of Physiology: Cell Physiology, vol. 290, no. 4, pp. C1146-C1159, 2006.

[229] T. Kirchberger, C. Moreau, G. K. Wagner et al., "8-Bromo-cyclic inosine diphosphoribose: towards a selective cyclic ADP-ribose agonist," Biochemical Journal, vol. 422, no. 1, pp. 139-149, 2009.

[230] S. M. Huber, "Oncochannels," Cell Calcium, vol. 53, no. 4, pp. 241-255, 2013.

[231] B. Nilius, J. Prenen, G. Droogmans et al., "Voltage dependence of the $\mathrm{Ca}^{2+}$-activated cation channel TRPM4," The Journal of Biological Chemistry, vol. 278, no. 33, pp. 30813-30820, 2003.

[232] P. Launay, A. Fleig, A. L. Perraud, A. M. Scharenberg, R. Penner, and J. P. Kinet, "TRPM4 is a $\mathrm{Ca}^{2+}$-activated nonselective cation channel mediating cell membrane depolarization," Cell, vol. 109, no. 3, pp. 397-407, 2002.

[233] D. Liu, Z. Zhang, and E. R. Liman, "Extracellular acid block and acid-enhanced inactivation of the $\mathrm{Ca}^{2+}$-activated cation channel TRPM5 involve residues in the S3-S4 and S5-S6 extracellular domains," The Journal of Biological Chemistry, vol. 280, no. 21, pp. 20691-20699, 2005.

[234] S. Han, H. H. Koo, Q. Lan et al., "Common variation in genes related to immune response and risk of childhood leukemia," Human Immunology, vol. 73, no. 3, pp. 316-319, 2012.

[235] M. B. Morelli, S. Liberati, C. Amantini et al., "Expression and function of the transient receptor potential ion channel family in the hematologic malignancies," Current Molecular Pharmacology, vol. 6, no. 3, pp. 137-148, 2013.

[236] J. C. Aster, W. S. Pear, and S. C. Blacklow, "Notch signaling in leukemia," Annual Review of Pathology, vol. 3, pp. 587-613, 2008.

[237] L. W. Runnels, L. Yue, and D. E. Clapham, "TRP-PLIK, a bifunctional protein with kinase and ion channel activities," Science, vol. 291, no. 5506, pp. 1043-1047, 2001.

[238] R. Wondergem and J. W. Bartley, "Menthol increases human glioblastoma intracellular $\mathrm{Ca}^{2+}, \mathrm{BK}$ channel activity and cell migration," Journal of Biomedical Science, vol. 16, no. 1, article 90, 2009.

[239] B. Nilius, G. Owsianik, T. Voets, and J. A. Peters, “Transient receptor potential cation channels in disease," Physiological Reviews, vol. 87, no. 1, pp. 165-217, 2007.

[240] M.-K. Chung, A. D. Güler, and M. J. Caterina, “TRPV1 shows dynamic ionic selectivity during agonist stimulation," Nature Neuroscience, vol. 11, no. 5, pp. 555-564, 2008.
[241] M. J. Caterina, M. A. Schumacher, M. Tominaga, T. A. Rosen, J. D. Levine, and D. Julius, "The capsaicin receptor: a heatactivated ion channel in the pain pathway," Nature, vol. 389, no. 6653, pp. 816-824, 1997.

[242] A. Perálvarez-Marín, P. Doñate-Macian, and R. Gaudet, "What do we know about the transient receptor potential vanilloid 2 (TRPV2) ion channel?" FEBS Journal, vol. 280, no. 21, pp. 54715487, 2013.

[243] C. I. Saunders, D. A. Kunde, A. Crawford, and D. P. Geraghty, "Expression of transient receptor potential vanilloid 1 (TRPV1) and 2 (TRPV2) in human peripheral blood," Molecular Immunology, vol. 44, no. 6, pp. 1429-1435, 2007.

[244] G. Spinsanti, R. Zannolli, C. Panti et al., "Quantitative RealTime PCR detection of TRPV1-4 gene expression in human leukocytes from healthy and hyposensitive subjects," Molecular Pain, vol. 4, article 51, 2008.

[245] G. Santoni, V. Farfariello, S. Liberati et al., "The role of transient receptor potential vanilloid type-2 ion channels in innate and adaptive immune responses," Frontiers in Immunology, vol. 4, 2013.

[246] M. Nagasawa, Y. Nakagawa, S. Tanaka, and I. Kojima, "Chemotactic peptide fMetLeuPhe induces translocation of the TRPV2 channel in macrophages," Journal of Cellular Physiology, vol. 210, no. 3, pp. 692-702, 2007.

[247] M. Nabissi, M. B. Morelli, M. Santoni, and G. Santoni, "Triggering of the TRPV2 channel by cannabidiol sensitizes glioblastoma cells to cytotoxic chemotherapeutic agents," Carcinogenesis, vol. 34, no. 1, pp. 48-57, 2013.

[248] M. Saito, P. I. Hanson, and P. Schlesinger, "Luminal chloridedependent activation of endosome calcium channels: patch clamp study of enlarged endosomes," Journal of Biological Chemistry, vol. 282, no. 37, pp. 27327-27333, 2007.

[249] M. J. Caterina, T. A. Rosen, M. Tominaga, A. J. Brake, and D. Julius, "A capsaicin-receptor homologue with a high threshold for noxious heat," Nature, vol. 398, no. 6726, pp. 436-441, 1999.

[250] M. P. Neeper, Y. Liu, T. L. Hutchinson, Y. Wang, C. M. Flores, and N. Qin, "Activation properties of heterologously expressed mammalian TRPV2: evidence for species dependence," The Journal of Biological Chemistry, vol. 282, no. 21, pp. 15894-15902, 2007.

[251] M. Kanzaki, Y. Q. Zhang, H. Mashima, L. Li, H. Shibata, and I. Kojima, "Translocation of a calcium-permeable cation channel induced by insulin-like growth factor-I," Nature Cell Biology, vol. 1, no. 3, pp. 165-170, 1999.

[252] K. Muraki, Y. Iwata, Y. Katanosaka et al., "TRPV2 is a component of osmotically sensitive cation channels in murine aortic myocytes," Circulation Research, vol. 93, no. 9, pp. 829-838, 2003.

[253] K. Shibasaki, N. Murayama, K. Ono, Y. Ishizaki, and M. Tominaga, "TRPV2 enhances axon outgrowth through its activation by membrane stretch in developing sensory and motor neurons," The Journal of Neuroscience, vol. 30, no. 13, pp. 4601-4612, 2010.

[254] D. Zhang, A. Spielmann, L. Wang et al., "Mast-cell degranulation induced by physical stimuli involves the activation of transient-receptor-potential channel TRPV2," Physiological Research, vol. 61, no. 1, pp. 113-124, 2012.

[255] T. Voets, J. Prenen, J. Vriens et al., "Molecular determinants of permeation through the cation channel TRPV4," The Journal of Biological Chemistry, vol. 277, no. 37, pp. 33704-33710, 2002. 
[256] B. Nilius, J. Vriens, J. Prenen, G. Droogmans, and T. Voets, "TRPV4 calcium entry channel: a paradigm for gating diversity," The American Journal of Physiology-Cell Physiology, vol. 286, no. 2, pp. 195-205, 2004.

[257] W. Everaerts, B. Nilius, and G. Owsianik, "The vanilloid transient receptor potential channel TRPV4: from structure to disease," Progress in Biophysics and Molecular Biology, vol. 103, no. 1, pp. 2-17, 2010.

[258] T. C. Ho, N. A. Horn, T. Huynh, L. Kelava, and J. B. Lansman, "Evidence TRPV4 contributes to mechanosensitive ion channels in mouse skeletal muscle fibers," Channels, vol. 6, no. 4, pp. 246-254, 2012.

[259] I. O. Vassilieva, V. N. Tomilin, I. I. Marakhova, A. N. Shatrova, Y. A. Negulyaev, and S. B. Semenova, "Expression of transient receptor potential vanilloid channels TRPV5 and TRPV6 in human blood lymphocytes and Jurkat leukemia T cells," The Journal of Membrane Biology, vol. 246, no. 2, pp. 131-140, 2013.

[260] J. Cui, J. S. Bian, A. Kagan, and T. V. McDonald, "CaT1 contributes to the stores-operated calcium current in Jurkat Tlymphocytes," The Journal of Biological Chemistry, vol. 277, no. 49, pp. 47175-47183, 2002.

[261] W. G. Junger, "Immune cell regulation by autocrine purinergic signalling," Nature Reviews Immunology, vol. 11, no. 3, pp. 201212, 2011.

[262] O. R. Baricordi, D. Ferrari, L. Melchiorri et al., "An ATPactivated channel is involved in mitogenic stimulation of human T lymphocytes," Blood, vol. 87, no. 2, pp. 682-690, 1996.

[263] L. Yip, T. Woehrle, R. Corriden et al., "Autocrine regulation of Tcell activation by ATP release and $\mathrm{P} 2 \mathrm{X} 7$ receptors," The FASEB Journal, vol. 23, no. 6, pp. 1685-1693, 2009.

[264] T. Woehrle, L. Yip, A. Elkhal et al., "Pannexin-1 hemichannelmediated ATP release together with $\mathrm{P} 2 \mathrm{X} 1$ and $\mathrm{P} 2 \mathrm{X} 4$ receptors regulate T-cell activation at the immune synapse," Blood, vol. 116, no. 18, pp. 3475-3484, 2010.

[265] A. Filippini, R. E. Taffs, and M. V. Sitkovsky, "Extracellular ATP in T-lymphocyte activation: possible role in effector functions," Proceedings of the National Academy of Sciences of the United States of America, vol. 87, no. 21, pp. 8267-8271, 1990.

[266] U. Schenk, A. M. Westendorf, E. Radaelli et al., "Purinergic control of T cell activation by ATP released through pannexin-1 hemichannels," Science Signaling, vol. 1, no. 39, article Ra6, 2008.

[267] A. Aguirre, K. F. Shoji, J. C. Sáez, M. Henríquez, and A. F. Quest, "FasL-triggered death of Jurkat cells requires caspase 8-induced, ATP-dependent cross-talk between Fas and the purinergic receptor P2X7," Journal of Cellular Physiology, vol. 228, no. 2, pp. 485-493, 2013.

[268] X.-J. Zhang, G.-G. Zheng, X.-T. Ma et al., "Expression of P2X7 in human hematopoietic cell lines and leukemia patients," Leukemia Research, vol. 28, no. 12, pp. 1313-1322, 2004.

[269] B. Jiang, N. Hattori, B. Liu, K. Kitagawa, and C. Inagaki, "Expression of swelling- and/or pH-regulated chloride channels (ClC-2, 3, 4 and 5) in human leukemic and normal immune cells," Life Sciences, vol. 70, no. 12, pp. 1383-1394, 2002.

[270] G. L. Wang, Y. Qian, Q. Y. Qiu, X. J. Lan, H. He, and Y. Y. Guan, "Interaction between $\mathrm{Cl}^{-}$channels and CRAC-related $\mathrm{Ca}^{2+}$ signaling during T lymphocyte activation and proliferation," Acta Pharmacologica Sinica, vol. 27, no. 4, pp. 437-446, 2006.

[271] M. D. Cahalan and R. S. Lewis, "Role of potassium and chloride channels in volume regulation by T lymphocytes," Society of General Physiologists Series, vol. 43, pp. 281-301, 1988.
[272] R. S. Lewis, P. E. Ross, and M. D. Cahalan, "Chloride channels activated by osmotic stress in T lymphocytes," The Journal of General Physiology, vol. 101, no. 6, pp. 801-826, 1993.

[273] P. E. Ross, S. S. Garber, and M. D. Cahalan, "Membrane chloride conductance and capacitance in Jurkat T lymphocytes during osmotic swelling," Biophysical Journal, vol. 66, no. 1, pp. 169-178, 1994.

[274] J. H. Chen, H. Schulman, and P. Gardner, "A cAMP-regulated chloride channel in lymphocytes that is affected in cystic fibrosis," Science, vol. 243, no. 4891, pp. 657-660, 1989.

[275] A. Lepple-Wienhues, I. Szabò, T. Laun, N. K. Kaba, E. Gulbins, and F. Lang, "The tyrosine kinase p56(lck) mediates activation of swelling-induced chloride channels in lymphocytes," Journal of Cell Biology, vol. 141, no. 1, pp. 281-286, 1998.

[276] S. S. Garber, "Outwardly rectifying chloride channels in lymphocytes," The Journal of Membrane Biology, vol. 127, no. 1, pp. 49-56, 1992.

[277] J. K. Bubien, K. L. Kirk, T. A. Rado, and R. A. Frizzell, "Cell cycle dependence of chloride permeability in normal and cystic fibrosis lymphocytes," Science, vol. 248, no. 4961, pp. 1416-1419, 1990.

[278] R. D. Krauss, J. K. Bubien, M. L. Drumm et al., "Transfection of wild-type CFTR into cystic fibrosis lymphocytes restores chloride conductance at G1 of the cell cycle," The EMBO Journal, vol. 11, no. 3, pp. 875-883, 1992.

[279] T. V. McDonald, P. T. Nghiem, P. Gardner, and C. L. Martens, "Human lymphocytes transcribe the cystic fibrosis transmembrane conductance regulator gene and exhibit CF-defective cAMP-regulated chloride current," The Journal of Biological Chemistry, vol. 267, no. 5, pp. 3242-3248, 1992.

[280] C. Mueller, S. A. Braag, A. Keeler, C. Hodges, M. Drumm, and T. R. Flotte, "Lack of cystic fibrosis transmembrane conductance regulator in $\mathrm{CD}^{+}$lymphocytes leads to aberrant cytokine secretion and hyperinflammatory adaptive immune responses," American Journal of Respiratory Cell and Molecular Biology, vol. 44, no. 6, pp. 922-929, 2011.

[281] I. Wessler and C. J. Kirkpatrick, "Acetylcholine beyond neurons: the non-neuronal cholinergic system in humans," British Journal of Pharmacology, vol. 154, no. 8, pp. 1558-1571, 2008.

[282] S. Pillozzi and A. Becchetti, "Ion channels in hematopoietic and mesenchymal stem cells," Stem Cells International, vol. 2012, Article ID 217910, 9 pages, 2012.

[283] Y. Ganor, M. Besser, N. Ben-Zakay, T. Unger, and M. Levite, "Human $\mathrm{T}$ cells express a functional ionotropic glutamate receptor GluR3, and glutamate by itself triggers integrinmediated adhesion to laminin and fibronectin and chemotactic migration," Journal of Immunology, vol. 170, no. 8, pp. 43624372, 2003.

[284] G. Miglio, C. Dianzani, S. Fallarini, R. Fantozzi, and G. Lombardi, "Stimulation of N-methyl-d-aspartate receptors modulates Jurkat T cell growth and adhesion to fibronectin," Biochemical and Biophysical Research Communications, vol. 361, no. 2, pp. 404-409, 2007.

[285] G. Miglio, F. Varsaldi, and G. Lombardi, "Human T lymphocytes express $\mathrm{N}$-methyl-D-aspartate receptors functionally active in controlling T cell activation," Biochemical and Biophysical Research Communications, vol. 338, no. 4, pp. 1875-1883, 2005.

[286] K. Omilusik, J. J. Priatel, X. Chen et al., "The Ca $\mathrm{Ca}_{v} 1.4$ calcium channel is a critical regulator of $\mathrm{T}$ cell receptor signaling and naive T cell homeostasis," Immunity, vol. 35, no. 3, pp. 349-360, 2011. 
[287] V. Robert, E. Triffaux, M. Savignac, and L. Pelletier, "Calcium signalling in T-lymphocytes," Biochimie, vol. 93, no. 12, pp. 2087-2094, 2011.

[288] C. Y. Park, A. Shcheglovitov, and R. Dolmetsch, "The CRAC channel activator STIM1 binds and inhibits L-type voltagegated calcium channels," Science, vol. 330, no. 6000, pp. 101-105, 2010.

[289] A. Moghrabi, D. E. Levy, B. Asselin et al., "Results of the DanaFarber Cancer Institute ALL Consortium Protocol 95-01 for children with acute lymphoblastic leukemia," Blood, vol. 109, no. 3, pp. 896-904, 2007.

[290] W. Landier and S. Bhatia, "Cancer survivorship: a pediatric perspective," The Oncologist, vol. 13, no. 11, pp. 1181-1192, 2008.

[291] C. S. Tremblay and D. J. Curtis, "The clonal evolution of leukemic stem cells in t-cell acute lymphoblastic leukemia," Current Opinion in Hematology, vol. 21, no. 4, pp. 320-325, 2014.

[292] A. B. Lee-Sherick, R. M. A. Linger, L. Gore, A. K. Keating, and D. K. Graham, "Targeting paediatric acute lymphoblastic leukaemia: novel therapies currently in development," British Journal of Haematology, vol. 151, no. 4, pp. 295-311, 2010.

[293] A. Kiani, A. Rao, and J. Aramburu, "Manipulating immune responses with immunosuppressive agents that target NFAT," Immunity, vol. 12, no. 4, pp. 359-372, 2000.

[294] P. Liu, Z. Xiao, F. Ren et al., "Functional analysis of a migraineassociated TRESK $\mathrm{K}^{+}$channel mutation," The Journal of Neuroscience, vol. 33, no. 31, pp. 12810-12824, 2013.

[295] L. A. Pardo and W. Stühmer, "Eag1: an emerging oncological target," Cancer Research, vol. 68, no. 6, pp. 1611-1613, 2008.

[296] H. J. Witchel and J. C. Hancox, "Familial and acquired long QT syndrome and the cardiac rapid delayed rectifier potassium current," Clinical and Experimental Pharmacology and Physiology, vol. 27, no. 10, pp. 753-766, 2000.

[297] C. T. Jordan, "The leukemic stem cell," Best Practice and Research in Clinical Haematology, vol. 20, no. 1, pp. 13-18, 2007.

[298] N. Misaghian, G. Ligresti, L. S. Steelman et al., "Targeting the leukemic stem cell: the Holy Grail of leukemia therapy," Leukemia, vol. 23, no. 1, pp. 25-42, 2009. 

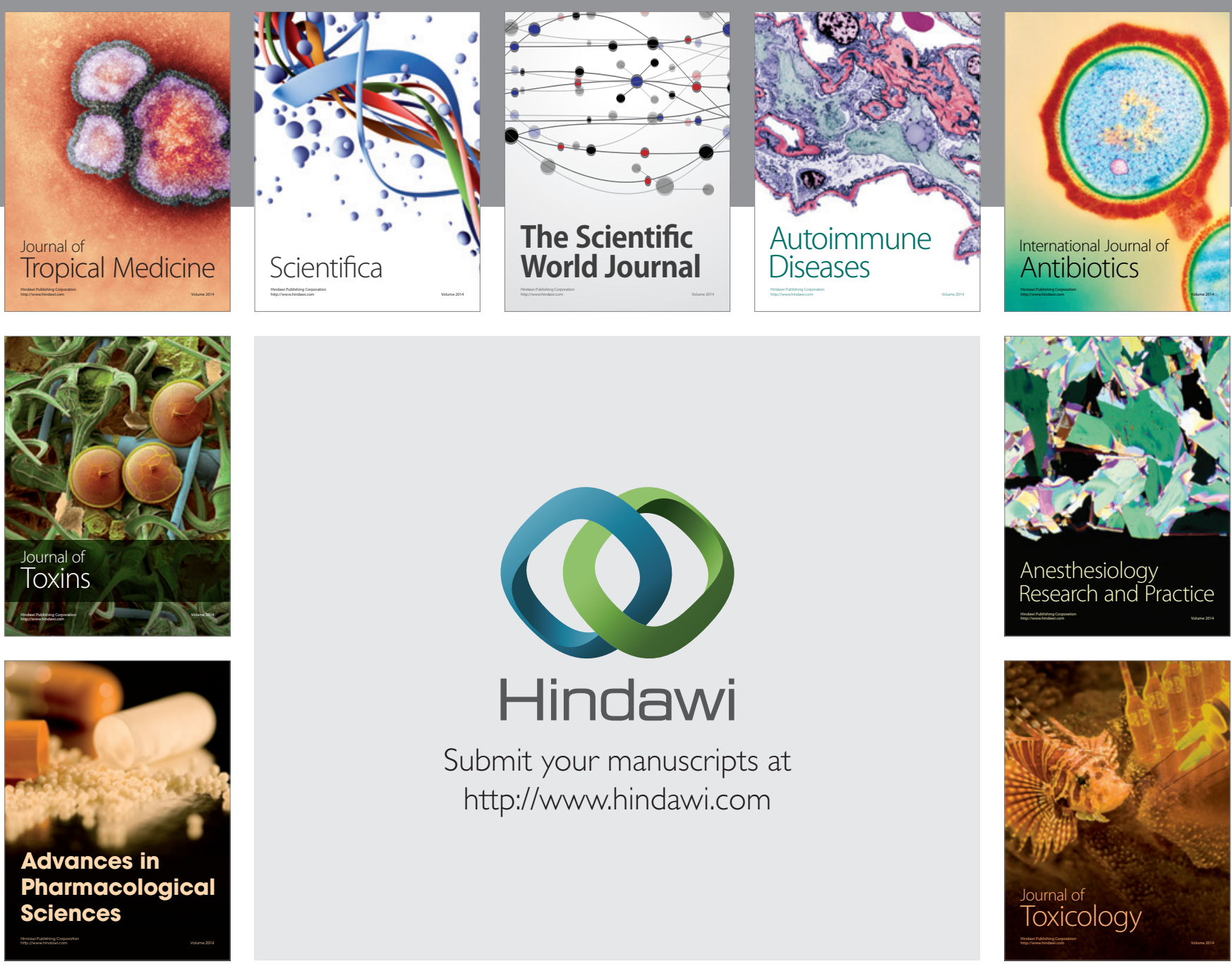

\section{Hindawi}

Submit your manuscripts at

http://www.hindawi.com
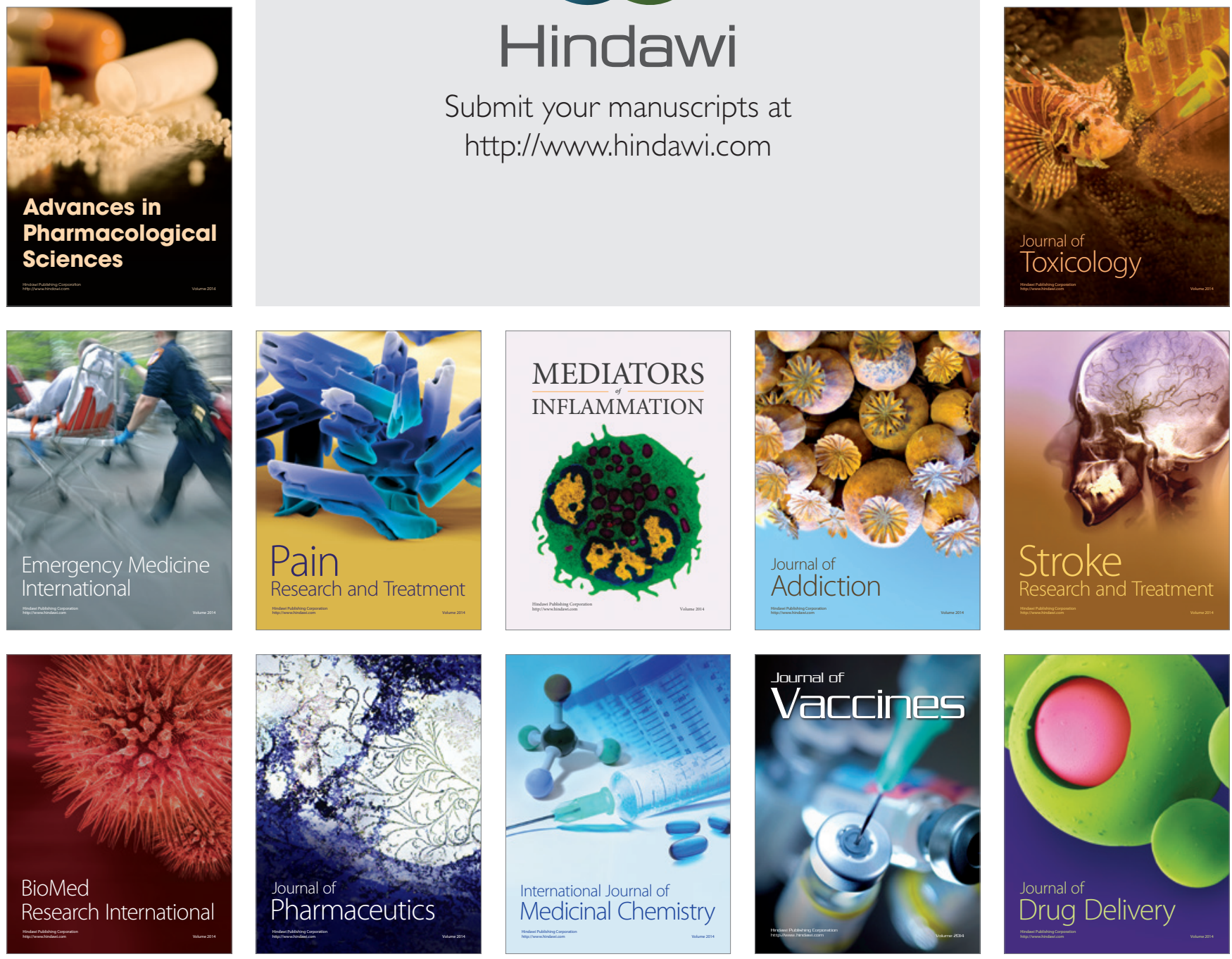